\title{
OECD Patent Statistics Manual
}
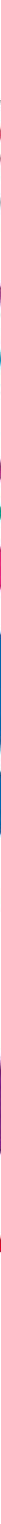



\section{OECD Patent Statistics Manual}

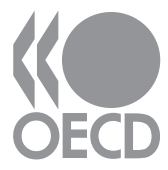




\section{ORGANISATION FOR ECONOMIC CO-OPERATION AND DEVELOPMENT}

The OECD is a unique forum where the governments of 30 democracies work together to address the economic, social and environmental challenges of globalisation. The OECD is also at the forefront of efforts to understand and to help governments respond to new developments and concerns, such as corporate governance, the information economy and the challenges of an ageing population. The Organisation provides a setting where governments can compare policy experiences, seek answers to common problems, identify good practice and work to co-ordinate domestic and international policies.

The OECD member countries are: Australia, Austria, Belgium, Canada, the Czech Republic, Denmark, Finland, France, Germany, Greece, Hungary, Iceland, Ireland, Italy, Japan, Korea, Luxembourg, Mexico, the Netherlands, New Zealand, Norway, Poland, Portugal, the Slovak Republic, Spain, Sweden, Switzerland, Turkey, the United Kingdom and the United States. The Commission of the European Communities takes part in the work of the OECD.

OECD Publishing disseminates widely the results of the Organisation's statistics gathering and research on economic, social and environmental issues, as well as the conventions, guidelines and standards agreed by its members.

This work is published on the responsibility of the Secretary-General of the OECD. The opinions expressed and arguments employed herein do not necessarily reflect the official views of the Organisation or of the governments of its member countries.

Also available in French under the title:

Manuel de l'OCDE sur les statistiques de brevets

Corrigenda to OECD publications may be found on line at: www.oecd.org/publishing/corrigenda.

(c) OECD 2009

Cover illustration:

(C) Rian Hughes/Stockbyte/Getty Images

You can copy, download or print OECD content for your own use, and you can include excerpts from OECD publications, databases and multimedia products in your own documents, presentations, blogs, websites and teaching materials, provided that suitable acknowledgment of OECD as source and copyright owner is given. All requests for public or commercial use and translation rights should be submitted to rights@oecd.org. Requests for permission to photocopy portions of this material for public or commercial use shall be addressed directly to the Copyright Clearance Center (CCC) at info@copyright.com or the Centre français d'exploitation du droit de copie (CFC) contact@cfcopies.com. 


\section{Foreword}

$\prod$ his manual has been prepared by the OECD Secretariat in conjunction with the Working Party of National Experts on Science and Technology Indicators (NESTI) in order to provide users and producers of patent statistics with basic guidelines for compiling and analysing these data.

The importance which the OECD attaches to the use of patent statistics goes back to the late 1970s. The OECD issued a first edition of this manual in 1994. At the "Blue Sky" conference on "New science and technology indicators for a knowledge-based economy", organised by the OECD in 1996, experts identified patents as a promising avenue for improving our quantitative understanding of science and technology (S\&T) activities in a rapidly evolving economic and policy context. Since then, statistical work on patents has advanced significantly, at the OECD, in member countries and in academia. This manual takes account of these developments.

The manual shows what patent statistics can be used for, what they cannot be used for, and how to count patents in order to maximise information on S\&T activities while minimising "noise" and bias. Patent data provide unique insights into the processes and outcomes of inventive activities (e.g. the location of inventive activities, inventive networks, emerging technologies, etc.). Used with other data, they support the analysis of other dimensions of innovation that are of policy interest, such as the role of intellectual property in economic performance, entrepreneurship, and the tracking of linkages in the S\&T system. Yet, patent-based indicators suffer from several weaknesses and, as a result, they should be designed and interpreted with care, hence the need for this manual.

The Patent Statistics Manual belongs to the Frascati family of OECD manuals dealing with the measurement of scientific and technical activities, along notably with the Frascati Manual (R\&D), the Oslo Manual (innovation), and the Canberra Manual (human resources for S\&T), the last two of which are joint publications with Eurostat. These manuals are the outcome of work by the OECD and its group of national experts to conceptualise S\&T activities and develop statistical methods of measuring their most pertinent aspects along internationally agreed lines.

Andrew Wyckoff

Acting Director for Science, Technology and Industry, OECD
Fred Gault

Chair of NESTI

initiating

the first revision
Ward Ziarko

Current Chair of NESTI 
Acknowledgements. The drafting of the OECD Patent Statistics Manual was entrusted to Pluvia Zuniga and Dominique Guellec (OECD), with contributions from Hélène Dernis, Mosahid Khan, Teruo Okazaki and Colin Webb (OECD). A preliminary version was reviewed by national and international bodies involved in patenting (the European Patent Office, the Japan Patent Office, the United States Patent and Trademark Office and the World Intellectual Property Organization); by major users of patent data (Eurostat, the National Science Foundation of the United States and the NISTEP of Japan); and by a group of international experts in the field, including Prof. Akira Goto (Fair Trade Commission, Japan), Prof. Stuart Graham (Georgia Tech, United States), Françoise Laville (Observatoire des sciences et techniques, France), Catalina Martinez (CSIC, Spain), Prof. Ulrich Schmoch (FhG-ISI, Germany) and Prof. Jun Suzuki (Institute for Future Technology, Japan). 


\section{Table of Contents}

Foreword $\ldots \ldots \ldots \ldots \ldots \ldots \ldots \ldots \ldots \ldots \ldots \ldots \ldots \ldots \ldots \ldots \ldots \ldots \ldots, \quad 3$

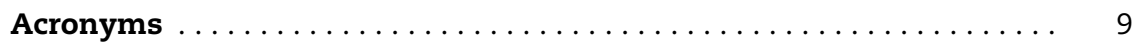

Chapter 1. Objectives and Scope of the Manual............... 11

Reference.................................... 16

Chapter 2. Patents as Statistical Indicators of Science and Technology . 17

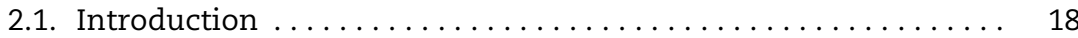

2.2. Legal foundations of patents $\ldots \ldots \ldots \ldots \ldots \ldots \ldots \ldots \ldots \ldots \ldots$

2.3. Administrative routes for protection $\ldots \ldots \ldots \ldots \ldots \ldots \ldots . \ldots \ldots$

2.4. Economic foundations of patents ................. 21

2.5. The information content of patent documents........... 24

2.6. Patents as statistical indicators of inventive activity ........ 26

2.7. Patent databases............................. 29

2.8. Topics of investigation $\ldots \ldots \ldots \ldots \ldots \ldots \ldots \ldots \ldots \ldots \ldots \ldots \ldots, 30$

Notes........................................ 32

References ...................................... 34

Annex 2.A1. ........................................ 35

Chapter 3. Patent Systems and Procedures $\ldots \ldots \ldots \ldots \ldots \ldots \ldots \ldots . \ldots \ldots$

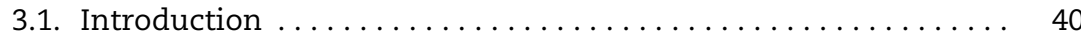

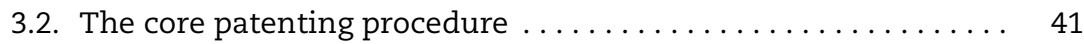

3.3. National and regional procedures $\ldots \ldots \ldots \ldots \ldots \ldots \ldots \ldots . \ldots \ldots \ldots$

3.4. International patent applications $\ldots \ldots \ldots \ldots \ldots \ldots \ldots \ldots, 53$

Notes....................................... 55

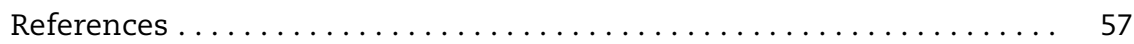

Chapter 4. Basic Criteria for Compiling Patent-Based Indicators ....... 59

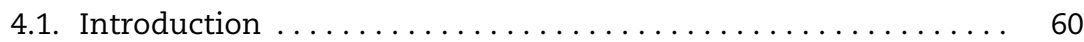

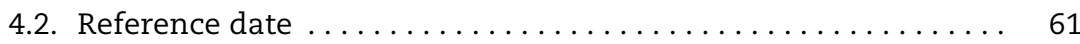

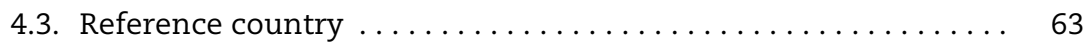

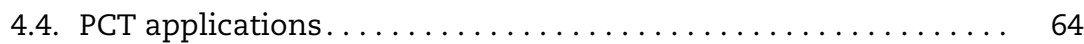

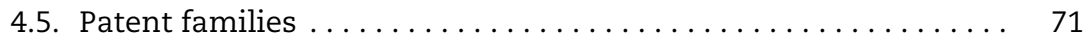

4.6. Normalised country-level patent indicators ........... 74

Notes. . . . . . . . . . . . . . . . . . . . . . . . . . . $\quad 75$ 
References ................................. 75

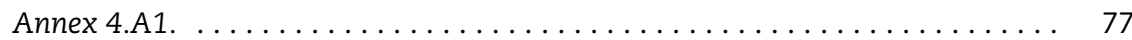

Chapter 5 . Classifying Patents by Different Criteria . . . . . . . . . . 83

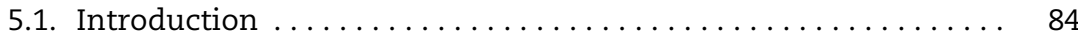

5.2. Technology fields . . . . . . . . . . . . . . . . . . 84

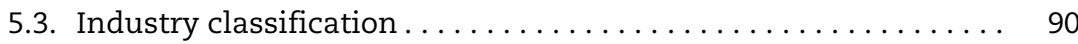

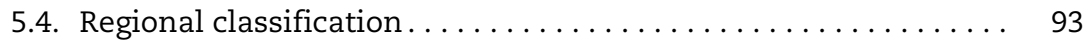

5.5. Institutional sectors . . . . . . . . . . . . . . . . . . 94

5.6. Patents by companies . . . . . . . . . . . . . . . . 97

5.7. Patents by inventors . . . . . . . . . . . . . . . . . . 99

Notes. . . . . . . . . . . . . . . . . . . . . . . . . . . . . . . . . . . . . 100

References .................................. 101

Chapter 6. The Use and Analysis of Citations in Patents . . . . . . . . . 105

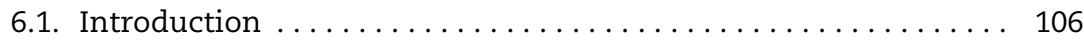

6.2. What are citations? . . . . . . . . . . . . . . . . . . 106

6.3. Uses and applications of citations indicators . . . . . . . . . 107

6.4. Citation practices in patent offices . . . . . . . . . . . . 108

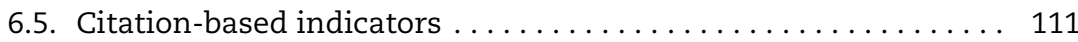

6.6. Non-patent literature. . . . . . . . . . . . . . . . . . 116

6.7. Other indicators based on the categories of citations

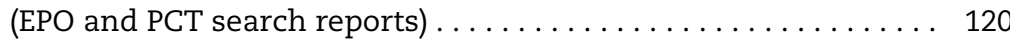

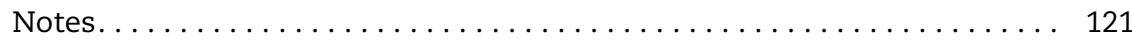

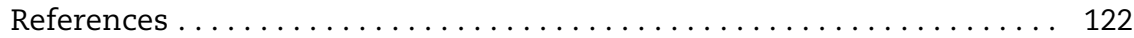

Chapter 7. Indicators of the Internationalisation

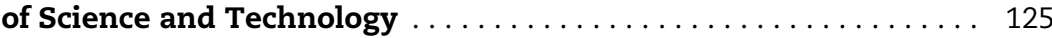

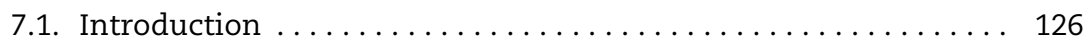

7.2. Indicators. . . . . . . . . . . . . . . . . . . . 127

7.3. Ownership and research strategies . . . . . . . . . . . . 132

Notes. . . . . . . . . . . . . . . . . . . . . . . . . . . . . . 133

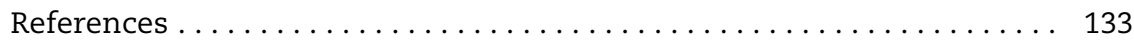

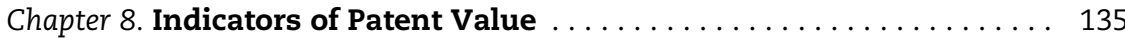

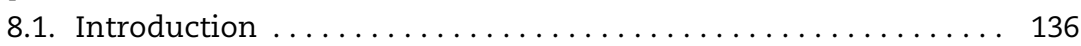

8.2. Forward citations . . . . . . . . . . . . . . . . 138

8.3. Indicators based on procedural information and applicants' behaviour........................... 139

8.4. Other indicators . . . . . . . . . . . . . . . . . . . 144

Notes. . . . . . . . . . . . . . . . . . . . . . . . . . . . . . . . . . . . 146

References ................................. 148

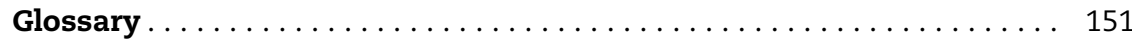




\section{List of Boxes}

1.1. A sample of regular patent statistics . . . . . . . . . . . 15

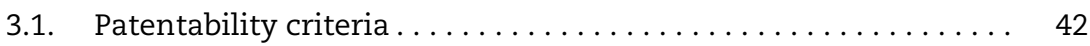

3.2. Main provisions of the TRIPs Agreement ... . . . . . . . . . 44

4.1. Methodologies for nowcasting ................. 69

4.2. Nowcasting methods based on transfer rates . . . . . . . . 70

4.A1.1. Other definitions of patent families. . . . . . . . . . . . 78

6.1. The problem of equivalents. . . . . . . . . . . . . . 110

7.1. Regional dispersion of patenting ................ 131

8.1. Reforms concerning the designation of states . . . . . . . . . 143

8.2. A combined indicator (European protection):

the scope year index. . . . . . . . . . . . . . . . 144

\section{List of Tables}

3.1. Differences between the three main patent offices. . . . . . . . 47

4.A1.1. Differences in patent counts (EPO filings and grants) depending on the reference selected, $2000 \ldots \ldots \ldots \ldots \ldots$

4.A1.2. Country shares in EPO applications with various criteria

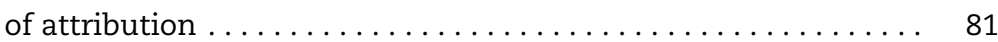

5.1. Main characteristics of IPC codes (example) . . . . . . . . . 86

5.2. Examples of keywords/clues used to identify patentee sectors. . 96

6.1. Occurrence of patent and non-patent references (USPTO and EPO) . . . . . . . . . . . . . . . . . . . . . 109

6.2. Occurrence of USPTO and EPO journal and non-journal references............................ 117

6.3. Occurrence of USPTO and EPO non-journal sources . . . . . . . 118

6.4. Citation categories at the EPO and PCT . . . . . . . . . . . . 120

8.1. Main indicators of patent value discussed in the literature. . . . 140

8.2. Shares of countries in total patent applications under different indicators (priority date 2000) . . . . . . . . . . 141

\section{List of Figures}

2.A1.1. Front page of an EPO patent application ............ 35

2.A1.2. Sample front page of a JPO patent application ........... 36

2.A1.3. Front page of a USPTO published patent application . . . . . . . 37

2.A1.4. Front page of a PCT application $\ldots \ldots \ldots \ldots \ldots \ldots \ldots \ldots \ldots . \ldots \ldots$

3.1. Timeline for PCT procedures................. 54

4.1. Share of countries in patents taken at the three major regions,

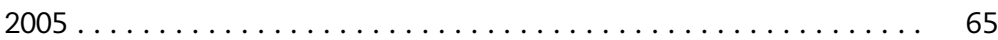

4.2. Patents applied for under the PCT procedure, EPO designations....................... 66 
4.3. Share of countries in patents filed under the PCT procedure,

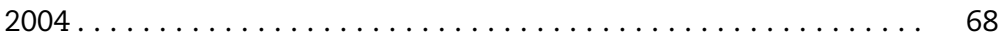

4.4. Share of Euro-PCT applications entering the regional phase,

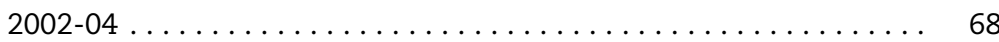

4.5. Share of countries in total triadic patent families,

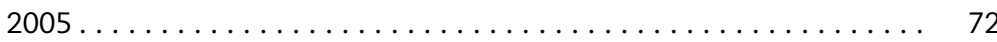

4.6. Example of close and extended patent families. . . . . . . . 73

4.7. Triadic patent families over GDP, $2005 \ldots \ldots \ldots \ldots \ldots \ldots . \ldots 74$

4.8. Triadic patent families per million population, 2005. . . . . . . 74

5.1. Trends in patenting of fuel cells, share of patents filed

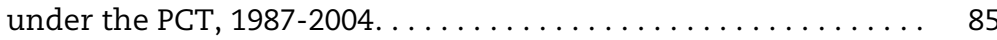

5.2. Share of countries in fuel cell patents, $1987-2004 \ldots \ldots \ldots \ldots . . .29$

5.3. Share of related-techniques in fuel cell patents,1987-2004 . . . . 89

5.4. Specialisation index of biotechnology patents filed at the EPO,

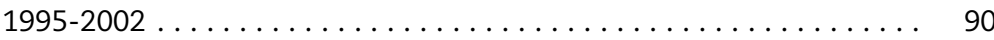

5.5. Patenting by industry and business R\&D,PCT applications

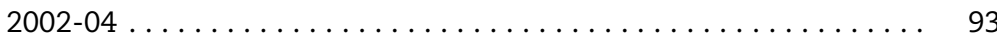

5.6. ICT patents by region in Europe, the United States and Japan . . 95

6.1. Share of NPL in citations in search reports of PCT patent applications . . ...................... 119

6.2. Share of NPLin citations - all patents . . . . . . . . . . . . 119

6.3. Share of NPL in citations - ICT . . . . . . . . . . . . . . . 119

7.1. Globalisation of S\&T based on patent indicators .......... 129

7.2. Foreign ownership of domestic inventions.... . . . . . . . . . 129

7.3. Domestic ownership of inventions made abroad . . . . . . . . . 130

7.4. Composition of cross-border ownership in PCT applications ... 133 


\section{Acronyms}

\begin{tabular}{|c|c|}
\hline AFA & Activity of Foreign Affiliates Database \\
\hline ARIPO & African Regional Intellectual Property Organization \\
\hline BEA & Bureau of Economic Analysis (United States) \\
\hline CAFC & Court of Appeals of the Federal Circuit (United States) \\
\hline CIP & Continuation-in-Part \\
\hline CIPO & Canadian Intellectual Property Office \\
\hline DPMA & Deutsches Patent- und Markenamt (Germany) \\
\hline ECLA & European Classification System \\
\hline EPC & European Patent Convention \\
\hline EPLA & European Patent Litigation Agreement \\
\hline EPO & European Patent Office \\
\hline EU & European Union \\
\hline FhG-ISI & Fraunhofer Institute for Systems and Innovation Research \\
\hline GATT & General Agreement on Trade and Tariffs \\
\hline ICT & Information and communication technologies \\
\hline IIP & Institute of Intellectual Property (Japan) \\
\hline INID & $\begin{array}{l}\text { Internationally agreed numbers for the identification } \\
\text { of bibliographic data }\end{array}$ \\
\hline INPI & Institut National de la Propriété Intellectuelle (France) \\
\hline IPC & International Patent Classification \\
\hline IPRP & International preliminary report on patentability \\
\hline ISA & International search authorities \\
\hline ISIC & International Standard Industrial Classification \\
\hline ISR & International search report \\
\hline NACE & $\begin{array}{l}\text { Classification of Economic Activities in the European } \\
\text { Community }\end{array}$ \\
\hline NAICS & North American Industry Classification System \\
\hline NBER & National Bureau of Economic Research (United States) \\
\hline NISTEP & National Institute of Science and Technology Policy (Japan) \\
\hline NSF & National Science Foundation (United States) \\
\hline NUTS & $\begin{array}{l}\text { Nomenclature of territorial units for statistics } \\
\text { (Nomenclature des unités territoriales statistiques) }\end{array}$ \\
\hline OECD & Organisation for Economic Co-operation and Development \\
\hline OST & Observatoire des Sciences et des Techniques (France) \\
\hline
\end{tabular}


PATSTAT Worldwide Statistical Patent Database (EPO)

PCT Patent Co-operation Treaty

SIC Standard Industrial Classification

SIPO State Intellectual Property Office of the People's Republic of China

SMEs Small and medium-sized enterprises

STAN Structural Analysis Database

TL Territorial level

TRIPS Trade-related intellectual property rights

USPC United States Patent Classification System

USPTO United States Patent and Trademark Office

WIPO World Intellectual Property Organization

WOISA Written opinion of the international search authorities

WTO World Trade Organization 
Chapter 1

Objectives and Scope of the Manual 
$\mathrm{T}$

he aim of this manual is to provide basic information about patent data used in the measurement of science and technology (S\&T), the construction of indicators of technological activity, as well as guidelines for the compilation and interpretation of patent indicators.

Alongside other science and technology indicators, such as R\&D expenditure and personnel, innovation survey data, etc., patents provide a uniquely detailed source of information on inventive activity. Patent data complement other S\&T data, and it is generally good to use several types of data in conjunction ( $R \& D$, innovation, patents) as a means of cross-validation and to help in interpretation. These indicators have their strengths and weaknesses; they also reflect various stages in the innovation process. This manual is part of the "Frascati" family of OECD manuals, which includes the Frascati Manual on R\&D, the Oslo Manual on innovation, the Technology Balance of Payments (TBP) Manual, and the Canberra Manual on human resources for science and technology.

Patent statistics have been used to assess S\&T activities for a long time. Widely reported work was carried out in the 1950s by Jakob Schmookler, a US scholar, who used patent counts as indicators of technological change in particular industries. The use of patent data expanded in parallel with the power of computers. The OECD held a conference on new S\&T indicators in 1985, at which patent statistics were central to several presentations, and S\&T publications increasingly included a section on patent indicators. Reflecting a broadening use of patent data by academics, Zvi Griliches published in 1990 a now classic paper assessing ways of using such data. The OECD produced its first Patent Manual in 1994. At the same time, patent offices were expanding efforts to monitor patenting activity through extensive statistics. Several companies have flourished by selling patent-based business intelligence using a statistical approach. Data increasingly became available electronically, and the EPO Worldwide Patent Statistics Database (PATSTAT), which gathers standardised data from almost all of the world's patent offices, was published in 2006 by the European Patent Office.

Patents are a means of protecting inventions developed by firms, institutions or individuals, and as such they may be interpreted as indicators of invention. Before an invention can become an innovation, further entrepreneurial efforts are required to develop, manufacture and market it. Patent indicators convey information on the output and processes of inventive activities. Patents protect inventions and, although the relationship is not a simple one, research has 
shown that when the proper controls are applied, there is a positive relationship between patent counts and other indicators related to inventive performance (productivity, market share, etc.). This relationship varies across countries and industries and over time. Along with the information reported in patent documents, the statistical exploitation of these data offers unique insight into invention processes. Patents provide information on the technological content of the invention (notably its technical field) and the geographical location of the inventive process. Because patents identify owners and inventors, they can reveal the organisation of the underlying research process when matched with complementary data (e.g. alliances between firms or between firms and public research organisations, the respective role of multinationals and small firms, size and composition of research teams, etc.). Patents can also provide information about inventors' mobility and networks, and they make it possible to track the diffusion of knowledge (the influence of particular inventions on other, subsequent inventions).

Another advantage of patent data is broad availability at relatively low cost. Patent data are administrative data. Patent databases are compiled by patent offices for internal purposes in order to manage their administration of patent examinations and to disseminate information. They are available on the Internet for public consultation. Adapting these databases for statistical use requires further investment, but they are now quite broadly available. The reduction in computer costs makes it easier to use these data on a large scale and in decentralised and open way. No confidentiality rules forbid access to published patent information, although publication generally only takes place 18 months after the first filing. As a result, patent data are publicly available for most countries across the world, often in long time series.

Patent indicators have drawbacks as well, which is why they must be used and interpreted with caution. Not all inventions are patented. Companies can prefer secrecy, or rely on other mechanisms in order to gain market dominance. There is evidence of differing patenting behaviour across industries and countries and over time. The value distribution of patents is known to be skewed, as a few have very high technical and economic value whereas many are ultimately never used. Simple counts, which give the same weight to all patents regardless of their value, can therefore be misleading, notably in the case of small samples. Different standards across patent offices and over time affect patent numbers although underlying inventive activities may remain unaffected.

Patent data are complex. It is necessary to have precise knowledge of patenting laws and procedures and the patenting behaviour of companies to be able to apply proper controls and filters to the data, obtain meaningful indicators, and interpret them correctly. The complexity of patent data is due to various factors, e.g. the diversity of patent offices and procedures (which 
can be national or regional in their judicial scope); the variety of ways to file for patent protection (national or international) and the changing behaviour of applicants in this regard; and the patent document's differing status and dates in line with the complexity of procedures (applications, grants, international phase, etc.). In addition, experts may still be debating some patent information (value indicators, number of citations/claims, etc.).

With the burgeoning of patent-based statistics, it is necessary to share knowledge on how to use the data and to develop standards that will improve the quality of indicators and reduce the scope for possible misinterpretation. For instance, it is still common for analysts to compare patent counts from different patent offices to assess countries' performance, although these are usually not directly comparable. This manual: i) provides background information necessary to understand or to compile patent-based statistics; and ii) proposes standards (formulae for indicators and vocabulary) for compiling patent indicators. However, standards are proposed only in areas in which experts have reached some consensus. In certain areas, notably the most recent, no consensus has yet emerged, and the manual will indicate the various options under discussion. The target audience of the manual is: i) users and compilers of patent statistics in statistical agencies and S\&T agencies; and ii) users of patent databases who conduct analytical work on the dynamics of technology at the company, regional or national level.

This is a revised version of the 1994 OECD manual (The Measurement of Scientific and Technological Activities: Using Patent Data as Science and Technology Indicators), which marked a first step in the process of clarifying and harmonising patent-based indicators. It described the legal and economic background of patents - a necessary step before designing statistics - and listed indicators that could be constructed from patent databases. It also named a number of methodological problems encountered when calculating indicators based on patents. Since 1994, experience with patent data has developed substantially, and it is the ambition of this revised version of the manual to take account of that experience. The manual reflects notably, but not exclusively, the experience of the OECD and members of the Taskforce on Patent Statistics in developing statistical standards for compiling patent indicators for measuring inventive activity. Members of this task force are: the European Patent Office (EPO), the Japan Patent Office (JPO), the United States Patent and Trademark Office (USPTO), the World Intellectual Property Organization (WIPO), Eurostat, and the US National Science Foundation (NSF).

Today, most if not all national and international S\&T statistical reports include a section on patents (see Box 1.1). At the same time, an increasing number of policy reports use patent data to monitor developments in particular technical or institutional fields. A new field of academic research has emerged which makes use of patent data. 


\section{Box 1.1. A sample of regular patent statistics}

\section{S\&T publications}

United States (2006): Science and Engineering Indicators (National Science Foundation).

Patents granted to US and foreign inventors by country/economy of origin. Top patenting corporations.

Japan (2004): Science and Technology Indicators (National Institute of Science and Technology Policy - NISTEP).

Number of domestic and foreign patent applications originating in selected national patent offices.

Eurostat (2007): Statistics in Focus, statistical books and pocket books on science, technology and innovation in Europe.

EPO and USPTO patents, by country, by region.

Triadic patent families.

OECD (2007): Compendium of Patent Statistics.

Triadic patent families, ICT, biotechnology and nanotechnology patents.

Cross-border ownership of inventions, cross-border co-inventorship in patents.

France (2006): Observatoire des Sciences et Techniques, Indicateurs de sciences et de technologies 2006.

Finland (2006): Patenting, Statistics Finland.

\section{Patent offices and related organisations}

WIPO Statistics (2006): PCT Statistical Indicators Report.

PCT international applications (by origin, language of filing, technical field). PCT international applications by receiving office.

Trilateral Statistical Report (Yearly): EPO, JPO and USPTO.

Patent activity by blocs: first filings, origin and targets of applications, grants.

Inter-bloc activity: flows of applications, patent families.

European Patent Office: Annual Report.

Japan Patent Office: Annual Report.

US Patent and Trademark Office: Patent Statistics Reports.

US Patent and Trademark Office: Annual Report and Patent Statistics Reports.

This manual is structured as follows. Chapter 2 addresses the meaning of patent indicators: the legal foundations, the economic dimension, the information contained in patent documents, and the type of analytical questions that patent indicators can address. Chapter 3 details patenting procedures, focusing on Europe, Japan, the United States and the international procedure (Patent Cooperation Treaty). Chapter 4 reports the general rules 
that apply when compiling patent indicators: reference date, reference country, international us. national patent applications, and patent families. Chapter 5 describes the various classifications which can apply to patents: technical field, industry, institutional sector and region, and reviews methods of attributing patents to particular companies or inventors. Chapter 6 deals with patent citations: their meaning and their use in indicators. Chapter 7 reviews patent-based indicators of the internationalisation of S\&T activities. Chapter 8 discusses indicators of patent value, such as renewal, family size, number of technical classes, etc.

\section{Reference}

Griliches, Z. (1990), "Patent Statistics as Economic Indicators: A Survey", Journal of Economic Literature, No. 28, pp. 1661-1707. 


\section{Chapter 2}

\section{Patents as Statistical Indicators of Science and Technology}




\subsection{Introduction}

The statistical properties of patent data are determined by their legal characteristics and by their economic implementation, as these influence which inventions are protected, by whom, what information is disclosed (hence made accessible to statisticians), how important patents are for industries, etc. This chapter provides an overview of the legal and economic foundations of patents. It describes the basic concepts necessary for the use of patent as indicators of science and technology (S\&T).

\subsection{Legal foundations of patents}

Patents are legal instruments used in economic life. A patent is a legal title protecting an invention (Article 28 of the Trade-Related Intellectual Property Rights [TRIPS] Agreement):

"I. A patent shall confer on its owner the following exclusive rights:

a) where the subject matter of a patent is a product, to prevent third parties not having the owner's consent from the acts of: making, using, offering for sale, selling, or importing for these purposes that product;

b) where the subject matter of a patent is a process, to prevent third parties not having the owner's consent from the act of using the process, and from the acts of: using, offering for sale, selling, or importing for these purposes at least the product obtained directly by that process.

II. Patent owners shall also have the right to assign, or transfer by succession, the patent and to conclude licensing contracts".

Patents grant their owner a set of rights of exclusivity over an invention (a product or process that is new, involves an inventive step and is susceptible of industrial application) as defined by the "claims". The legal protection conferred by a patent gives its owner the right to exclude others from making, using, selling, offering for sale or importing the patented invention for the term of the patent, which is usually 20 years from the filing date, and in the country or countries concerned by the protection. This set of rights provides the patentee with a competitive advantage. Patents can also be licensed or used to help create or finance a spin-off company. It is therefore possible to derive value from them even if their owner does not have its own manufacturing capability (e.g. universities). 
Patents are temporary rights, valid for a maximum of 20 years after the date of application, after which the invention they protect falls into the public domain. ${ }^{1}$ Patents are territorial rights which only apply to the country for which the patents have been granted. For instance, a patent granted in the United States will not confer exclusivity in Japan - it will only prevent the patenting of the same invention in Japan (since worldwide novelty is required to obtain a patent). Patents are granted to inventions in all fields of technology. In general, laws of nature, natural phenomena and abstract ideas are not patentable (there is of course debate about the boundaries of the system e.g. is software an "abstract idea" or is it a patentable invention?).

\subsection{Administrative routes for protection}

Patents are obtained after following specific administrative procedures. ${ }^{2}$ In order to obtain a patent, the inventor has to file an application at a patent office which checks whether the invention fulfils the relevant legal criteria, and grants or rejects it accordingly. There are different alternative "routes" for protection available to inventors, who will choose one or another depending on their national or worldwide business strategy.

- National route. When an inventor (an individual, company, public body, university, non-profit organisation) decides to protect an invention, the first step is to file an application with a national patent office (generally the national office of the applicant's country). The first application filed worldwide (in any patent office) for a given invention is known as the priority application, to which is associated a priority date. The patent office then begins "searching and examining" the application in order to learn whether or not a patent may be granted, i.e. whether the invention is directed to patentable subject matter, is novel, inventive ("non-obvious to persons skilled in the art") and capable of industrial application. The application is generally published 18 months after it is filed (publication date). The time lag between filing and grant or refusal of patents is not fixed; it ranges from two to eight years, with significant differences across patent offices.

- International route. Since 1883 , when procedures were standardised under the Paris Convention (about 170 signatory countries in 2006), applicants who wish to protect their invention in more than one country have 12 months from the priority date to file applications in other Convention countries, and if they do so the protection will apply from the priority date onwards in the countries concerned. Alternatively, inventors can use the PCT (Patent Cooperation Treaty) procedure, which has been in force since 1978 and is administered by the World Intellectual Property Organization (WIPO). The PCT procedure makes it possible to delay national or regional procedures significantly (until the end of the thirtieth month from the priority date) 
through a unified filing procedure (see Chapter 3). Applicants therefore have more time to fulfil national requirements and can use the time to evaluate chances of obtaining patents and of exploiting the invention (estimate competition, find licensed parties, etc.). ${ }^{3}$ It is now the most popular route among inventors targeting worldwide markets.

- Regional routes. Applicants can also submit a patent application to a regional office (e.g. Eurasian office, ARIPO). For instance, the EPO (European Patent Office) is a regional office with 32 members in 2007which searches and examines patent applications on behalf of European countries. EPO grants "European patents", which are valid in all its member states in which the holder has validated his rights. Validation requires translation into the national language and payment of national fees. In this national stage, European patents are subject to national laws.

National patent laws have to comply with international standards, now laid down in the TRIPS (Trade-related Aspects of Intellectual Property Rights), an international treaty which is part of the WTO (World Trade Organization) package signed in 1994. Provided that a country is a member of the WTO, TRIPS imposes strict conditions on that country, such as patentability of inventions in all fields of technology, minimal term of patents of 20 years, limitations of compulsory licensing, etc.

After it is granted by an administrative authority, a patent can still be challenged by third parties. They can do so through the legal system, requesting that a patent be revoked or deemed invalid. In such cases, the patent holder must go to court in order to enforce the disputed patent, alleging third-party infringement. This is, again, a purely national process, even in Europe. ${ }^{4}$

The procedure for obtaining a patent involves the disclosure of much information for legal or administrative purposes. This information is potentially of great interest to statisticians. The front page of patent applications to the WIPO, EPO, JPO and USPTO are shown in Figures 2.A1.1 to 2.A1.4. Useful information found in patent documents includes:

- Number and type of application, publication number, etc. ${ }^{5}$

- Name and address of the inventor; name and address of the applicant or assignee (usually the company employing the inventor).

- Technical details regarding the invention: title, abstract, detailed description of the invention, indicating how it is constructed, how it is used and what benefits it brings compared with what already exists.

- A list of claims, which is a clear and concise definition of what the patent legally protects.

- A series of codes corresponding to items in a technology classification.

- A series of dates: date of priority, application, grant, etc. 
- A list of references to other patents or scientific literature considered as relevant to the determination of patentability of the invention.

\subsection{Economic foundations of patents}

The stated purpose of the patent system is to encourage invention and technical progress by providing a temporary period of exclusivity over the invention in exchange for its disclosure. By providing protection and exclusivity, a patent is a policy instrument intended to encourage inventors to invest in research and the subsequent innovative work that will put those inventions to practical use.

Patents reinforce inventiveness in different ways (Scotchmer, 2004, Guellec and van Pottelsberghe, 2007). Because they reveal new knowledge through disclosure of inventions, they diffuse information that might otherwise be kept secret, thereby enabling other inventors to develop new inventions. By diffusing information on inventions that have been achieved and are protected, the patent system also deters needless duplication of $R \& D$ efforts, encouraging researchers to focus on really new areas. In addition, as patents are legal titles, they can be traded. Patent rights thus facilitate the development of technology markets, which improves the allocation of resources (for technology use) in the economy. Patent rights allow the most efficient users to implement inventions (e.g. through licensing for instance) even if they did not necessarily invent them or to exchange technologies needed for further innovations.

The reason for providing a legal framework to protect inventions is that information is a public non-excludable and non-rival good. "Non-excludable" means that it is impossible to exclude those who did not bear the cost of invention from using the good (i.e. it permits "free riding"). A "non-rival" good is one the consumption of which by one person does not reduce the quantity available to other individuals (i.e. the marginal cost is zero). Patent rights make the invention excludable, as the authorisation of the inventor is needed to use it, while keeping it non-rival, so that many entities can use it at the same time.

However, information (knowledge) is not a perfect public good and it can be protected in ways other than patents, or in most cases, in a way that complements patents (Blind et al., 2002). Other strategies to protect returns to inventions are secrecy, ${ }^{6}$ rapid launch and short product development cycles, low prices and other competitive approaches (production and marketing capabilities; after-sales service; long-term contracts). Various business surveys have confirmed the use of these strategies (Levin et al., 1987; Cohen et al., 2000). For instance, in the Carnegie Mellon Survey (1994) of American firms, it was found that secrecy and lead time were ranked overall as the two most effective appropriability mechanisms for product innovations, each with scores of just over $50 \%$. Furthermore, companies declared that patent applications are only submitted for $52 \%$ of product inventions 
and 33\% of process inventions. In the NISTEP Survey (Goto and Nagata, 1997) of Japanese firms, it was found that lead time (41\%) was also ranked as the most effective appropriability mechanism for product innovations, and that complementary assets for manufacturing (33\%) followed protection by patents (38\%). In the EPO applicant panel survey of 2006, it was found that about $50 \%$ of inventions become patented, with the highest proportions in audio, video, and media and electronics (about 70\%). The lowest proportions were in biotechnology and pure and applied organic chemistry, at about $25 \%$.

Patents face a trade-off. They encourage new inventions ex ante, but have a cost ex post. By giving exclusive use to a particular company, a patent will limit competition and allow higher prices, thereby excluding customers who would have been ready to pay the marginal cost of a good but cannot pay the mark-up charged by the patent owner. This is considered the central dilemma created by patents: they improve the dynamic efficiency of the economy (by fostering innovation, hence growth and value creation), but they do so to the detriment of static efficiency (reduced competition and thus higher prices, which excludes some consumers). ${ }^{7}$ Patent policy provides various tools to deal with this dilemma. In particular, both the duration of patent protection and its breadth (how different another product must be in order not to be an infringement) are instrumental in influencing the balance between protection and diffusion: longer and broader patents favour protection, while shorter and narrower ones favour diffusion.

Policy design is more difficult in the case of cumulative invention (or complementary invention, i.e. inventions building on each other). In this case, certain studies argue that patents can limit the use of technologies which are necessary for further innovation, as follow-on inventors should not infringe patented knowledge although they need it for their own inventions. This configuration of cumulative inventions raises the policy issue of how to balance the protection given to the initial invention and to the follow-on invention. This dilemma exists for instance in biotechnology, as regards particular treatments (which are patented) associated with certain genetic pathways (which are also patented). In the case of new inventions relying on several inventions patented in the past, which happens in biotechnology and software, the new inventor needs to negotiate access to each of the existing inventions. In these cases, it has been argued that transactions are potentially so costly as to deter the new invention in the first place. There are some patentbased solutions for reducing transaction costs, such as patent pools (consortia of companies agreeing to cross-license their patents and license them to third parties), and patent clearing house models which aim to standardise transactions (in terms of contracting clauses, royalty rates, etc.). However, in order to ensure conformity with patent rights and a well-functioning market, patent policies must abide by competition policies and anti-trust laws. ${ }^{8}$ 
Because of these advantages and drawbacks in the use of patents as policy instruments, there is an ongoing debate among economists about the best design for a patent system and whether it is in the interest of society to have such a system in the first place. No absolute consensus has emerged, but there is broad agreement on the following points:

- Patents granted should be of "high quality", meaning that they should cover significant inventions only and reveal the actual content of the invention.

- Competition policy should keep close watch on the patent system.

- The patent system should be used as a complement to other instruments of innovation policy, notably science policy, sectoral policies and public procurement.

- Mechanisms that facilitate the circulation of and access to patents should be encouraged, although not to the detriment of competition (e.g. patent pools, licensing contracts, etc.).

Since the early 1980s, important market and policy changes have helped to expand the role of patents in the economy. With increased international competition, the emergence of information technologies and biotechnology, and the increased importance of start-ups and firms specialised in $R \& D$, the use of patents has become more widespread among innovative firms. The growing relevance of technological competition in markets has increased the importance of intellectual property rights in companies' economic value. In parallel, since the early 1980s, patent policy worldwide has been oriented towards strengthening the rights of patent holders. In the United States, the Federal Court Improvements Act, enacted in March 1982, created the Court of Appeals of the Federal Circuit (CAFC) to consolidate patent decisions (the CAFC was assigned jurisdiction over appeals of patent cases in all federal circuits); and from 1980 the Bayh-Dole Act enabled non-profit research groups to patent and commercialise technologies developed with federal funds, in view of facilitating their commercialisation.

In Europe, the creation of the European Patent Office (established in 1977) led to stronger patents in many countries. In Japan, a series of reforms since the late 1990s has tended to reinforce patent holders' rights. The signature of the TRIPS in 1994 showed countries' willingness to push for greater harmonisation of patent rights. As a result of these moves, the number of patent applications worldwide rose considerably between the mid-1990s and the mid-2000s and continues to rise. For instance, the number of patent applications at the EPO grew by $6 \%$ a year on average over the period 1995-2005, while at the USPTO applications rose by an average of $7 \%$ a year (OECD, 2007). ${ }^{9}$

The patent landscape changed markedly as a result, as new actors have emerged (universities) and non-standard uses of patents have expanded (e.g. licensing, raising capital). It is important to keep this changing context in 
mind when interpreting patent statistics, especially time trends and crosscountry or cross-industry comparisons.

\subsection{The information content of patent documents}

A patent document contains a large amount of information, all of which has potential for statistical analysis. This is not only true for the bibliographic information gathered on the front page, but also even for the abstract, the claims, and the description of the invention, which can be subjected to textual analysis. For statistical purposes, information contained in a patent document can be grouped into three distinct categories:

- Technical description of the invention.

- Development and ownership of the invention.

- History of the application.

Most of the types of information explained below are available regardless of the patent office at which the application is filed, as information requirements and procedures are quite standardised throughout the world. Some of the procedural information is not available from the patent documents themselves, but is recorded and published by patent offices in other ways.

\subsubsection{Technical description of the invention}

- Title and abstract (describes the invention).

- The list of "claims". This describes the innovative content of the claimed field of exclusivity. The claims define the scope of protection of the patent rights (legal boundaries). It can be more or less broad or narrow, depending on the content and number of claims.

- The technical classes to which the invention pertains (based on patent classification). These are fixed by patent examiners. The most commonly used classification is the International Patent Classification (IPC) system. In parallel, the national (e.g. USPC at the USPTO) or regional (ECLA at the EPO) patent classification is contained in the patent document (e.g. ECLA is very detailed, with more than 100000 categories; it is a breakdown of the IPC).

- Prior art. Each patent lists prior art relevant to the invention. The prior art determines the boundaries of what is in the public domain and what the applicant is entitled to in relation to the claims. The cited (patent and nonpatent) references help to define the patent's claims and its specific uses and applications.

- Patent references. These are citations to previous relevant technology protected by or described in other patents filed anywhere in the world, at any time, in any language. 
- Non-patent references. These include scientific publications, conference proceedings, books, database guides, technical manuals, descriptions of standards, etc.

\subsubsection{Development and ownership of the invention}

- The list of inventors and their respective addresses. Inventors are individuals, usually employees of the patent applicants. In the United States, inventors are the applicants.

- The list of applicants (assignees in the United States) and their respective addresses. Applicants will have legal title to (be the owners of) the patent if it is granted. In the vast majority of cases, the applicants will be companies and the inventors their employees. However, it is also possible for the same person to be an inventor and an applicant (e.g. independent inventors). ${ }^{10}$

\subsubsection{History of the application}

- Publication number, application number, patent (grant) number. These numbers have various formats depending on the patent office. They can be used as identifiers when performing data analysis on patent databases.

- Priority number. This is the application or publication number of the priority application, if applicable. It makes it possible to identify the priority country, reconstruct patent families, etc.

- Priority date. This is the first date of filing of a patent application, anywhere in the world (usually in the applicant's domestic patent office), to protect an invention. It is the closest to the date of invention.

- Date of filing. This is the first day that protection will apply in the country concerned if the patent is granted.

- Date of publication. Patents are normally published (i.e. the information is available to the public) 18 months after the priority date. Prior to the publication of a patent document, the content of the document remains secret. ${ }^{11}$

- List of designation. For patent applications filed using the European Patent Convention or Patent Cooperation Treaty procedures, applicants are required to designate the member countries in which protection is being sought.

- Date of refusal or withdrawal. This indicates that the invention did not fulfil the statutory criteria (novelty, non-obviousness or industrial applicability) for patentability, or that the applicant decided to suspend the patent application during the examination process.

- Date of grant. There is a delay between the application date and the date of patent approval. In general, it takes between two and eight years for a patent to be granted. 
- Date of lapse. A patent can lapse prior to the statutory expiry date if renewal fees are not paid or if it is revoked by the courts. This "post-grant information" is usually available from "patent registers", which also record (depending on the country) changes in ownership, declared licensing contracts, etc. ${ }^{12}$

\subsection{Patents as statistical indicators of inventive activity}

Among the few available indicators of technology output, patent indicators are probably the most frequently used. Patent-based statistics have several uses. They allow for measuring the inventiveness of countries, regions, firms or individual inventors, under the assumption that patents reflect inventive output and that more patents mean more inventions. Empirical research has shown that patents are frequently a good predictor of economic performance. In a study of 258 R\&D professionals, Keller and Holland (1982) concluded that the number of an inventor's patents is significantly correlated with superior performance ratings and self-rating. In a study of 1200 companies in high-technology industries, Hagedoorn and Clood (2003) concluded that the number of patents filed by a company is a very good reflection of its technological performance. At the country level, de Rassenfosse and van Pottelsberghe (2008) have found a high correlation between patent numbers and R\&D performance.

Patents statistics are also used to map certain aspects of the dynamics of the innovation process (e.g. co-operation in research, diffusion of technology across industries or countries, etc.), or of the competitive process (the market strategy of businesses); they are also used to monitor the patent system itself. In addition, patents are helpful for tracking globalisation patterns. For example, using the inventor's address, patent indicators can be developed to monitor the internationalisation of research, i.e. international co-invention in S\&T activities or the mobility of inventors across countries.

Whereas patent applications are an indicator of successful research -notably in a particular line of research or in a programme - patents do not reflect all of the research and innovative efforts behind an invention. Conversely, an invention covered by a patent (a new product or process) need not actually be industrially applied. It is reported that many patents are never implemented, because, having submitting an application, the inventor realises that the invention does not have sufficient economic value or that a superior invention can be marketed more rapidly. According to the PATVAL survey (2005), about $40 \%$ of patents in the sample are not used for industrial or commercial purposes for strategic reasons or because the owners lack the complementary downstream assets to exploit them: $18.7 \%$ are not used and aim to block competitors, and $17.4 \%$ are considered "sleeping patents" that are not used at all. 
Patents can also be considered as an intermediate step between $R \& D$ (upstream) and innovation (the invention is used downstream in economic processes). Patents can be obtained at different stages of the R\&D process, notably in the case of incremental or cumulative inventions. In this sense, patents can be seen not only as an output of R\&D but also as an input to innovation and thus as both inputs and outputs in the invention process. This intermediate character makes patent data a useful bridge between R\&D data and innovation data (both of which are collected through business surveys).

Patent data have advantages and disadvantages for reflecting inventive activities. Their major advantages are:

- Patents cover a broad range of technologies for which there are sometimes few other sources of data (i.e. nanotechnology).

- Patents have a close (if imperfect) link to invention. Most significant inventions from businesses are patented, whether based on R\&D or not.

- Each patent document contains detailed information on the invention process: a reasonably complete description of the invention, the technology field concerned, the inventors (name, address), the applicant (owner), citations to previous patents and scientific articles to which the invention relates, etc. The amount of patent data available to researchers is huge. More than one million patents are applied for worldwide each year, providing unique information on the progress of invention. Patent data are public, unlike survey data which are usually protected by statistical secrecy laws.

- The spatial and temporal coverage of patent data is unique. Patent data are available from all countries with a patent system, i.e. nearly all of the world's countries. They are available - sometimes in electronic form - from first patent systems, which go back to the 19th century in most OECD countries.

- Patent data are quite readily available from national and regional patent offices. The marginal cost for the statistician is much lower than for conducting surveys although it is sometimes still significant (data need to be cleaned, formatted, etc.). Unlike survey data, collection of patent statistics does not put any supplementary burden on the reporting unit (e.g. business) because the data are already collected by patent offices in order to process applications.

However, as indicators of technological activity, patents have certain drawbacks:

- Not all inventions are patented. Inventions with few economic possibilities may not justify the cost of patenting. Inventions that make a trivial contribution to the art and non-technological inventions do not qualify under the legal requirements of patenting. Strategic considerations may lead the 
inventor to prefer alternative protection (secrecy), with the result that the patent data do not reflect such inventions (e.g. Pavitt, 1988).

- The propensity to file patent applications differs significantly across technical fields. For instance, in the electronics industry (e.g. semiconductors) a patented invention can be surrounded by patent applications on incremental variations of the invention, with a view to deterring the entry of new competitors and to negotiating advantageous cross-licensing deals with competitors. As a result of this "patent flooding" strategy, some technical fields have a larger number of patents than others. Companies' propensity to patent also differs: new or small and medium-sized enterprises (SMEs) notably those that lack large-scale production - have more difficulty covering the costs of a patent (although national policies attempt to deal with this problem by providing SMEs with subsidies or discount rates).

- Several studies have shown that the value distribution of patents is highly skewed (e.g. Pakes and Schankerman, 1986; Harhoff et al., 1999). Many patents have no industrial application (hence, are of little or no value to society), whereas a few have very high value. Nonetheless, the disclosure of information represents a benefit for society, as it increases the stock of knowledge. With such heterogeneity, simple patent counts can be misleading. This is not specific to patents, but a reflection of a prominent feature of the inventive process which also applies to R\&D expenditure (which often results in little success, but sometimes in huge success).

- Differences in patent law and practices around the world limit the comparability of patent statistics across countries. It is therefore preferable to use homogenous patent data (coming from a single patent office or single set of patent offices).

- Changes in patent laws over the years call for caution when analysing trends over time. The protection afforded patentees worldwide has been stepped up since the early 1980s, and companies are therefore more inclined to patent than before. The list of technologies covered has grown longer over time and in some countries now includes software and genetic sequences, which were previously excluded. Other variables such as office administration can have a substantial impact on patent counts, notably patents granted, during a particular time period.

- Patent data are complex, as they are generated by complex legal and economic processes. It is therefore important to take into account all of these factors when compiling and interpreting patent data, as failing to do so leads to erroneous conclusions.

Most of the limitations outlined above can be overcome by using appropriate methodologies to address data bias and limitations in order to limit their impact. For example, the issue of the skewed distribution of patent value can be 
addressed by weighting patent counts by number of citations, or by selecting a sub-sample of patents that are of similar value (e.g. triadic patents capture high-value patents, see Chapter 4). Similarly, to surmount the drawbacks associated with differing propensities to patent across industries, one can restrict the analysis to a sector or industry or weight the data appropriately.

Depending on the question addressed, patent data can be used in conjunction with other data, such as R\&D or innovation survey data, to investigate innovation and technological performance. This combination makes it possible to corroborate (or negate) interpretations drawn from each separate source of data, and data linking allows for extracting more information (e.g. in certain circumstances the degree of success of R\&D can be inferred from patent filings). Certain researchers have linked patent data with other data, such as R\&D surveys or other business data (notably private databases); others have developed special surveys which complement patent data in order to better measure the variables of interest, e.g. surveys of technology companies about their use of patents (Carnegie Mellon survey; Cohen et al., 2000), surveys of inventors to learn the process that led to the patents or the value of patents (Gambardella et al., 2005).

\subsection{Patent databases}

Patent databases have been developed for a long time. Databases including bibliographic information (described in Section 2.3) and the full text of patents are basic tools in the research and examination procedures carried out at patent offices, as they record the patented prior art. In the last decade, databases have expanded, linking patent data to other information: company data (e.g. after standardisation of applicants' names and matching to companies' lists of names), industry classifications, codification of territorial levels (regions) based on addresses (inventors or applicants), etc.

Patent databases can include additional information on the examination processes, such as the legal status of examination and the filing and publication of the application. Some other types of data are rarely codified by patent data producers. For instance, changes in ownership during the examination process or during the life of a patent are seldom registered in the traditional patent databases that are made available by patent offices.

Although patent data are produced by the patent authorities, patent databases using such data are also produced and published by private entities. Users should be attentive to the types of patent information contained in the databases and the kinds of information that can be reflected in the statistics and indicators.

Some patent databases widely used for statistical and research purposes are: the NBER Patent Citations Data Files created by Jaffe, Trajtenberg and Hall, 
with the assistance of researchers at the NBER and Case Western Reserve University; the EPO Worldwide Patent Statistical Database (also known as EPO PATSTAT) created by the EPO with the OECD Patent Statistics Task Force; and the IIP (Institute of Intellectual Property) patent database, which gathers internal patent data from JPO (Seiri Hyojunka Data).

\subsection{Topics of investigation}

Indicators and studies based on patent data are extremely diverse in terms of the publication format (statistical directories, policy reports, academic research); the level of aggregation of the data compiled (national, regional, company level, industry or technical field level); the approach taken (compilation of indicators, performance of econometric estimates); and the analytical or policy questions addressed. The following is a non-exhaustive list of topics addressed in the extensive literature that uses patent data:

- Technological performance. Patents are used to monitor the technological performance of companies (or other organisations), regions or countries. Compared to other output indicators such as publications, patents are a more proper indicator of activities closer to technology development. They help track technological leadership or positioning in a given technology field or area (e.g. indexes of revealed technological advantages) and changes over time. As indicators of technological performance, the level of technological specialisation and/or strength of a geographical region or country (or company) helps policy makers to identify weak and strong areas in national or regional innovation systems.

- Emerging technologies. Patent-based indicators are a unique means sometimes the only one available - to track the rise of emerging technologies (e.g. nanotechnology, biotechnology). Particular technical fields can be built up by using keywords or by searching in abstracts and patent descriptions. The detailed information provided in patent documents permits the identification of the companies or agencies active in these fields, the modes of invention (e.g. inter-institutional collaboration), the mapping of technology clusters, etc. Patent data can be used in conjunction with data on scientific publications. Business surveys usually come at a later stage of development, as they require precise advance knowledge of the field (notably of the active entities).

- Knowledge diffusion and the dynamics of technical change. Because they provide a detailed description of how the inventions have been made and the prior art, patents are a reliable measure of knowledge transfer. Patent citations point to the use of previous inventions in new inventions, which makes it possible to identify the influence of particular inventions or particular sets of inventions and map their diffusion in the economy. Citations of other patents or the non-patent literature (notably scientific publications) are useful 
in quantifying knowledge transfers across organisations (e.g. company to company or university to industry), geographical regions and/or technology fields, as well as knowledge spillovers from specific inventing entities (e.g. multinational to domestic firms or from public research centres to industry).

- Geography of invention. As the addresses of the inventor and applicant are reported, patents can be allocated across regions at any degree of detail (although this involves a non-negligible amount of work as the raw data are not always well formatted). Hence patent data can be used to study the geographical properties of inventive processes, e.g. the role of local actors in regional or national innovation (universities, small companies, large companies, etc.), their interactions, the profile and impact of regional technological specialisation, etc. ${ }^{13}$

- Creativity and social networks. Patent information can be used to track the career and performance of individual inventors (e.g. their field of work, location, employer), or to analyse networks of inventors (who invents with whom, etc.).

- The economic value of inventions. An invention's value is an important indication of its economic impact. Patent data provide unique access to information about the value of inventions. Correlations between the value of a patent and the number and quality of its (forward) citations have been demonstrated; this information can be exploited to compile indicators of the relative value of patents. By matching applicants' names with company data, patent data can be linked to economic data such as stock market data, accounting data, etc.

- Performance and mobility of researchers. As the inventor's name is reported in patent documents, it is possible to investigate aspects of inventiveness at the level of individual researchers. This involves a great deal of data cleaning, as identifying individuals in databases with millions of names is not a straightforward task. However, this information can be used to investigate issues such as researcher mobility (across companies or countries), differences in profiles across fields, who works with whom, gender issues (when identifiable with the aid of complementary data), etc. (Trajtenberg et al., 2006).

- The role of universities in technological development. The impact of universities can be observed by compiling counts of the patents they have taken, their (forward) citations, etc. It can also be observed from the citations of academic research in patents filed by industry (Narin et al., 1999). In an increasing number of countries, number of patents is used by funding agencies or ministries to evaluate the performance of academic institutions or individual researchers. 
- Globalisation of R\&D activities. Patents include information on the inventive performance and activities of multinational firms. Through the applicants' and inventors' addresses, it is possible to track the patterns and the intensity of international co-invention (the measure of research collaboration between inventors located in different countries), foreign ownership of domestic inventions, and vice versa .

- Patenting strategies by companies. The history of the patent application is also available in the patent document. It reveals the timeline of the invention, the application's passage through the patent office's workflow, and the applicant's strategies (designated states, patent equivalents and priority dates, etc). This information is helpful in identifying the market strategy of the patent owner, notably the countries for which protection is being sought and their order of importance.

- Assessing the effectiveness of the patent system. Patent data can also be used to assess the effect of the patent system on inventions and diffusion. To what extent and in which ways does the economy benefit from the patent system? To what extent are strategies with alleged negative social impact (blocking, fencing, etc.) adopted by applicants? What is the effect of particular patent-related policies on national economic performance?

- Forecasting patent applications. Patent data compiled over time are also helpful in predicting future demand for patents. This is useful for patent offices' budgetary planning.

- Monitoring the internal working of the patent system. Not surprisingly, patent data can also be used to monitor the patent system itself, i.e. the volume of patenting activity by companies, the way patent offices operate, etc. However, this use of patent data is not a major focus of this manual, which concerns patent data as indicators of technology. In many cases, different statistical rules should apply when monitoring the patent system. For instance, dates that are purely administrative (e.g. issue date of the search report) and are of little interest from an economic perspective can be extremely important for assessing the internal performance of a patent office. Such use of patent data is mainly made by patent offices themselves (see the annual Trilateral Statistical Report published jointly by the EPO, the JPO and the USPTO, or the various statistical publications of the WIPO).

\section{Notes}

1. Certain jurisdictions provide extended terms for certain inventions (e.g. drugs) in order to compensate for the administrative delays in granting approval to market.

2. While most of the methodologies and patent indicators described apply to patents (known as "utility patents" in the United States) and utility models, the focus here is on the former as patents offer more standardised intellectual property rights 
over inventions worldwide than the latter. Utility models or "petty patents", like patents, give market exclusivity to their holder. As compared with patents, they are weaker (shorter life span, often six or ten years) and easier to obtain (less stringent patentability requirements). They are not available in all countries.

3. This procedure allows the claiming of first priority while keeping the right to file actual patent applications in member countries later. An international patent application has two phases. The first phase is the international phase in which patent protection is pending under a single patent application filed with the patent office of a contracting state of the PCT. The second phase is the national and regional phase, following the international phase, in which rights are continued by filing necessary documents with the patent offices of separate PCT contracting states. The decision on the granting of a patent remains the responsibility of each of the designated national or regional offices.

4. However, in Europe, the centralised EP opposition procedure as well as the centralised EP appeal procedure may lead to the revocation of a European patent as an alternative to legal action.

5. Following the WIPO standards, two-letter INID codes ("internationally agreed numbers for the identification of bibliographic data") are indicated to identify bibliographic elements on the front page of a patent document. They help to harmonise the usage and appearance of patent specifications and related material, and provide a means of conveying information without using foreign languages or scripts.

6. However, trade secrets are subject to legal protection in the framework of TRIPS (see art. 39).

7. The extent and duration of market power depends on several factors, e.g. the degree of substitutability of technologies, the rate of technological change, etc.

8. Some practices in the exploitation of patents can restrict competition in technology markets beyond the rights embodied in the intellectual property right, e.g. tying the sale of other unpatented products or materials to patented inventions (tie-in), restraining licensees' commerce outside the scope of the patent (tie-out), imposing veto power over grants of further licences, setting royalties not reasonably related to sales of the patented products, etc.

9. In contrast, the number of patent applications at the JPO was relatively stable over the period 1991-2005 (OECD, 2007).

10. Changes in ownership over time are not always recorded in patent databases. In the majority of patent offices, the last information released reports the last owner(s) registered, and registration of a new owner, in the event of such a change, is not compulsory.

11. In some cases, applicants can request early publication of the patent application prior to the habitual dates (see Chapter 3, Section 3.3.2).

12. In certain offices, patent applications can also "lapse" during examination, due to refusal or non-payment of fees, or "induced withdrawal" after a discouraging search report or for applicants' own business reasons.

13. Attention must be paid when interpreting geographical patent data, notably in terms of activities by companies, as their research activity is spread geographically and the address of invention is not necessarily where the research actually took place. 


\section{References}

Blind, K., J. Edler, R. Frietsch and U. Schmoch (2006), "Motives to Patent: Empirical Evidence from Germany”, Research Policy, Vol. 35, pp. 655-672.

Cohen, W.M., R.R. Nelson and J.P. Walsh (2002), "Links and Impacts: The Influence of Public Research on Industrial R\&D”, Management Science, 48, No. 1, January, pp. 1-23.

Cohen, W.M., R.R. Nelson and J.P. Walsh (2000), "Protecting Their Intellectual Assets: Apropriability Conditions and Why US Manufacturing Firms Patent (or Not)", NBER Working Paper No. W7552.

Gambardella, A., D. Harhoff and B. Verspagen (2005), “The Value of Patents”, mimeo.

Goto, A. and A. Nagata (1997), “Technological Opportunities and Appropriating Returns from Innovation: Comparison of Survey Results from Japan and the US", NISTEP Report No. 48, National Institute of Science and Technology Policy, March.

Guellec, D. and B. van Pottelsberghe (2007), The Economics of the European Patent System, Oxford University Press.

Hagedoorn, J. and M. Cloodt (2003), "Measuring Innovative Performance. Is there an advantage in using multiple indicators?", Research Policy, Vol. 32, pp. 1365-1379.

Keller, R.T. and W.E. Holland (1982), "The Measurement of Performance among R\&D Professional Employees: A Longitudinal Analysis", IEEE Transactions of Engineering Management, No. 29, pp. 54-58.

Levin, R.C., A.K. Klevorick, R.R. Nelson and S.G. Winter (1987), “Appropriating the Returns from Industrial Research and Development", Brookings Papers on Economic Activity, Vol. 3, pp. 783-820.

Pavitt, K. (1988), “Uses and Abuses of Patent Statistics”, in A.F.J. van Raan (ed.), Handbook of Quantitative Studies of Science and Technology, Elsevier Science Publishers, Amsterdam.

de Rassenfosse, G. and B. van Pottelsberghe (2008), "A Policy Insight into the R\&D Patent Relationship", ULB Working Paper.

Scotchmer, S. (2004), Innovation and Incentives, MIT Press.

Trajtenberg M., G. Shiff and R. Melamed (2006), “The 'Names Game': Harnessing Inventors' Patent Data for Economic Research", NBER Working Papers 12479, National Bureau of Economic Research, Inc. 


\section{ANNEX 2.A1}

Figure 2.A1.1. Front page of an EPO patent application

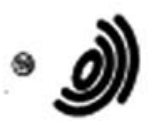

Europälsches Patentamt

Europeen Patont Offlco

Office europben des brevets

(2) Puetcosion number:

EUROPEAN PATENT APPLICATION

농

(11) Aspleationnumber: E1tosury,

(2) Dusu of king: 1E.16:rs 5il m.cas:H02 K 15/02, H01F 29/10, H01F 41/02

\section{0 A1}

Q Prisrity: 18.1078 ausaserra

(4) Dute of puticasion of applatibn: 24.02 2n Denotis $20 / 3$ 89algratod Contracting Sanes: Ar BE CH DE Fh aB IT
WUNE 88

(8) Pelcatisn rumter of the earlier appleation in ascordinse whth Art. 78 Esc: 0010 sss
V11 Acplsark: Cass O-Mede Pty. Led, 20 MaEtvoy Srever, Woleribo New Bsush Woles, 2017 (AU)

6. Invmer: Btariey, Louls, 22 Penyare Asos, Beverley HIK New Soath Waiss rapa (AU)

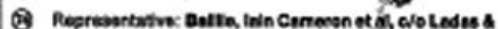

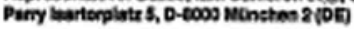

8) Eloctical equpment and its tatricesion.

63. An inderstive cloctric mastins auch as in hastien moter or a transicrmer hevim thild and rober cores, on resposttrely. primary and saccondery cores, osch sach core beito Somned of metal serb [200] sunchad to have e plirality of holes spesed and located at prodecormined posithores along the otrlp (204) 90 that, When the otrip is wound abous a central exs, the toles (206, 2t6, 226)

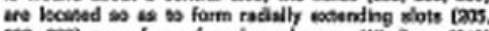

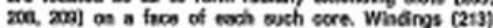
con be pleced in the slots of the field ecre and is the is slots of tratslomer corea. A cordactor [2005] can be 'slaced in the alate of the retor cora.

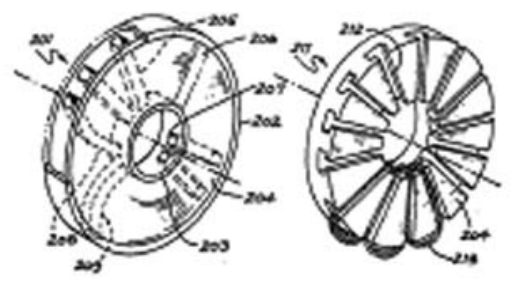


Figure 2.A1.2. Sample front page of a JPO patent application

This is a sample, not a copy of a real application

(19)日本国特許疔(JP)

(12)仝開 特 許 点報( A )

(11)特許出願公開番号

特開2000-244579

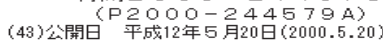

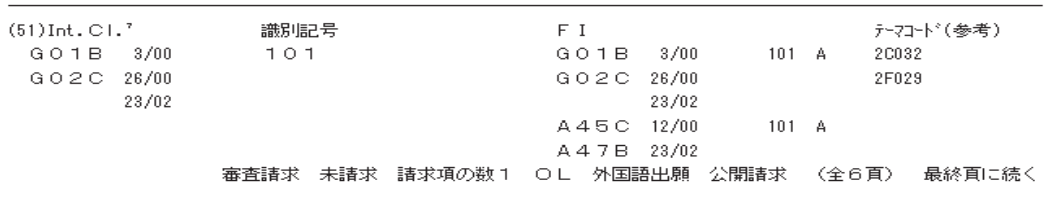

\begin{tabular}{|c|c|}
\hline (21)出願番号 & 特願平 11-128456 \\
\hline (22)出願曰 & 平成11年11月10日(1999.11.10) \\
\hline (31)僋先眚主張番号 & 83304359.9 \\
\hline (32)㮩先日 & 平成10年11月12日 $(1998.11 .12)$ \\
\hline (39)㑭先栍主張国 & Эラス〈FR〉 \\
\hline
\end{tabular}

特許洼第30案筆1愐適用申請有り 平成10年9月21日讨

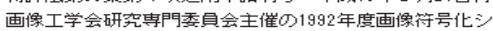

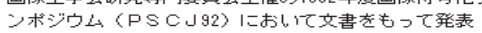

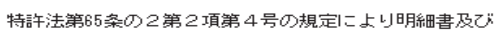
图面り一部む捍㦲する。
(71)出願人 390000011 パテント コーボレーション
Patent Ca poration アメリカ合衅国ケンタッキールドル ピー・オー・ボックス 35090 ルイビルガ
(71)出願人，090000423 レリアアララウン タワー 1500 (無番地〉
日本特許舜时株式会社
東京著早代田区内幸町 4丁目 5 番 6 号
(72)舜明者 哞明 太郎
神夸川具横須艻市壳才丁目2200番地
(74)代理人，123458789 齐理士 代理 太郎 外2名〉

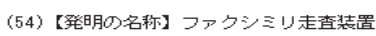

(57)【要袧】 (䍜正有)

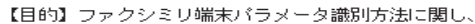

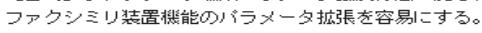

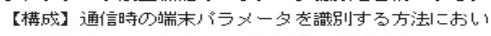
て、端本,

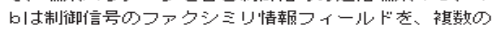

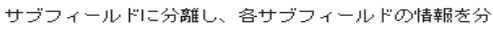
離するコックシミり情報コィールドのデータ中こ現㧈 ない特定の識別コードを挿みしてアァつシミり情報コィ

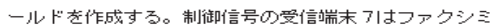

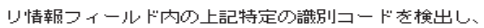

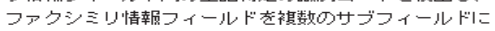

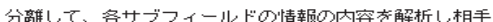
端末 0 㟨末小 ラメーンを掋張する場合はユニーアコードを捙入して可

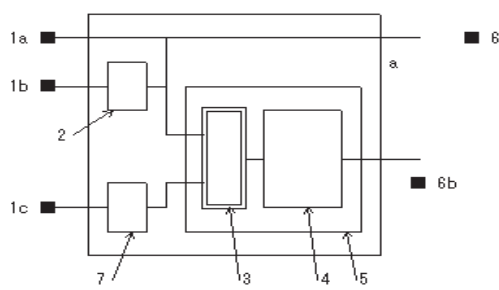

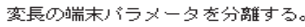


Figure 2.A1.3. Front page of a USPTO published patent application

(19) United States

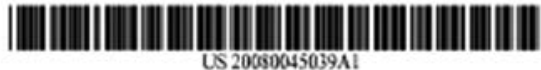

(12) Patent Application Publication (10) Pub. No.: US 2008/0045039 A1 Conti et al.

(43) Pub. Date: Feb. 21, 2008

(54) Mr.ntoD OF FORMIVG NITRIDE FII.MIS WTIH HGH COMPRFSSIVE STRESS YOR IMPONED PVET DEVTCE PERFORMANCE

(0)) Imetices Rikhard A. Ceati, Kisobah NY US: Reawd P. Bearese, Worimaers Fals NY (US); Nang R. Klymb. Hoscest Jeatica. NY (tsk Anita Madan. Dusbary, NY (US), Mklasi C. Stais. Roullapic, NY (US), Ray II. Therman. Sienville, NY ISS Kwoug Hen Wane Wisgingers Falk NY (US): Dacuen Yang. Herenadl Joxtica. NY (US)

Comspoedene Aalies:

INTEKS.TTONAL. BUSNESS M..CIIVES

CORPORATION

DEPT. 18G

BLDG. 301-6X:

DNT0 ROUTE 5?

HOPEWEL.L JUNTION NY 1253 (US)

(73) Asimas IXTERx.stovi. Bustvxs MACHINES CORPORATION Ambik. NY (US) NONE.tUS SYS TEMS, IVC. Son los, CA (US)

(21) Appl. No: Ita73721

(22) Filal: Oet. 17, aw?

\section{Related US. Applikatha Data}

(62) Diviain of applicative Na. I1/lea, nos, fikd en Ju. 6. $2 \times 06$

$$
\text { Putlication Clessilfcichn }
$$

(51) Ine. $\mathrm{O}$.

$$
\text { Foll } 2131 \text { (2056.01) }
$$

(52) U. $\mathrm{Cl}$. ...

(57)

ARSTRACT

A rectod is powibed for melieg a FET device in whica a airible byer creties the PFET gese stovare, where te ahribl layer las a coctpressive stress with a magnase

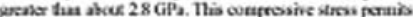
improval derise perfermanse in the PFET. The sitnile lyer is drpevited usire a high-desaity plams (HDP') procesex

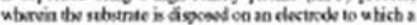
biss pover in the range of abos: $50 \mathrm{~W}$ io socel $500 \mathrm{~W}$ is

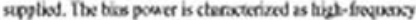

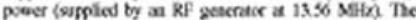

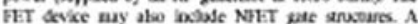
bbalig layer is deposted oner the NFET pate strovares so

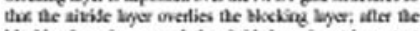

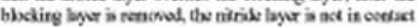
with the NFET gove vrestuns. The titride tret has a thidkess in the noye of shoes $300-3000 \mathrm{~A}$.

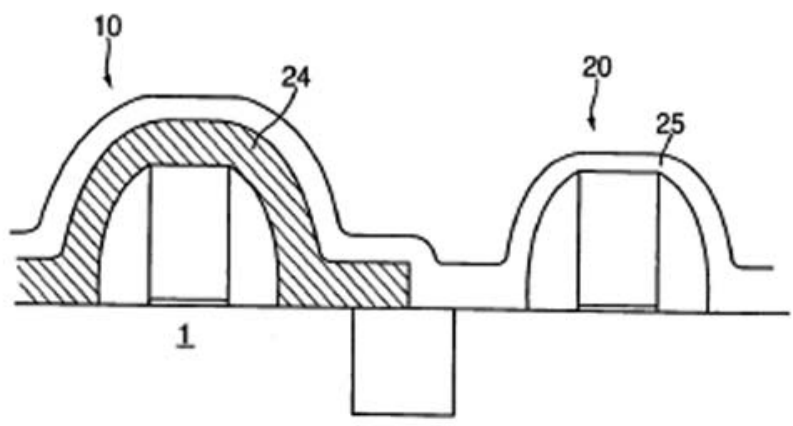


Figure 2.A1.4. Front page of a PCT application

\section{(12) INTERNATIONAL APPLICATION PUBLISHED UNDER THE PATENT COOPERATION TREATY (PCT)}

(19) World Intellectual Property Organization International Bureau

(43) International Publication Date 18 December 2003 (18.12.2003)

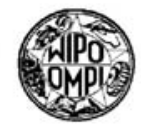

PCT

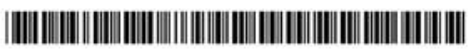

(10) International Publication Number WO 03/104470 A2
(51) International Patent Classification?: $\quad$ C12N 15/90, $9 / 12,15 / 11,15 / 79$, A61K 48/00

(21) International Application Number: PCT/CA03/00850

(22) International Filing Date: 5 June $2003(05.06 .2003)$

(25) Filing Language:

English

(26) Publication Language:

English

(30) Priority Data: $60 / 386,640$

(71) Applicant (for all designated States except US): HER MAJESTY IN RIGHT OF CANADA As represented By the MINISTER OF AGRICULTURE AND AGRI-FOOD CANADA [CA/CA]; Agriculture and Agri-food Canada, Saskatchewan Research Centre, 107 Science Place, Saskatoon, Saskatchewan S7N 0X2 (CA).

(72) Inventors; and

(75) Inventors/Applicants (for US only): ROZWADOWSKI,
Kevin, L. [CA/CA]; 86 Harvard Crescent, Saskatoon, Saskatchewan S7N 3R1 (CA). LYDIATE, Derek, J. [GB/CA]; 101 Albert Street, Saskatoon, Saskatchewan S7N 1 E6 (CA).

(74) Agents: Kingwell, Brian, G. et al.; Smart and Biggar Box 11560 , Vancouve 650 West Georgia Street, Suite 2200 Vancouver, British Columbia V6B 4N8 (CA).

(81) Designated States (national): $\mathrm{AE}, \mathrm{AG}, \mathrm{AL}, \mathrm{AM}, \mathrm{AT}$ (utility model), AT, AU, AZ, BA, BB, BG, BR, BY, BZ, CA, $\mathrm{CH}, \mathrm{CN}, \mathrm{CO}, \mathrm{CR}, \mathrm{CU}, \mathrm{CZ}$ (utility model), CZ, DE (utility model), DE, DK (utility model), DK, DM, DZ, EC, EE (utility model), EE, ES, FI (utility model), F, GB, GD, GE GH, GM, HR, HU, ID, IL, IN, IS, JP, KE, KG, KP, KR, KZ, LC, LK, LR, LS, LT, LU, LV, MA, MD, MG, MK, MN MW, MX, MZ, NI, NO, NZ, OM, PH, PL, PT, RO, RU, SC, SD, SE, SG, SK (utility model), SK, SL, TJ, TM, TN TR, TT, TZ, UA, UG, US, UZ, VC, VN, YU, ZA, ZM, ZW

(84) Designated States (regional): ARIPO patent (GH, GM, KE, LS, MW, MZ, SD, SL, SZ, TZ, UG, ZM, ZW), Eurasian patent (AM, AZ, BY, KG, KZ, MD, RU, TJ, TM), European patent (AT, BE, BG, CH, CY, CZ, DE, DK, EE,

[Continued on next page]

(54) Title: RETRONS FOR GENE TARGETING

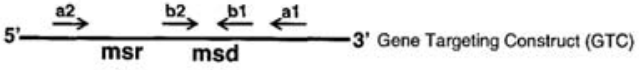

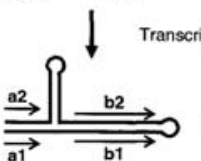

Gene Targeting Message RNA (gtmRNA)

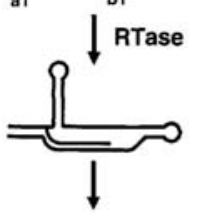

Self-priming

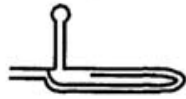

OR

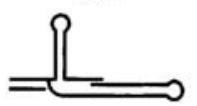

(57) Abstract: The invention provides methods and nucleic acid constructs that may be used to modify a nucleic acid of interest at a target locus within the genome of a host. In some aspects, the invention contemplates producing in vivo a gene targeting substrate (GTS), which may be comprised of both DNA and RNA components. The gene targeting substrate may comprise a gene targetig nucleotide sequence (GTNS), which is homologous to the target locus, but comprises a sequence modification compared to the target locus. The gene targeting substrate may be produced by reverse transcription of a gene targeting message RNA (gtmRNA). The gene targeting message RNA may be folded for self-priming for reverse transcription by a reverse transcriptase. The gene targeting message RNA may in turn be the product of transcription of a gene targeting construct (GTC) encoding the gene targeting message RNA. The gene targeting construct may for example be a DNA sequence integrated into the genome of the host, or integrated into an extrachromosomal element. Following expression of the gene targeting systems of the invention, hosts may for example be selected having genomic modifications at a target locus that correspond to the sequence modification present on the gene targeting nucleotide sequence.

In some embodiments, the structure of retrons may be adapted for use in the gene targeting systems of the invention. 
Chapter 3

\section{Patent Systems and Procedures}




\subsection{Introduction}

To obtain a patent for an invention, the individual or institution which owns the invention (an enterprise, or a public or private institution such as a university or a government body) has to file an application at the patent office. An applicant who wants to have patent protection in multiple countries can file for a patent in each country separately, file a patent application at a regional office, or file a patent application at the international patent office and request entry into the national stage in each country in which patent protection is sought.

The application and the processing of patents follow strict administrative and legal rules and procedures, set out in international treaties and national statutes (law and regulation). These procedures and rules have a direct impact on the value and the meaning of patent data. It is necessary to take them into account when interpreting patent statistics. This is all the more important as these rules are not fully harmonised across countries and have changed over time, and minor variations in the procedure can have drastic effects on the resulting numbers.

This chapter presents a summary of patenting procedures at the most important patent offices and patenting routes: the European Patent Office (EPO), the Japan Patent Office (JPO), the United States Patent and Trademark Office (USPTO) and the Patent Cooperation Treaty (PCT). It starts with the standard rules common to all patent offices and it then examines national and regional variations. Finally, it looks at the procedures for international applications.

The procedure for granting patents, the requirements placed on the patentee and sometimes the extent of exclusive rights vary widely among countries according to national laws and international agreements. As will become apparent, all patent applications, whether international or regional, should ultimately have a national status, as they need to be validated by national patent offices. In consequence, national specificities, concerning both the patenting process and post-grant activity (e.g. maintenance, enforcement and invalidation procedures) determine how patents function in economic life. These aspects need to be taken into account when choosing particular patent data and computing and interpreting patent indicators. 


\subsection{The core patenting procedure}

The procedure for obtaining a patent involves several steps which are similar in all countries:

- First, the entity seeking patent protection (usually a company, but also an individual, university or governmental body) must file a patent application at a patent office. In the application, the applicant must disclose the invention in sufficient detail for the average skilled person to be able to understand and make use of it. The most important part of the application is the section on claims, the list of aspects of the invention for which the applicant is claiming exclusive rights. The applicant must pay certain administrative fees, which vary widely across patent offices. ${ }^{1}$

- Second, the patent office appoints an examiner (or a group of examiners, with one leader) to take charge of the application. The examiner is assumed to be an expert in the particular technical field. Usually the examiner first performs a novelty search; this involves checking the prior art documents deemed relevant to the particular invention. These documents include the precedents in the scientific and technical literature relevant to the invention (or part of it) and constitute the prior art against which the novelty of the invention will be measured. In general, only documents that were published before the date of filing of the application (or day of filing of the priority application, if there is one) are to be considered in the search. The patent application document, along with the search report, is made public 18 months after the filing date (with an exception for certain applications to the USPTO). ${ }^{2}$

- Third, the examiner (usually but not necessarily the same as in step two) studies the patent application in order to decide whether the invention is "non-obvious" and involves an "inventive step" relative to the prior art identified in the earlier search. The applicant has the right to submit a written opinion (to discuss the examiner's findings and interpretation of the literature found), and to modify the scope of the claims defined in the application if necessary. The grant means that no reasons for refusal are found as all the criteria for patentability are met: patentable subject matter, novelty, inventive step (non-obviousness to a person skilled in the art) and industrial applicability (see Box 3.1).

- Fourth, when granted, a patent can be maintained for a maximum duration of 20 years from the filing date. ${ }^{3}$ The patent holder is required to pay renewal fees to the patent office to maintain the patent (these are annual in most countries). The patent office will revoke patents that are not renewed. A patent can be challenged, usually by competitors who consider the patent invalid and should not have been granted because the patent office did not detect a significant weakness in the patent filing or did not correctly implement the statute. A patent can be challenged in the patent office itself in certain 


\section{Box 3.1. Patentability criteria}

Subject matter: To be patentable, an invention must concern certain fields of knowledge, which one may characterise approximately as being "technological". The law is more specific and varies somewhat across jurisdictions. Aesthetic creations, laws of nature and abstract ideas are excluded in all jurisdictions. Software is patentable in the United States, as are business methods. The practice in these two fields is more restrictive in Japan and even more in Europe (which excludes "software as such").

- Novelty: To be patentable, an invention must be novel in the absolute sense. That means it was not available to the public in any way before the filing date of the patent, and had not been described in any publication before that date. Novelty is a universal concept: an invention is deemed not to be new in one country if similar prior art is found in another country, in any language, at any period of time.

- Non-obviousness/Inventive step: Even if an invention is found to be novel in the strict sense, it may still not be patentable when the novelty is considered obvious to a person with ordinary skill in the art. The term obvious is a legal term of art and is used in different senses from country to country. In order to be patented, the inventive step and non-obviousness must reflect the same general patentability requirement that is part of most patent laws, according to which an invention should be sufficiently inventive, i.e. non-obvious. The expression "inventive step" is predominantly used in Germany, in the United Kingdom and under the European Patent Convention (EPC), while the expression "nonobviousness" is predominantly used in United States patent law. In the United States, it is argued that something is obvious if the differences between the subject matter to be patented and the prior art are such that the subject matter as a whole would have been obvious at the time the invention was made to a person having ordinary skills in the art to which said subject matter pertains. In Europe, patent application involves an inventive step if it solves a technical problem in a non-obvious way.

- Industrial applicability: This requirement mainly aims to distinguish between aesthetic and scientific inventions. The term "industry" is interpreted in a broad sense; it includes agriculture, for example. It excludes methods of treatment of the human or animal body by surgery or therapy and diagnostic methods practised on the human or animal body. The so-called perpetual motion machines also fail to meet this requirement. In the United States, this requirement is referred as "utility"; however, the interpretation and scope of this term is generally the same as that of industrial application. International patent treaties often use "utility" and "industrial applicability" synonymously. 
jurisdictions (e.g. opposition at the EPO; re-examination at the USPTO (through boards of appeal); invalidation procedure trials at the JPO), and in courts. Courts have the last say in the enforcement of the patent statute.

Patents filed at a national (or regional) office provide protection only within that jurisdiction. For example, a patent granted by the USPTO will only provide patent rights within the United States. If the inventor (applicant) wishes to protect the same invention in Japan, then a separate patent application has to be filed at the JPO, either directly or via the PCT at the World Intellectual Property Organization (WIPO). Filing at WIPO does not prevent the applicant from filing at national offices.

The decision to apply for patent protection in a country (or countries) depends first on the applicant's business strategy. In most cases, a patent application is filed at the national patent office of the inventor (applicant) in order to protect the invention in the domestic market and followed by foreign filings. However, it is not mandatory to file the first application at the applicant's national patent office. An applicant can file a patent application initially at any patent office in the world. In the United States, however, a foreign filing licence may be required before filing in a foreign country.

The country in which the first application is filed is referred to as the priority country and the date of first application is commonly referred to as the priority date. Patent applications filed at a patent office by residents of that country are referred to as domestic applications (for statistical purposes) and applications by non-residents are referred to as foreign applications.

\subsubsection{International harmonisation of patent laws}

Various international treaties have been established over the years in order to streamline the application process and make patenting procedures more efficient for inventors (or applicants) who target multiple countries. These application and examination procedures are governed by rules and regulations of the national (or regional) patent office and international treaties (such as the Paris Convention and the PCT) where applicable.

A considerable amount of harmonisation of patent rules across countries took place during the 1990s, notably through the creation of the Trade-related Aspects of Intellectual Property Rights (TRIPS) Agreement at the World Trade Organization (WTO) (see Box 3.2). The TRIPS Agreement is an international treaty administered by the WTO which sets out minimum standards for most forms of intellectual property regulation within all member countries of the WTO. It was negotiated at the end of the Uruguay Round of the General Agreement on Tariffs and Trade (GATT) in 1994. It incorporates and builds upon the latest versions of the primary international intellectual property agreements administered by the World Intellectual Property Organization 


\section{Box 3.2. Main provisions of the TRIPs Agreement}

The objectives of the TRIPS are defined in Article 7: "The protection and enforcement of intellectual property rights should contribute to the promotion of technological innovation and to the transfer and dissemination of technology, to the mutual advantage of producers and users of technological knowledge and in a manner conducive to social and economic welfare, and to a balance of rights and obligations." Unlike other international agreements on intellectual property, TRIPS introduced a dispute settlement mechanism, which can authorise trade sanctions against non-compliant states. Specifically, TRIPS deals with harmonisation of copyright and related rights, such as rights of performers, producers of sound recordings and broadcasting organisations; geographical indications, including appellations of origin; industrial designs; integrated circuit layout designs; patents, including the protection of new varieties of plants; trademarks; trade dress; and undisclosed or confidential information, including trade secrets and test data. Articles 3 and 4 set out the two main principles of treatment for WTO members:

- National treatment (Art. 3): Each Member shall accord to the nationals of other Members treatment no less favourable than that it accords to its own nationals with regard to the protection of intellectual property, subject to the exceptions already provided in, respectively, the Paris Convention (1967), the Berne Convention (1971), the Rome Convention or the Treaty on Intellectual Property in Respect of Integrated Circuits.

- Most Favoured Nation Treatment (art. 4): With regard to the protection of intellectual property, any advantage, favour, privilege or immunity granted by a Member to the nationals of any other country shall be accorded immediately and unconditionally to the nationals of all other Members.

(WIPO), the Paris Convention for the Protection of Industrial Property, and the Berne Convention for the Protection of Literary and Artistic Works, agreements that date back to the 1880s. It applies basic international trade principles to member states regarding intellectual property, including national treatment and most favoured nation treatment. Major changes introduced by TRIPS include: the statutory duration of patents should be at least 20 years after application; patents should cover all fields of technology (including drugs, previously excluded in a number of countries); patents should be published 18 months after priority. Further negotiations have taken place in the 2000s at WIPO and among developed countries in order to further harmonise patent statutes and procedures across countries, but such harmonisation has proven difficult to achieve. 


\subsubsection{The costs of filing patents and duration of procedures}

Filing a patent is a costly matter for the applicant. The cost of patenting can be broken down into four main categories associated with the granting process and the maintenance of protection:

- Administrative fees: filing fees, search, examination, country designation, grant/publication fees and validation fees (in Europe).

- Process costs: costs associated with the drafting of the application and with the monitoring of the procedure (interaction with examiners and the patent office) on the applicant's side. These costs can be incurred in-house (corporate IP department) or externalised (private patent attorneys).

- Translation costs in the case of applications abroad. Such costs mainly arise once a patent is granted, and depends on the page length of the patent. The more countries covered, the higher the translation costs.

- Maintenance costs are renewal fees to keep the patent valid during a maximum period of 20 years, plus possible fees to be paid to the patent agents serving as intermediaries between the patent holder and the patent office. ${ }^{4}$ Renewal fees vary significantly across countries.

There are also the costs of enforcement, i.e. of defending patent rights by identifying and fighting infringement (e.g. through lawsuits) or invalidation or opposition by other parties, etc. Calculating patent costs is a complex task, as several components are not easy to quantify and depend on the applicant's motivations for filing a patent. Several factors determine the total cost of a patent (e.g. the number of claims, the number of pages, the route, the quality of external services, the desired speed and the geographical scope for protection). Larger patents (i.e. with more claims and/or pages) and patents that are intended to be filed in a large number of EPC member states are more expensive in terms of both procedural and external costs. The cost is further linked to the duration of the procedure (especially when there is a great deal of written communication between the patent attorney and the patent office) as well as the desired speed of the granting process. In view of the high variability of costs across technical fields and countries, it is difficult to give meaningful average figures on the cost of filing patents. In addition, such costs should be related to the size of the market covered (i.e. the potential market for which exclusivity is sought for the invention).

A survey of patent applicants conducted in 2004 investigated the cost of patents (EPO/Roland Berger, 2005). The cost of obtaining a standard Eurodirect patent (direct filing to the EPO or extension of an earlier national patent application) in 2003 was estimated at EUR 30530 (EPO and Roland Berger Market Research) while the (estimated) costs of a Euro-PCT (filing through PCT at the WIPO, designating the EPO) averaged around EUR $46700 .^{5}$ The difference with 
Euro-direct patent applications arises mainly from higher translation costs, due to a larger number of pages (description and claims), supplementary official fees related to the international phase, and validation in a larger number of countries (eight instead of six). A company from a European country (EPO member state) will pay on average EUR 24100 to have a Euro-direct patent granted and validated; a US company will pay EUR 10250 to receive a USPTO grant; a Japanese company will pay EUR 5460 to acquire a JPO grant. The higher cost in Europe is basically due to translation costs at the processing and validation stages. Although they vary across patent offices, official fees play a minor role in the total difference: applicants' reported figures are EUR 3470 at the EPO, EUR 2050 at the USPTO and EUR 1570 at the JPO.

The duration of the procedures is also highly variable across patent offices and has changed over time. From 2005 to 2006, the average pendency time for examination (time between filing and a grant) at the EPO increased by $8 \%$ to about 44 months. In the JPO, average pendency is stable at 31.8 months while at the USPTO the number of pending applications continues to increase. From 2005 to 2006, pendency at the USPTO rose slightly from 30.6 months to 31.3 months (Trilateral Statistical Report, 2006). The increase in pendency raises particular statistical issues. For instance the yearly statistics of applications and grants are increasingly disconnected; procedural statistics (rates of grant, of refusal, of withdrawal) are distorted over time and time trends are difficult to interpret.

All stages of the patenting procedure generate large amounts of information about the invention for which protection is sought. Information regarding the procedural stage of patent applications provides insight on the applicant's strategy but also generates statistical difficulties:

- First, no statistics are available until 18 months after the priority date, since the application is not published until then. ${ }^{6}$ This creates an obstacle for analysts as it limits the legally possible timeliness of patent data.

- The search report includes valuable information, such as the references to prior art (patent and non-patent references), which can be viewed as the precedents to the invention covered by the patent.

- The list of countries in which the application is filed, or the international route it takes (PCT), is an indication of the applicant's market strategy (local, regional or worldwide). It is also indicative of the invention's value, as one would expect the expected revenue from the patented invention to exceed the prospective cost of patenting in the first place.

- The length of the patenting procedure (the time it takes for the patent office to reach a decision) is indicative both of the strategy of the applicant (who can seek a quick grant or aim to lengthen the procedure) and the efficiency of the patent office (ability to manage its workload). The fact that an application is granted or refused is indicative of its quality. 


\subsection{National and regional procedures}

All patent offices have their particular statute, and there are variations from the "core" presented above. Differences can be in "substantive patent law" (what is patentable or not, etc.) or in the procedures, although the distinction between the two is not always clear. The most specific procedures are to be found at the EPO, as it is not a national but a regional/international patent office. Table 3.1 summarises some of the major differences in the rules

Table 3.1. Differences between the three main patent offices

\begin{tabular}{|c|c|c|c|}
\hline & EPO & JPO & USPTO \\
\hline Patent grants are based on & First to file & First to file & First to invent \\
\hline Patent duration & 20 years & 20 years & 20 years \\
\hline Application language & English, French or German ${ }^{a}$ & Japanese $^{b}$ & English $^{c}$ \\
\hline Area covered & $\begin{array}{l}\text { EPC member and "extension" } \\
\text { countries }^{d}\end{array}$ & Japan & United States \\
\hline Request for examination & Yes, within 6 months & Yes, within 3 years $^{e}$ & No \\
\hline Publication of application & $\begin{array}{l}18 \text { months from the priority } \\
\text { date }\end{array}$ & $\begin{array}{l}18 \text { months from the priority } \\
\text { date }\end{array}$ & $\begin{array}{l}18 \text { months from the priority } \\
\text { date }^{f}\end{array}$ \\
\hline $\begin{array}{l}\text { Are there some subject matters } \\
\text { excluded from patentability or } \\
\text { not considered to be inventions? }\end{array}$ & $\mathrm{Yes}^{g}$ & Yes $^{h}$ & Yes $^{i}$ \\
\hline Opposition system & Yes $^{j}$ & No & $\mathrm{No}^{k}$ \\
\hline
\end{tabular}

a) An application can be submitted in any official language of any EPC member state. However, within three months of filing the application, but no more than 13 months after the earliest priority date, a translation of the application into one of the official EPO languages (English, French or German) is required.

b) It is possible to file a patent request in Japanese and the specification, claims, drawings and abstract in English. A Japanese translation of the English documents must be filed within 14 months of the initial filing date.

c) Possible to file in any language other than English provided that English translation is submitted within two months.

d) A European patent does not automatically provide protection in all EPC member countries (or the extension countries). The applicant has to validate the EPO patent separately, once it has been granted, at the respective national patent offices for the patent to be effective in those countries.

e) Request for examination period: three years for patents filed since October 2001 and seven years for those filed before October 2001.

f) An application that has not and will not be the subject of an application filed in foreign countries does not need to be published if an applicant so requests.

g) Subject matters not considered to be inventions are: discoveries, scientific theories and mathematical methods; aesthetic creations; schemes, rules and methods for performing mental acts, playing games or doing business, and programmes for computers; and presentations of information. Subject matter excluded from patentability: plant or animal; and methods for treatment of the human or animal body by surgery or therapy and diagnostic methods practiced on the human or animal body.

h) Subject matters not considered to be inventions are: discoveries; scientific theories and mathematical methods; mental activities; mere presentation of information; business methods; isolated parts of human beings; and diagnostic, therapeutic and surgical methods for the treatment of humans and animals.

i) Subject matters not considered to be inventions are: scientific theories and "abstract" mathematical methods; mental acts; presentation of information; and traditional knowledge.

j) Within nine months of the publication of the mention of the grant of the European patent, any person may give notice to the EPO of opposition to the European patent granted. Opposition can only be filed on the following grounds: the patent's subject matter is not patentable; the patent does not disclose the invention clearly and completely; or the patent's subject matter extends beyond the content of the application as filed.

k) Re-examination procedure; post-grant review of the validity of the claims of a patent in view of a prior art patent or printed publication believed to have a bearing on the patentability of any claim of the patent in question. The patent owner or any third party may request re-examination at any time after grant. 
applied by the three major offices. Active negotiations at international level aim to remove such differences in the future.

The grant procedures are not identical across these patent offices. For instance, the examination at the EPO has two phases (search and substantive examination ${ }^{7}$ ) whereas in the national procedures before the JPO or the USPTO, the two phases are carried out together. After examination, the patent office informs the applicant of its decision (EPO: announcement of a grant; JPO: the decision to grant; USPTO: notice of allowance). If a patent cannot be granted in the form in which it was filed, the intention to reject the application is communicated (EPO: examination report; JPO: notification of reason for refusal; USPTO: office action of rejection). The applicant may then make amendments to the application, notably in the claims, after which examination is resumed. This procedural step lasts as long as the applicant continues to make appropriate amendments. Then, either the patent is granted or the application is finally rejected or withdrawn by the applicant. In all three patent offices, an applicant may withdraw or abandon the application at any time before the application is granted or finally rejected. The following section describes in more detail some of the differences between patent offices that need to be taken into account when computing patent statistics.

\subsubsection{USPTO}

In the United States, the Constitution empowers Congress to make laws to "promote the progress of science and useful arts...." The laws passed by Congress regarding the patent system were codified in Title 35 of the United States Code and created the United States Patent and Trademark Office.

The USPTO displays the following differences with the standard patent procedure and some characteristics unique to their patent system, such as:

- The United States grants a patent to the first to invent rather than the "first to file" (all other countries). This means that the first to file can see that right contested in front of the USPTO by another party claiming to have made the invention earlier although with no patent filing (a later patent filing).

- The United States has a so-called grace period for assessing novelty. Publications (e.g. academic journals) by the inventor during the grace period, which can range to up to one year before the filing, are not regarded when determining the novelty of the invention.

- The statutory duration of patents has been 20 years from application since 1995 (when the United States made the TRIPS part of its national laws), but it was 17 years after grant previously. ${ }^{8}$ Renewal fees have to be paid 3.5, 7 and 11.5 years after grant (they are annual in most other countries).

- An application to the USPTO is automatically regarded as a request for examination (in most other countries, the applicant has a certain period 
after reception of the search report before deciding whether to file an examination request or not; e.g. EP procedure). It means notably that applicants will have to proceed to examination even if they realise after the search that the novelty of their invention is not certain. However, a growing number of applications to the USPTO are taking the PCT route, for which this rule does not apply.

- Until recently, US patents were only published after grant. This has changed, and patent applications in the United States are now published 18 months after their filing date, unless they have been withdrawn or have been filed with a non-publication request (if the applicant declares that he will not file a related application in another country that quotes the priority of the USPTO first filing).

- When submitting a patent application, applicants (or inventors) are requested to supply a list of the state of the art. Contrary to the patenting procedure at the EPO, everyone involved in a US patent application has a "duty of candour", from the inventor to the patent attorney, to bring to the attention of the USPTO any prior art of which the inventor (or others involved in the filing of the patent application, such as the patent attorney) is aware or becomes aware and which might be relevant to patentability. This is a legal requirement and non-compliance by the patent applicant can lead to the subsequent revocation of the patent. This has led to an inflation of submitted prior art, to which the USPTO reacted in 2005 by encouraging applicants to limit the number of submitted references to 25 . These institutional differences explain in part why the number of citations is notably higher in each USPTO patent than in patents from other offices (Table 3.1).

- Since 8 June 1995, the USPTO has offered inventors the option of filing a provisional application for patent which is designed to provide a lower-cost first patent filing in the United States. It is a patent application which does not mature into an issued patent unless the applicant takes further steps. A provisional application allows filing without a formal patent claim, or any information disclosure (prior art) statement. It provides the means to establish an early effective filing date in one or more continuing patent applications later claiming the priority date of an invention disclosed in earlier provisional applications by one or more of the same inventors. ${ }^{9}$

- Applicants have the possibility, after application, to make quite substantial amendments to their initial filing owing to the progress of their research or in reaction to examiners' requests. This procedural step is iterated as long as the applicant continues to make appropriate amendments; in consequence, the grant can be delayed. The continuation-in-part (CIP) type of application results from a second or subsequent application being filed, which includes new material protected, while the original application is pending. 
- If an issued patent is found to be defective, the patent owner can surrender the patent and re-file the original application to correct the defect. One such defect is that the issued patent fails to claim the full scope of the invention. Inventors can re-submit the patent application with broader and/or new claims and attempt to get the full coverage they are entitled to. They are not, however, allowed to add new features to their invention. A re-issue application which attempts to get broader coverage than the original issued patent must be filed within two years from the grant date of said original issued patent.

\subsubsection{JPO}

The patent statute of Japan has been reformed several times since the late 1980s, bringing it closer in line with other countries' statutes. Major specificities with implications for statistics are as follows:

- The JPO grants patents under the first-to-file system, i.e. the principle according to which when two parties apply for a patent for the same invention, the first party to file will be granted the patent.

- Japan has also a grace period. Up to six months before the filing, if the invention has been published or presented at an academic body designated by the Commissioner or if it has been displayed at an exhibition held by a government or a body designated by the Commissioner, it is not regarded as having lost novelty.

- The JPO publishes the content of an application in the Official Gazette after 18 months have elapsed from the date of priority. ${ }^{10}$ However, a request for examination has to be filed within three years of the application date to start the substantive examination process. In 2001, the time limit for the request for examination was reduced from seven to three years (three years for patents filed since October 2001 and seven years for patents filed before October 2001). If the applicant fails to file the request for examination within the time limit, the application is regarded as withdrawn.

- The length of time during which applicants can decide whether or not to request examination may be one reason for the large number of applications to the JPO compared with other jurisdictions, as inventors could take over eight years to make a decision. The rule change also explains the surge in the number of examinations requested (and grants) after 2004 due to a sort of "calendar effect". This high number can also be explained by the one claim rule which prevailed in Japan until 1975. The current unity of application is the same as the unity of invention in other jurisdictions (as defined in the PCT). This essentially permits groups of linked inventions to form a single inventive concept to be examined in a single application. In spite of these reforms, applications to the JPO still have a significantly lower number of claims than in other patent offices. An inventor might need to file several 
applications at the JPO as compared to only one at other offices in order to obtain the same level of protection. However, since applicants try to secure broad and strong rights for their technology, the number of claims per application has risen since the late 1980s.

- At the JPO, renewal fees are due as a lump-sum fee for the first three years and each year from the fourth year of the date of grant. The requirement for applicants to disclose information on prior art in applications was introduced as of 1 September 2002 and entered full force on 1 May 2006. Patent examiners conduct the prior art search. There is no limitation on the number of references to be included.

- Patents granted by the JPO can be appealed by third parties. Even after a patent is registered, any person may appeal for invalidation of the patent if it has a flaw. This system was introduced in 2003 when the post-grant opposition system was abolished and the invalidation trial system was revised (effective from 1 January 2004). Under the new invalidation trial procedure: i) the trial may be demanded at any time; ii) both parties are involved in an inter partes procedure during the trial; and iii) the plaintiff may appeal a verdict upholding the patent in question to the Tokyo High Court.

\subsubsection{EPO}

The Convention on the Grant of European Patents, widely known as the European Patent Convention (EPC) was signed in 1973 and entered into force in 1977. As a result of the EPC, the European Patent Office (EPO) ${ }^{11}$ was created to grant European patents based on a centralised examination procedure. By filing a single European patent application in one of the three official languages (English, French and German), it is possible to obtain patent rights in all EPC countries. ${ }^{12}$

- Patents granted by the EPO have the same legal rights and are subject to the same conditions as national patents (granted by the national patent office) in each EPC country for which the patents have been granted. Once granted by the EPO, a European patent is therefore a "bundle" of national patents, which must be validated at the national patent office of the designated states for it to be effective in EPC member countries. ${ }^{13}$ Within three months of the grant of a European patent, the applicant has to complete various formalities. For example, the national patent office of a designated state might require the applicant to provide a translation in one of its official languages and pay for the publication fees of the patent.

- A European patent application can originate from: i) direct filing to the EPO without a priority claim (i.e. first filing), ii) extension of an earlier national patent application (within 12 months of first filing), or iii) from an international application filed using the PCT procedure. The first two categories are known as "Euro-direct" while the third is known as "Euro-PCT". Figure 3.1 illustrates 
these different patenting routes involving the EPO. Since the early 2000s, patent applications to the EPO from national offices have significantly decreased as a share of total applications filed at the EPO. Indeed, the majority of the EPO patent applications originate from the PCT (Euro-PCT). In 2006, the share of all PCT applications entering the national-regional phase was $62 \%$ at the EPO (it was $46 \%$ at the USPTO and $45 \%$ at the JPO) (Trilateral Statistical Report, 2006). ${ }^{14}$ The pattern is similar in terms of the share of PCT in total patents granted by trilateral patent offices: in $2006,52 \%$ of patents granted by EPO were PCT applications, compared to $11 \%$ at the UPSPTO and $5.1 \%$ at the JPO (ibid.).

- This complex legal setting is a source of statistical difficulty, notably when counting "national patents" and "national applications" in European countries. Strictly speaking, all applications to the EPO since 2004 are also national applications, as the applicant has the right, in case of a grant, to obtain a patent in the country concerned. This also applies if the applicant has no intention of seeking protection in that country, as happens in a majority of cases for small European countries. Hence, the notion of a "national patent application" is blurred. This is not specific to European countries, however, as a similar principle of automatic designation is now in place at the PCT (see Section 3.4.2). As a result, to compile exhaustive statistics on national applications in a given country, it is necessary to use national, EPO and PCT data together. In addition, Europe patents valid in any country include not only those examined and granted by the national patent office, but also those granted by the EPO and validated nationally.

Other specificities of the EPO procedure include:

- Contrary to the USPTO, the submission of references to the prior art when filing an application is optional. Examiners are responsible for constructing the list of references to prior art (provided in the search report) against which patentability is judged. The European search report should include as references the most important documents or the earliest publication of equally important documents. According to EPO philosophy, a good search report contains all relevant information within a minimum number of citations.

- Once the European search report has been published, the applicant has six months to file a request for examination and pay the corresponding fees; otherwise the application is deemed to be withdrawn.

- An opposition to patents granted by the EPO can be filed by third parties within a period of nine months following the grant. This is an interesting source of statistical data. As opposition is a costly process, it is likely that patents that are opposed are those that create more difficulty (potential economic costs) for competitors, hence have higher value. The fact that a patent is opposed can therefore be seen as an indicator of high value (Harhoff and Reitzig, 2002). 


\subsection{International patent applications}

\subsubsection{The priority principle}

The earliest international treaty on the protection of invention dates from 1883 (the Paris Convention for the Protection of Industrial Property), with 169 signatory countries as of January 2005. The Paris Convention established the system of priority rights, under which applicants have up to 12 months from first filing their patent application (usually in their own country) in which to make subsequent applications in other signatory countries and claim the priority date of the first application. Prior to the Paris Convention, foreign applications could be refused on the ground that the invention was no longer novel as it had been disclosed in an earlier (priority) application. ${ }^{15}$

The priority rights rule has important implications for the calculation of patent statistics, because in most countries there will be a time lag of 12 months between domestic and foreign application dates corresponding to a given invention. This is to say, that for a domestic application the "priority date" is equivalent to the "application date" and for foreign applications there is a 12-month lag between the "priority date" and the "application date". If the application date is used to reflect the time of the invention, it will introduce a bias in the timing of domestic and foreign inventions. The priority date will reflect the proper time period of the discovery of both domestic and foreign inventions. For this reason, when compiling patent statistics to reflect inventive activities, it is recommended to use the priority as the reference date.

\subsubsection{The Patent Cooperation Treaty}

The Patent Cooperation Treaty was signed in 1970 and entered into force in 1978. It is managed by the World Intellectual Property Organization (WIPO). As of 31 July 2006 there were 133 contracting states to the PCT. The PCT does not deliver patents. Instead, the PCT procedure provides the possibility to seek patent rights in a large number of countries by filing a single international application (PCT application) with a single patent office (receiving office) and then enter the national stage in the desired countries at a later date. ${ }^{16}$ All applications (international or regional) must ultimately have a national status, i.e. they need to be validated (granted) in the national patent offices where patent protection is desired.

In functional terms, the PCT procedure gives the applicant the possibility to delay the national or regional procedures and thereby postpone the respective fees and translation costs up to 30 months after the priority filing. The applicant can therefore benefit from more information (regarding the prospective value of the patent) before incurring the high cost of filing applications in a large number of national offices. In that sense, a PCT application can be considered an option for future applications to patent offices around the world. 
The PCT application starts with filing of an international application either at the national (or regional) patent office or with WIPO. This has to be done in the 12-month period following the priority filing, but it can be done immediately as a priority filing (Figure 3.1). The applicant must be a national or resident of one of the PCT signatory states. A PCT application automatically includes all PCT signatory states as designating states (designating states are countries in which the applicant wishes to protect an invention). ${ }^{17}$

After receipt at the WIPO, the application is transmitted to one of the appointed International Search Authorities (ISA), which are patent offices appointed by WIPO (including, for example, the EPO, JPO and USPTO). The ISA prepares an international search report (ISR), which is published at the same time as the application. It is built in the same way as the search reports for the national procedures. The ISR lists references to published patent documents and technical journal articles that might affect the patentability of the invention. The ISR is normally provided by the ISA to the applicant nine months after the filing of the application in the event of a first filing and 16 months after the priority date in the event of a subsequent filing (i.e. claiming the priority of a first filing). In addition to the ISR, since January 2004, a detailed written opinion on the patentability of the claimed invention is produced (the WOISA, written opinion of the ISA). The WOISA is a non-binding opinion on whether the invention appears to meet the patentability criteria in light of the search report results. The international application and the ISR are published after a period of 18 months from the priority date (written opinions are not published).

After receiving the ISR and the WOISA, the applicant can also request an international preliminary examination (IPE), which will generate an international preliminary report on patentability (IPRP). IPRP is a second evaluation of the potential

Figure 3.1. Timeline for PCT procedures

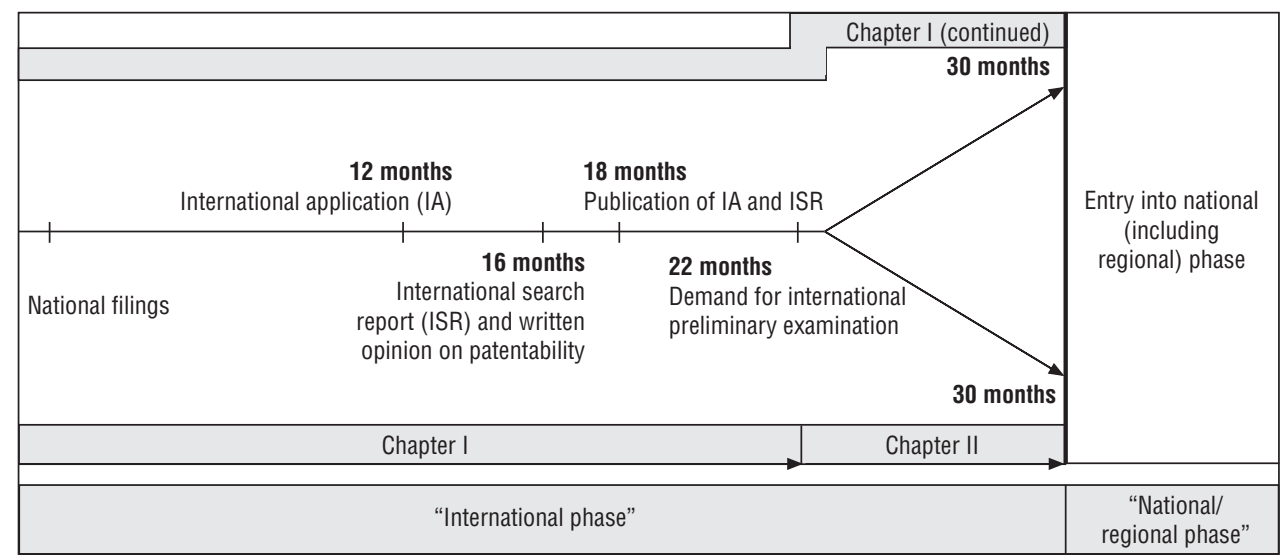


patentability of the invention. The request for an IPE must be filed within 22 months of the priority date (or three months after the issuance of the ISR, whichever is later). If the applicant does not request an international preliminary examination, the WOISA will be converted into an IPRP. ${ }^{18}$ Finally, at 30 months from the priority date, the international phase ends and the international application enters the national or regional phase (i.e. the countries in which the applicant actually wants to apply for a patent). ${ }^{19}$ As mentioned, all international or regional applications must ultimately have a national status.

In the case of the PCT it should be noted that after the transfer to the national or regional phase, it takes approximately six more months before this step is published at the regional/national office. In the case of Euro-PCT the information on the effective transfer to the EPO is available 36 months after priority (first filing). The late availability of this information strongly influences the computation of patent statistics and the timeliness of patent indicators at national patent offices. ${ }^{20}$ In the next chapter, the issue of timeliness is discussed and various methods for "nowcasting" patent applications are briefly presented.

\section{Notes}

1. In general, there is a waiting period between the request for examination and the first office action, such as first notice of refusal or decision to grant. At the JPO, the average waiting period was 25.8 months in $2005,23.8$ months at the EPO, and 23.4 months at the USPTO (Trilateral Statistical Report, 2006).

2. No search report is made available in USPTO pre-grant publications or in JPO patent applications.

3. Many jurisdictions provide extended terms for drugs in order to compensate for the administrative delays in granting approval to market.

4. Fees are due each year at the national patent offices of the EPC member countries or after three, seven and eleven years at the USPTO. Fees generally increase progressively over time. Once a patent is granted by the EPO, it must be validated in each desired national patent office of the EPC member countries. At the JPO, renewal fees are due as a lump-sum fee for the first three years and then annually from the fourth year of the date of grant.

5. This amount comprises the fees for the EPO grant procedure, the costs of representation by a patent attorney before the EPO, the translation and validation costs, and the renewal fees for maintenance of the patent.

6. Patent offices publish aggregate counts of recent applications for the purpose of monitoring their own activity, but these data are not accessible to outside users and cannot be exploited for analytical purposes.

7. First, a search is done in order to establish the state of the art with respect to the invention. The applicant receives a search report accompanied by an initial opinion on patentability. In a second phase, the inventive step and industrial applicability are considered in the substantive examination. 
8. Patents which were applied for prior to 8 June 1995, and which were or will be in force after 8 June 1995, have a patent term of 17 years from the date of patent grant or 20 years from the date of filing of the earliest related patent application, whichever is longer.

9. Because no examination of the patentability of the application in view of the prior art is performed, the USPTO fee for filing a provisional patent application is significantly lower than the fee for filing a standard non-provisional patent application.

10. Since 2000, applicants at the JPO can request early publication of the patent application within 1.5 years of the date of filing in order to deter imitation by third parties. Starting from the date of publication, applicants can claim compensation for infringement.

11. The EPO is not an institution of the European Union. At present there is no single EU-wide patent, although there has been concurrent discussion towards the creation of a "Community patent" within the European Union since the 1970s. In its Communication to the European Parliament and the Council (3 April 2007 COM, 165 Final) "Enhancing the Patent System in Europe", the Commission "is of the opinion that the creation of a single Community patent continues to be a key objective for Europe". In view of the difficulties in reaching an agreement on the community patent, other legal agreements have been proposed outside the European Union legal framework to reduce the cost of translation (of patents when granted) and litigation, namely the London Agreement and the European Patent Litigation Agreement (EPLA).

12. As of 2007, 32 countries are party to the treaty. In addition, the EPO has an "extension agreement" with five countries, which makes it possible to extend European patents to those countries upon request at the time of European patent application.

13. If the amount paid for designations is at least equivalent to seven times one designation fee, then all the contracting states are automatically considered designated, but the applicant can still remove any of them.

14. As a result, higher proportions of PCT applications passing to phase II are registered at the EPO. This is due to the supranational dimension of the EPO, which provides an opportunity to proceed with a unique procedure for several countries.

15. Furthermore, an applicant is entitled to claim priority even if the information in the subsequent application is not exactly the same as the earlier application, or if there are several "priority" applications combined into a single foreign application. As a result, when considering priority claims, one can expect different numbers of applications to have been filed in various countries.

16. This manual uses the terms "PCT application" and "international application" interchangeably.

17. Until January 2004, the applicant had to designate on the application form a specific list of countries in which protection might later be sought. This obligation was then removed (but applicants can list countries in which they do not intend to seek protection, although that will not change the application fees).

18. The IPRP provides the applicant with additional information on the patentability of inventions; therefore, applicants are in a better position to decide whether it is worthwhile to proceed to the national/regional phase. 
19. However, any national law may fix time limits which expire later than 30 months. For instance, it is possible to enter the European regional phase at 31 months from the priority date. National and regional phases can also be started earlier on the express request of the applicant [Art. 20(3) or 40(2)].

20. In the case of continuations (e.g. CIP in United States) the lag between priorities (first filing and filing in other countries) can be longer (in general all priorities refer to one year after the first priority); which will then affect the timeliness of publication of patents at other jurisdictions.

\section{References}

European Patent Office, Japan Patent Office and United States Patent and Trademark Office, Trilateral Statistical Report, 2006 edition.

Harhoff, D. and M. Reitzig (2002), "Determinants of Opposition Against EPO Patent Grants: The Case of Biotechnology and Pharmaceuticals", CEPR Discussion Papers, No. 3645 . 



\section{Chapter 4}

\section{Basic Criteria for Compiling Patent-Based Indicators}




\subsection{Introduction}

To compile patent statistics, certain methodological choices have to be made. The challenge faced by statisticians is to select the relevant variables for compiling statistics among many alternatives. The methodological choices made significantly influence the statistics derived and their interpretation. Patent statistics can only be meaningfully interpreted if there is adequate knowledge of the criteria and methodologies used to compile them.

The decision to select one criterion over another depends on the phenomena to be measured and on user needs. As an example, different indicators of the number of patent applications to the patent office of country A can be designed in order to reflect the inventive performance of other countries, the market power of entities from various countries in country A (patent portfolio ownership), or the attractiveness of country A's patenting system. In particular, if the aim is to measure the inventive performance of countries, then the criterion for calculating the indicator ought to be the inventor's country of residence, whereas if the aim is to measure ownership of inventions, then applicant's country of residence is the most appropriate criterion. Likewise, if the goal is to evaluate the attractiveness of countries for protection, then the country (or countries) in which patent protection is sought is the most adequate criterion.

The most common basic methodological choices associated with compiling patent statistics are: the reference date, the country of attribution, and the treatment of internationally comparable aggregates (PCT, families). More refined indicators based on these criteria can be considered by technology area, region, institutional origin, etc.

As a general rule, it is recommended not to put together indicators coming from different patent offices. For instance, the number of patents applied for in Korea by Korean applicants is not comparable to the number of patents applied for in Australia by Australian (or even Korean) applicants. As will be seen, legal and administrative procedures differ across patent offices, and there is a home bias in the behaviour of applicants (domestic applicants tend to file more patents in their home country than non-resident applicants). Hence the analysis in this chapter applies to data drawn from a single office (or to patent families). 


\subsection{Reference date}

The problem in choosing the year to which a patent is attributed is that every patent document includes several dates, reflecting the timing of the invention, the patenting process and the strategy of the applicant (Dernis et al., 2001; Hinze and Schmoch, 2004).

- The priority date (first date of filing of a patent application, anywhere in the world, to protect an invention) is the earliest and therefore can be considered as the closest to the invention date. Chapter 3 described the various routes for filing a patent application. The process of patent protection starts with a first filing, an initial patent application prior to any subsequent filing to extend the protection to other countries. ${ }^{1}$

- The application date is the date on which a patent is filed at a specific patent office. There is a 12-month lag between residents and foreigners for traditional direct procedures and up to 30 months for PCT procedures. Usually, an applicant will file an application at the national office (this generates the priority date) and later extends the application to other countries either by filing the application directly to the relevant patent offices (this generates an application date with up to a 12-month lag with the priority date) or by filing a patent application using the PCT procedure (the lag is 12 months for the PCT filing itself and up to 30 months for the transfer to the national phase). ${ }^{2}$

- The publication date (18 months from the priority date except for certain applications to the USPTO, which are published only if/when granted) reflects the time at which information about the invention is disclosed to the general public and made available to statisticians.

- The grant date is the date on which patent rights are conferred to the applicant by the authorised body. It takes three years on average at the USPTO and five years at the EPO for a patent to be granted, but it can take up to ten years in some cases.

For the purpose of reflecting inventive performance, indicators based on application and/or grant date suffer from a range of biases associated with the patent process. Data are dependent on various administrative delays (i.e. the examination process) and the strategic behaviour of the patentee. The data are not comparable across countries as the lag between priority date and application (or grant) dates differs from country to country: country A's inventors will usually file applications in the patent office of country A immediately after the invention occurred, whereas foreigners will apply one year later (priority year). As a result, counting the two types of inventions by year of application means that inventions from different years are compared. This can introduce biases in times of rapid technological change or for countries in which technology is growing rapidly. 
Use of the grant date means: i) that the counting is restricted to grants (excluding non-granted applications); ii) the information reported is already in the past (it takes three to five years on average to grant a patent); iii) inventions from many different years are counted together. At all offices, there is a processing and examination time, which can be very lengthy in some cases. In consequence, statistics based on granted patents are not strictly comparable across patent offices owing to the variability in the time needed to grant a patent in each patent office. In addition, as patent offices have faced a surge of their workload since the mid-1990s, the procedure has tended to lengthen, so that the number of grants would reflect the underlying dynamics only in a smoothed and delayed manner ("calendar effect"). ${ }^{3}$

One of the most meaningful dates from a technological or economic point of view is the priority date. It is the closest to the date of invention. Other details result from legal constraints (first priority) and administrative delays. There is evidence that companies that choose to patent an innovation do so early in the process, so that they have the option of withdrawing their filing later if the invention turns out to be disappointing.

Therefore, in order to reflect inventive performance, it is recommended to use the priority date to compile patent statistics. Depending on the patent indicator of interest, e.g. publication activity by the patent office (publication date) or legal status of patenting (grant date), the other criteria are also meaningful. However, they are less informative indicators of countries' performance.

Table 4.A1.1 illustrates how the choice of date affects the patent indicators. The total number of patents granted at the EPO to OECD countries in 2000 was 27139 if the date of grant is used as the reference date for granted patents; the number is 31210 if the priority date is chosen as the date of reference. Similarly, for patent applications, 146242 patents are recorded on the basis of priority date compared to 134410 for the application date. The average discrepancy between counts by priority date and counts by application date (for patent applications) was $9 \%$ in 2000 across OECD countries. For grants, the discrepancy was $28 \%$. The statistics for patents granted at the EPO show the impact of the choice of date on cross-country comparisons. For patents granted, using 2000 as the priority date, Germany has the highest percentage of patents among OECD countries, followed by the United States. The order is reversed if the count of patents is computed according to the grant date: the United States reports the largest share (26\%) followed by Germany (20.6\%) and Japan (20.3\%). In terms of patent applications, the United States has by far the largest share of patent applications (33.8\% and $33.7 \%$, under the priority date and application date criteria, respectively). 


\subsection{Reference country}

A patent document includes information on the inventor's country, applicant's country and priority country (country where first filing was made). These are all useful approaches and a comparative examination of their meaning is informative.

- Patent counts by applicant's country of residence designate "ownership" or control of the invention (i.e. the number of patents owned by residents of each country). Indicators of this type reflect the innovative performance of a given country's firms, regardless of where their research facilities are located.

- Patent counts by the inventor's country of residence indicate the inventiveness of the local laboratories and labour force of a given country. The address given in the patent document is usually the professional address of the inventor (the address of the lab at which the inventor works).

- Patent counts by priority office (country where the first application is filed, before protection is extended to other countries) indicate the attractiveness of a country's patenting process, the quality of intellectual property regulations (rules and cost of patenting), the reputation of the patent office and general economic features (e.g. market size). For instance, many Canadian firms file for patents first in the United States, followed by a possible extension in Canada at a later stage.

It is recommended to use the inventor's country of residence to compile patent statistics aimed at reflecting inventive activity. The country of residence of the applicant is useful for analysing the market allocation strategy of companies, notably multinational ones.

A frequent difficulty when compiling indicators by country of residence of the applicant is that the patent could be taken by an affiliate of the entity with control of the invention. Certain large multinational firms have affiliates specialised in patent filing, which may even be located in a country other than that of the parent company, thereby creating noise in the data. The location of such affiliates' applicants can also be guided by fiscal and other considerations. In such cases it is preferable to attribute the patent to the controlling entity (parent company); this requires matching the patent data with ownership information from other sources.

Table 4.A1.2 illustrates the impact of these criteria on patent statistics. It reports OECD country shares in applications to the EPO using different count criteria for geographical distribution. Higher shares as inventor country are reported by small countries such as Belgium, the Czech Republic, Hungary and Mexico (the difference with respect to total inventions is between 15 and 27\%). Inversely, the Netherlands, Switzerland and Finland have more patents as 
applicant countries than as inventor countries. This reflects the higher level of internationalisation of their research activities (domestic ownership of inventions made abroad). A notable example is Luxembourg, whose share as applicant country is double its share as inventor country.

Patents with multiple inventors from different countries. Recent years have seen an increase in the level of co-operation among researchers from different countries, reflecting the greater openness and internationalisation of S\&T activities. This information is found in patent documents which list inventors from different countries. Such patents can either be partly attributed to each country mentioned (fractional counts) or fully attributed to each country (whole counts). Fractional counts can be used if multiple inventors (or applicants or IPC classes) are provided in the patent data to credit each unit of analysis with its correct proportion and avoid double counting.

In particular, fractional counts can be used to compile patent statistics as this will reduce the bias of double counting if regional or world totals are computed, but whole counts are sometimes preferable, depending on the policy issue concerned (e.g. measurement of the internationalisation of technological activities by countries). ${ }^{4}$

\subsection{PCT applications}

\subsubsection{Counting PCT applications at the international phase}

Patent indicators constructed on the basis of information from a single patent office show certain weaknesses. The "home advantage" bias is one, since, proportionate to their inventive activity, domestic applicants tend to file more patents in their home country (or region) than non-resident applicants. Figure 4.1 illustrates the differences in countries' share of patents in patents taken at the USPTO, EPO and JPO. The relative share of foreign applicants is affected by factors not directly related to technology, such as the density and orientation of trade links between these countries and the country in which the patents are taken: higher exports or higher direct investment from country A to country B will trigger higher patent numbers from applicants of country A in country B so as to protect their technology. Two types of patent indicators are relatively free from this type of bias and are therefore more appropriate than national or regional filings for cross-country comparisons: PCT applications and patent families (the latter is addressed in Section 4.5).

The Patent Cooperation Treaty (PCT) procedure is international by design and is administered by the World Intellectual Property Organization. Each application filed through the PCT designates all signatory states of the PCT. This has been the case since 2004; previously, a list of designated states had to be provided by the applicant and the fees would vary according to the number of designated states. Thus, a PCT filing can be seen as a "worldwide patent 
Figure 4.1. Share of countries in patents taken at the three major regions, 2005
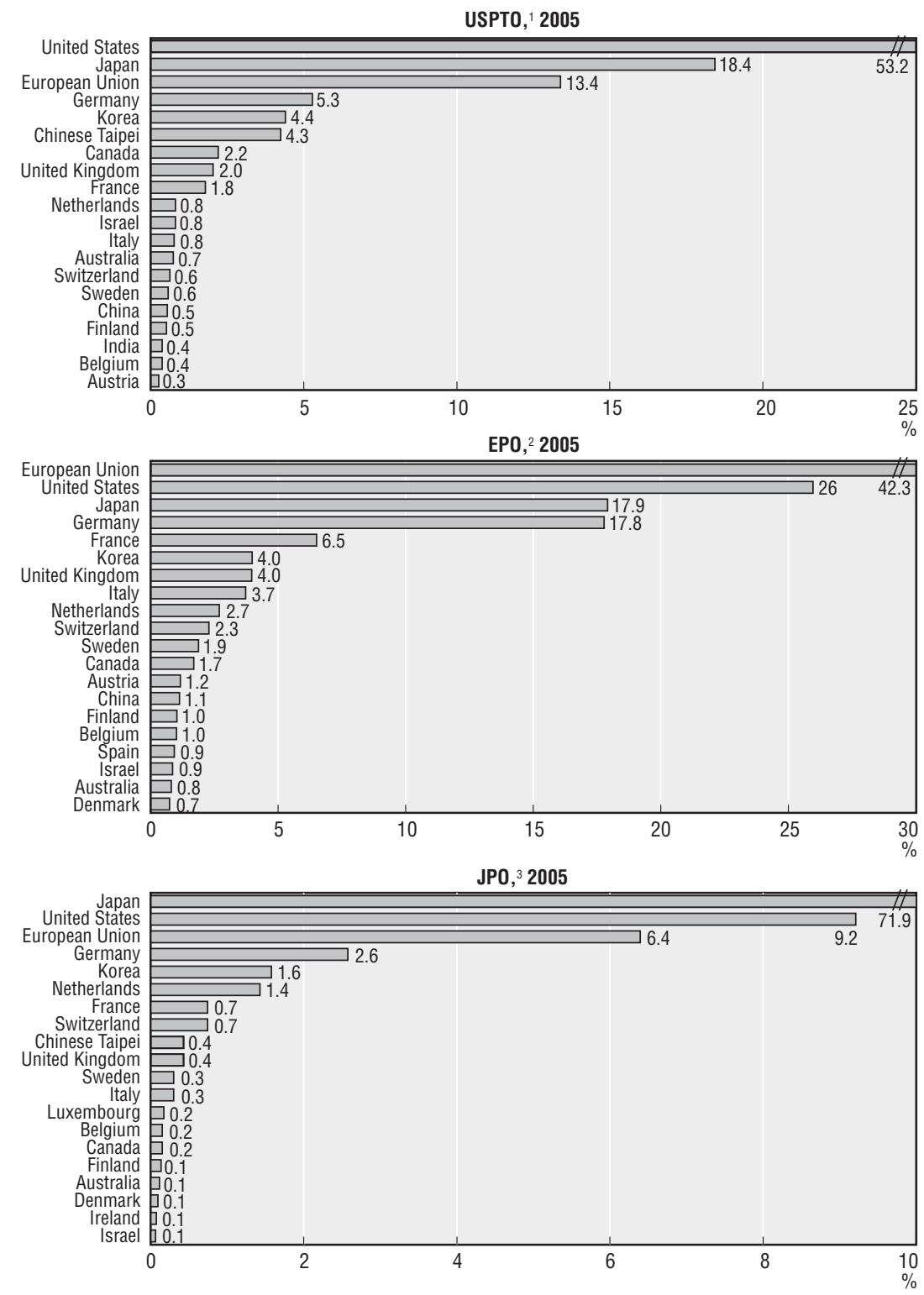

1. Patent applications to the USPTO. Patent counts are based on the first-named inventor's country of residence and the application date.

2. Patent applications to the EPO, including Euro-Direct and Euro-PCT regional phase. Patent counts are based on the priority date, the inventor's country of residence and fractional counts. Figures for 2004 and 2005 are estimates.

3. Patent applications to the JPO. Patent counts are based on the applicant's country of residence and the application date, fractional counts. Figures for 2001 to 2005 are estimates based on JPO annual reports.

Sources: USPTO Patent Statistics Reports; OECD, Patent Database, June 2007; IIP Patent Database, 2005 and JPO Annual Reports. 
application" and is much less biased than national applications. A further advantage of the PCT is that it is increasingly used by applicants from all member countries. Figure 4.2 displays the steady rise in the number of applications through the PCT procedure (with EPO designations). This makes the PCT an increasingly relevant basis for statistics. Since the early 2000s, most countries are well represented, including Japan and Korea (which began using the PCT procedure quite late). Further, the PCT reflects the technological activities of emerging countries quite well (Brazil, Russia, China, India, etc.). It should be recalled that use of the PCT expanded after 1990, so that for the transition period to about 2000 cross-country comparisons or time trends should be interpreted with care.

Figure 4.2. Patents applied for under the PCT procedure, ${ }^{1}$ EPO designations Total number, growth rate and major regions

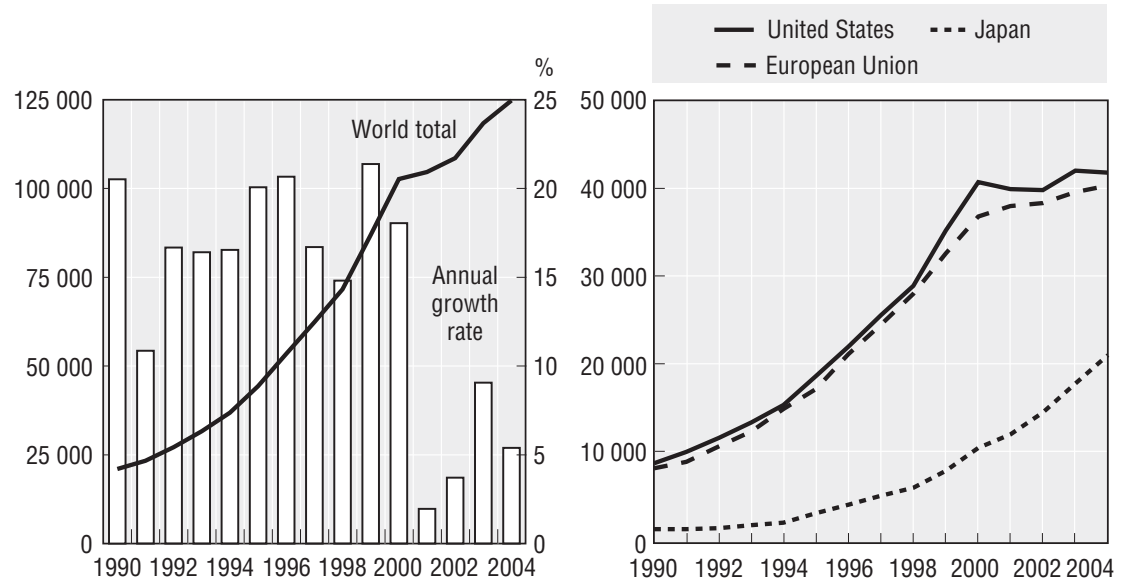

Note: Patent counts are based on the priority date, the inventor's country of residence and fractional counts.

1. Patent applications filed under the PCT, at international phase, designating the EPO.

Source: OECD, Patent Database.

PCT information has two drawbacks: first, it is not completely free of bias as applicants make uneven use of it across countries, owing to legal constraints or for economic reasons. Second, PCT applications are not patent applications in the same sense as national applications. They are options for future applications to patent offices around the world, as the PCT procedure consists of two phases: an international phase, possibly followed by a national/regional phase (see Chapter 2 for details). Because of the relatively low cost of the first phase, the PCT procedure is not very selective; applicants that are unsure of the value of their invention can file "just in case" and postpone the decision on a national/regional filing, with its associated higher costs, until later. Hence 
many PCT applications cover inventions that ultimately prove to have little value. Indeed, a fair share of PCT applications never reaches the national/ regional phase. This magnifies the drawback of patent counts that treat inventions of extremely uneven value equally. It should also be noted that even if the costs are lower than parallel application in several countries, the cost of a PCT application is still relevant and higher than that of a domestic application.

\subsubsection{Counting PCT applications at the national phase}

The two-phase procedure of the PCT has important implications for compiling patent statistics. Should the data on the international phase, which are only an option for future applications, be reported alongside other, standard, national applications? Or should only the PCT applications that proceed to the national/regional phase, where the decision is made on whether to grant or reject patent rights, be reported? The system of designation for the PCT application also has implications for reporting patent statistics. Should all designated countries be counted when compiling PCT applications at national level or only those in which the PCT application proceeds to the national/ regional phase?

For some countries, taking data on the international phase into account would alter the share of national patenting significantly (see Figures 4.3 and 4.4). For instance, for a country with 10000 national applications a year (a large majority of countries have fewer), the inclusion of PCT applications (more than 100000 applications a year) will greatly dilute the significance of national statistics, especially as most of these PCT applications will not be transferred to the country and will never become national applications. Available statistics show that a large proportion of initial PCT applications do not proceed to the national/regional phase (OECD, 2005).

However, a major drawback of including only the PCT applications which enter the national or the EPO regional phase is that it will adversely affect the timeliness of patent indicators. It may take up to 31 months from the priority date (i.e. the date of first filing of a patent application anywhere in the world) for PCT applications to enter the national or regional phase. Hence patent statistics that take this more selective approach will lag the date of interest by 31 months. $^{5}$

\subsubsection{Nowcasting patent applications}

One solution to the timeliness problem in PCT application is to estimate ("nowcast") the number of PCT applications to be transferred to a particular country. There are different ways to do this (see Box 4.1). To nowcast Euro-PCT filings, one way is to predict filings based on the transfer rate of patents filed 
Figure 4.3. Share of countries in patents filed under the PCT procedure, ${ }^{1} 2004$

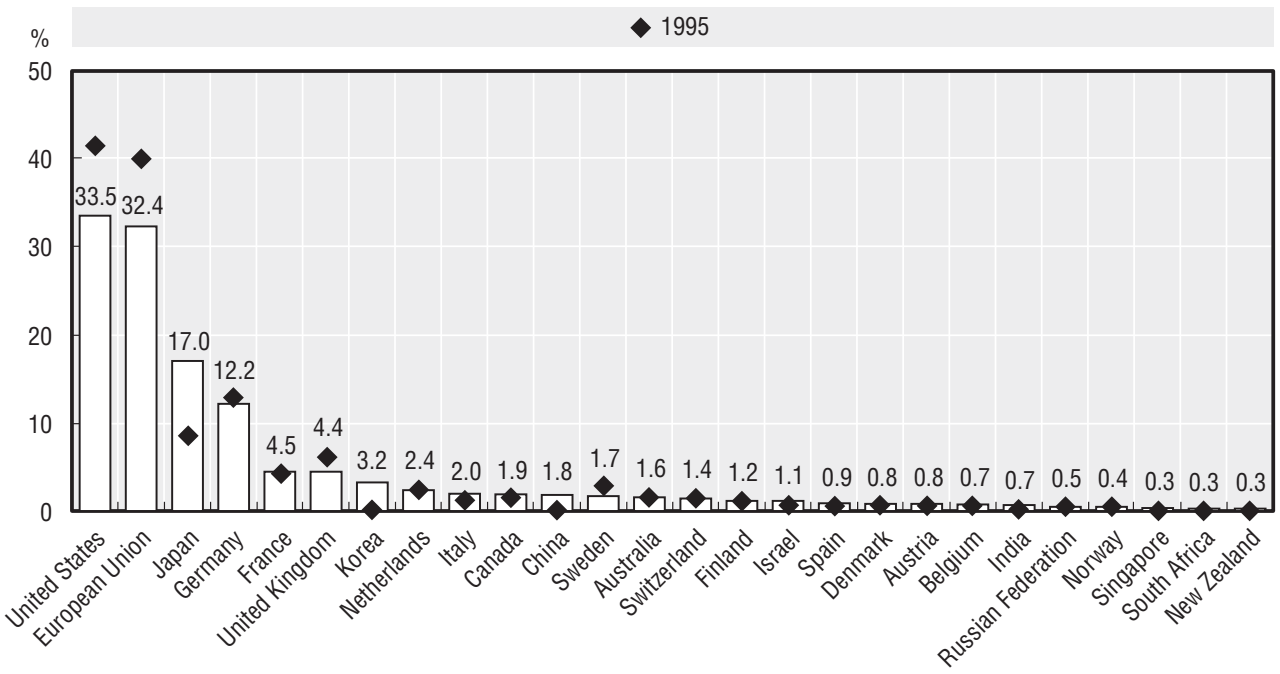

Figure 4.4. Share of Euro-PCT applications entering the regional phase, ${ }^{2}$ 2002-04

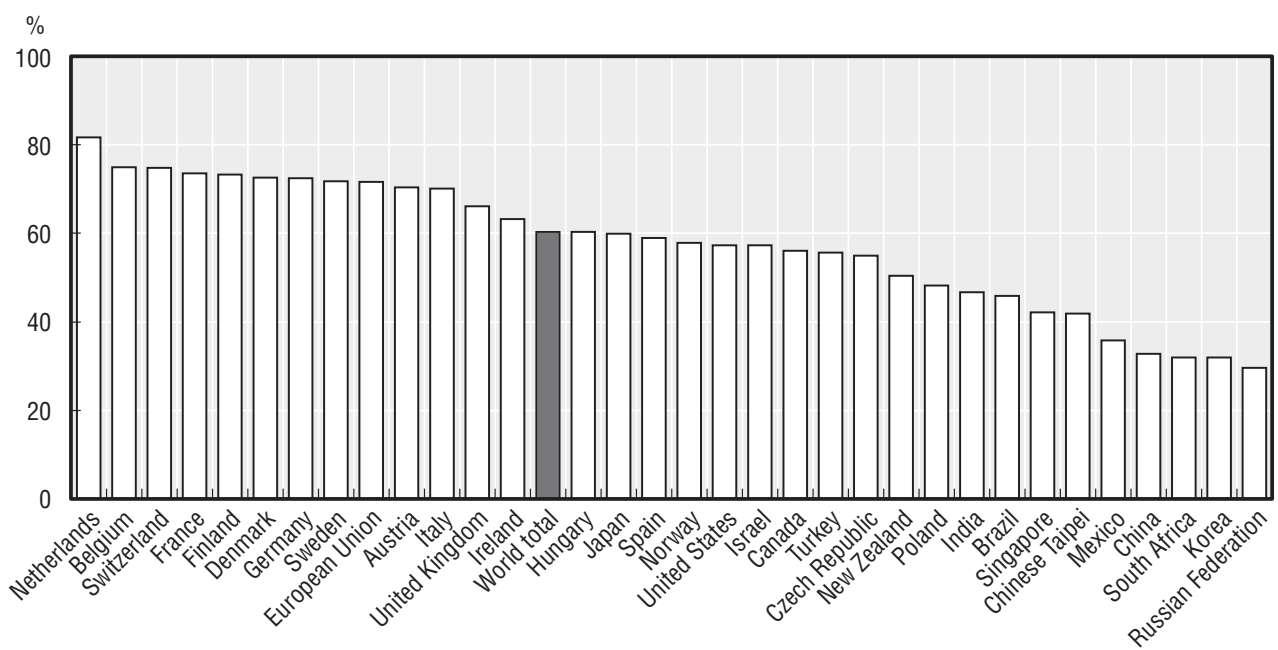

Note: Patent counts are based on the priority date, the inventor's country of residence and fractional counts.

1. Patent applications filed under the PCT, at international phase, designating the EPO.

2. The graph only covers countries with more than 250 patents filed under PCT for the period 2002-04.

Source: OECD, Patent Database. 


\section{Box 4.1. Methodologies for nowcasting}

Different methods for nowcasting patenting have been developed. Each patent office (e.g. USPTO, EPO, etc.) has its specificities, and a single model may not fit the intrinsic structure of the data, especially in terms of trends: stationary, linear, exponential, etc. Various studies have already tackled nowcasting or forecasting issues, testing different approaches for different datasets (EPO, PCT, by country, by industry, etc.). Among these studies, at least three types of estimating procedure were used:

- Trend analysis consists of simple extrapolation of trends over various time periods: the autoregressive integrated moving averages model (ARIMA) (Dehon and van Pottelsberghe, 2003).

- Transfer models predict using the transfer of first filings (priority) to the patent office - this requires a good evaluation of first filings (which are only partially available because the information has not yet been publicly released); transfer of PCT filings into regional phase (Schmoch, 1999; Dernis, 2007).

- Econometric models predict patenting based on empirical models (knowledge production functions, Hausman et al., 1984) using economic indicators such as R\&D expenditures - by sectors and source of funds; GDP; number of researchers; value added; indicators of technological opportunities (specific changes in certain technologies); indicators based on specific information from patent offices (budget, number of patent examiners, patent fees, etc.); probabilistic models, etc. (van Pottelsberghe de la Potterie and Dehon, 2003).

under PCT into the EPO regional phase, given that information on PCT patents at international phase is disclosed before they reach the regional/national phase (Schmoch, 1999). A two-step nowcasting procedure can be implemented based on the transfer rate (see Box 4.2; Dernis, 2007).

Patent offices forecast patent applications to plan future demand for services. Several methods based on regression analysis and approaches based on surveys can be used (see Box 4.1). Regression methods have the disadvantage that the forecasts are based solely on historical data and therefore assume the continuation of established trends. Straight-line regression models can be fitted to annual filings totals, but a more useful extension involves identifying trends in worldwide first filings and then monitoring their percentage transfer abroad to other offices within a year according to the Paris Convention principles of filings quoting an earlier priority. There are also interesting possibilities to model worldwide patent filings simultaneously at different offices via an approach based on the analysis of international priority filings 


\section{Box 4.2. Nowcasting methods based on transfer rates}

One way to nowcast patent filings is to predict future applications based on the transfer of previous years. For instance, a two-step procedure to nowcast EPO filings consists first in estimating the number of Euro-PCT filings that entered the EPO regional phase in year $t-2$ (Schmoch, 1999; Dernis, 2007). Then, estimations of Euro-PCT at regional phase are added to the number of direct EPO filings to get an estimate of total EPO filings with a priority in year $t-2$. A second step will evaluate the number of Euro-Direct filings and EuroPCT at international phase for priority date $t-1$, using partial $t-1$ data, before re-using the nowcasting methodology set up in step 1. A simple arithmetical method can be employed, using for instance year $t-1$ or average $\{t-1, t-2\}$ Euro-PCT transfer rates as an estimate of Euro-PCT transfer rates (EPCT_TR) in year $t$ :

$E P C T_{-} \mathrm{TR}_{1}=\frac{E P C_{t-1}}{P C T_{t-1}}$ or EPCT_TR $1=\frac{\left(E P C T_{t-1}+E P C T_{t-2}\right)}{\left(P C T_{t-1}+P C T_{t-2}\right)}$

where EPCT $T_{t}$ stands for Euro-PCT at regional phase in year $t$; and $\mathrm{PCT}_{t}$ the number of PCT designating the EPO in year t. Simple linear models can be estimated to obtain predictions on the Euro-PCT transfer rate in year $t$ as a function of either Euro-PCT transfer rate in year $\mathrm{t}-1$ or of the average transfer rate of the two former years. Additional variables can be added to the models, for instance the growth of PCT filings between $t$ and $t-1$. These methods provide robust estimates up to year $t-2$ even though patenting activity of small patenting countries or emerging economies are difficult to predict, in terms of both level and growth (Dernis, 2007). Patenting trends have been found to be more erratic for smaller patenting countries and certain emerging countries/economies (Khan and Dernis, 2005). It is recommended therefore to be cautious when applying these approaches to these countries.

for patent families. Econometric approaches are also used and typically involve the use of predictor variables such as gross domestic product (GDP) and research and development (R\&D) expenditures or $R \& D$ labour counts in the most important source countries for filings. Forecasting models frequently include a time series error structure for the various input and output series based on autoregressive integrated moving averages (ARIMA). Short-term forecasting of demand from monthly filings counts can also be useful for more detailed planning purposes, and offices of course also need to make workload forecasts for various stages of their examination procedures.

Surveys of applicants have the advantage that changes of opinion about patent filings practices can be picked up relatively quickly. The EPO and the JPO conduct surveys of their clients on an annual or biennial basis. Typically the sampled respondents are asked to quote their actual and forecast patent 
filings for the previous year and up to three years into the future. The resulting growth rate estimates can be pooled and averaged in various ways in order to obtain short-term quantitative forecasts of future patent filings. While this method allows offices to respond rapidly to changes in trends, the surveybased forecasts themselves may not be quite as good as the regression-based methods in normal circumstances, because the regression method institutionalises established trends. Surveys also have the advantage of being able to collect concomitant microeconomic information on applicants that can be useful to the patent offices in other ways to help them learn more about the needs and nature of their clients.

\subsection{Patent families}

Patent families are another way of working out patent indicators that are comparable across countries. The set of patents (or applications) filed in several countries which are related to each other by one or several common priority filings is generally known as a patent family. It is also often considered that a patent family comprises all patents protecting the same invention, although depending on the definition of family and how far the links among family members are stretched, this may be more or less true. Differences in national patent systems and procedures can lead to differences in the scope of protection applied for and granted in first and subsequent filings. This section presents some commonly used definitions of patent families, but acknowledges that this is an area of ongoing research in which new definitions are being explored by researchers and practitioners to better reflect applicant strategies.

The scope and composition of a patent family depend on the kind of priority links, types of patent documents and patent offices considered in its definition. A particular type of family is the triadic patent family (Grupp et al., 1996). According to the OECD definition (Dernis et al., 2001), a triadic patent family is a set of patent applications filed at the EPO and the JPO, and granted by the USPTO, sharing one or more priority applications. The restriction to USPTO grants (instead of applications) is due to the non-publication of applications by the USPTO until 2001, which rendered statistics based entirely on applications impossible. Another type of family is the one used in the Trilateral Statistical Report which counts all priorities filed, each being considered as a family. This method is useful for building statistics on flows from place of first filing to activities in other offices using Paris Convention priorities.

In terms of statistical analysis, triadic patent families improve the international comparability of patent-based indicators, as only patents applied for in the same set of countries are included in the family; home advantage and influence of geographical location are therefore eliminated. Second, patents included in the family are typically of higher value, as patentees only take on the additional costs and delays of extending protection to other 
countries if they deem it worthwhile. By introducing de facto a cut-off point regarding the value of patents included in this set, the upper tail of the distribution of patents by value is selected (in terms of worldwide applications), making patent family counts more informative than national or regional counts.

To count triadic patent families to reflect inventive performance, it is recommended to use the earliest priority date (first application of the patent worldwide), the inventor's country of residence, and fractional counts.

A quite restrictive definition of patent families is patent equivalents, which considers only patent documents sharing exactly the same priorities. This would correspond to a case in which an applicant files first for protection in his home country with a single application (single priority filing) and within a year files for protection in other countries. According to the Paris Convention rules the applicant has the right to claim the priority of the filing in the home country, so all subsequent filings would be equivalent to the priority. Patent equivalents are usually considered to be the most closely related patent family members and thus those most likely to be protecting the same invention.

One drawback of the OECD triadic patent families is their weak timeliness. For the USPTO, average time between application and grant is about 35 months, but can reach 44 months. Therefore, complete statistics on triadic patent families are not available before some three years after the date of interest. This disadvantage can be remedied by "nowcasting" patent families (see Section 4.4.3), i.e. using available information from the past to estimate the most likely numbers of future families (Dernis, 2007). As described in Box 4.2,

Figure 4.5. Share of countries in total triadic patent families, ${ }^{1} 2005$

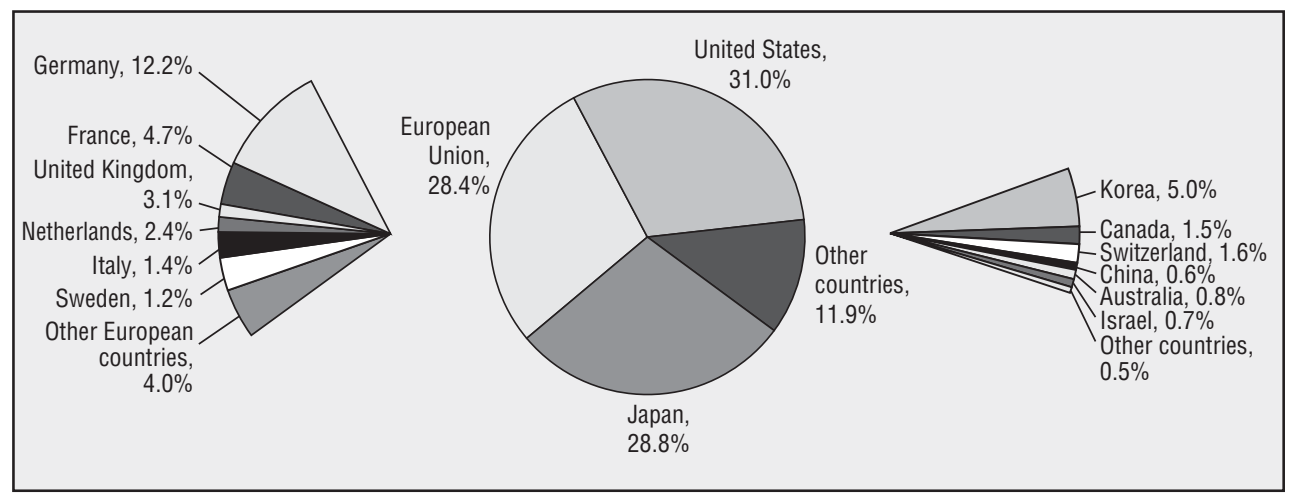

Patent counts are based on the earliest priority date, the inventor's country of residence and fractional counts. Data mainly derive from EPO Worldwide Statistical Patent Database (June 2007).

1. Patents all applied for at the EPO, USPTO and JPO. Figures from 1998 onwards are estimates. Source: OECD, Patent Database. 
a two-step method can be implemented to extend coverage of triadic patent families up to year $t-3$, possibly year $t-2$.

When compiling international indicators, one is faced with the choice between PCT applications and patent families. The choice will depend on the required timeliness and quality of the indicators. PCT applications have an advantage in terms of timeliness (they are published 18 months after priority) whereas patent families have an advantage in terms of quality (inventions of high value aiming to cover main international markets).

There are alternative definitions of patent families (see Box 4.A1.1 in Annex 4.A). The definition chosen will depend on the subject of interest. For instance, to study smaller inventions for an essentially local market, the "all priorities" definition is preferable to triadic patent families, which purposely eliminate such small inventions. However, to compile inventions of high value, which are comparable across countries, triadic patent families are preferable.

More extended patent family definitions can also be considered. Extended patent family members typically result from complex relationships, with multiple, yet at least one common, priority application from different countries, or relationships resulting from divisions, continuations or continuations-in-part as in the case of the USPTO (for an example, see Figure 4.6):

- Divisional application. This occurs when the applicant splits the initial application into divisional applications, each claiming a different invention included in the initial application.

- Continuations. These result from the filing of a second or subsequent application while the original application is pending. At the USPTO, continuation-in-part (CIP) results from the filing of a second or subsequent application which includes protected new material, while the original application is pending.

Figure 4.6. Example of close and extended patent families

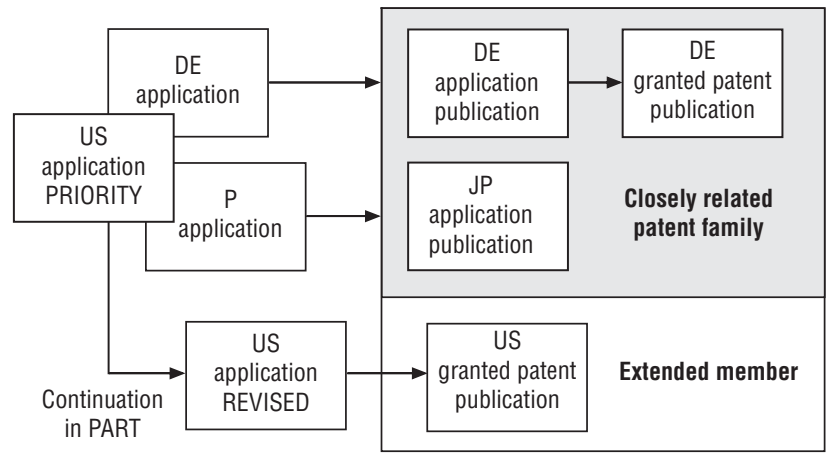




\subsection{Normalised country-level patent indicators}

National patenting activity depends on institutional factors, the nature of the legal system and various domestic factors related to the size of the

\section{Figure 4.7. Triadic patent families ${ }^{1}$ over GDP, ${ }^{2} 2005$}

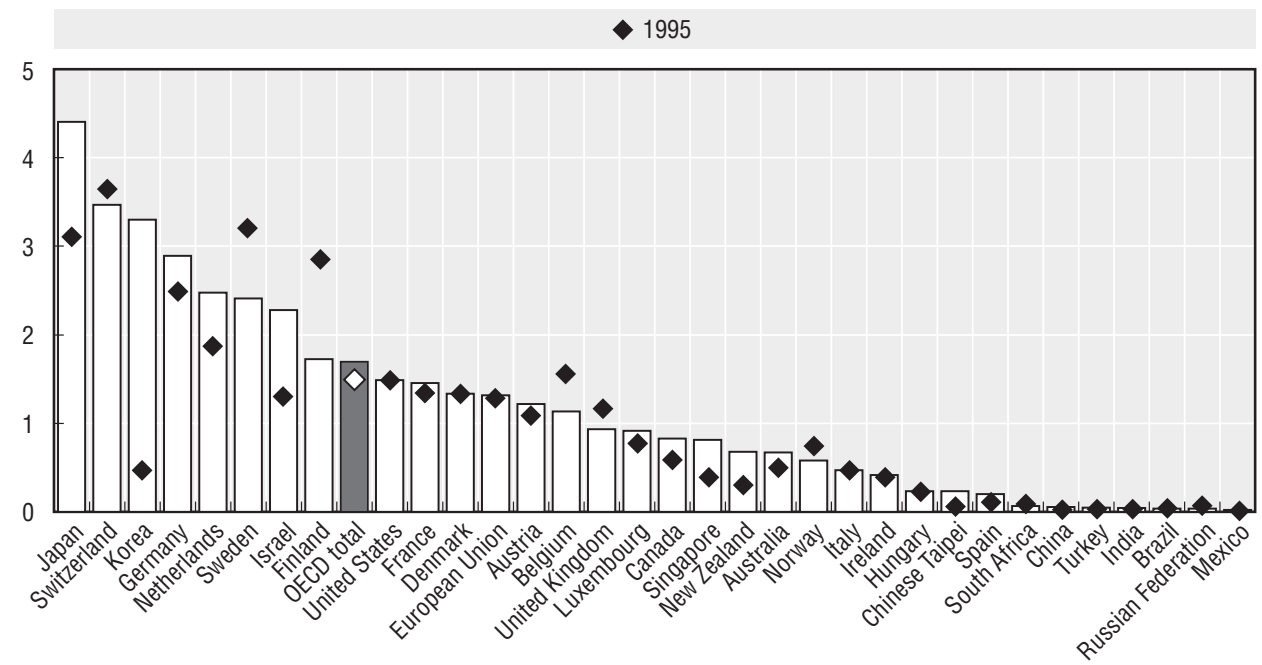

Figure 4.8. Triadic patent families ${ }^{1}$ per million population, 2005

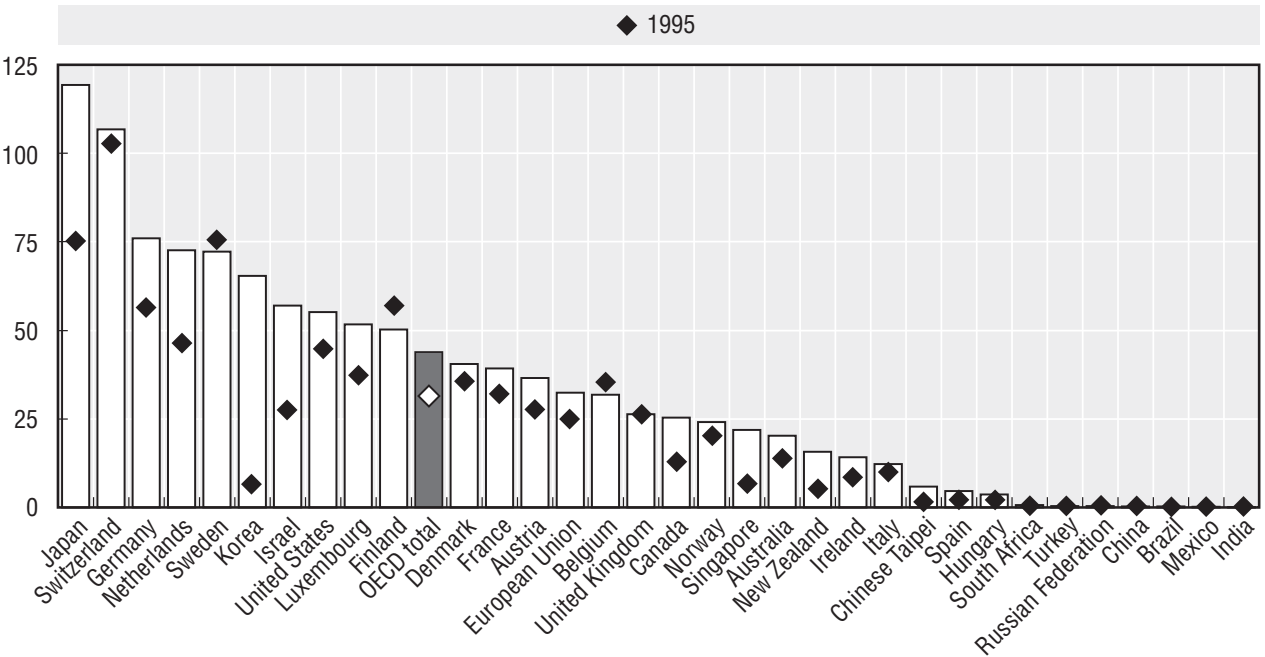

Note: Patent counts are based on the earliest priority date, the inventor's country of residence and fractional counts. Data mainly derive from EPO Worldwide Statistical Patent Database.

1. Patents all applied for at the EPO, USPTO and JPO. Figures for 2005 are estimates. Only countries/economies with more than 20 families in 2005 are included.

2. Gross domestic product (GDP), USD billions of 2000 using purchasing power parities.

Source: OECD, Patent Database. 
country: the size of the population, of the economy (GDP), and of its R\&D and research community. Patent counts can be normalised by these demographic, economic and $R \& D$ variables to obtain patent indicators which factor out size and can give unbiased information on the comparative patenting level of countries. The ranking of countries in international comparisons changes significantly when indicators are normalised.

Triadic patents by GDP and per capita are two indicators commonly used by the OECD as indicators of a country's "patent intensity" (Figures 4.7 and 4.8). Another commonly used indicator is a country's number of patents relative to its industry-financed $\mathrm{R} \& \mathrm{D}$. This indicator reflects the productivity of companies' investment in R\&D. It can take account of a possible lag between the performance of R\&D and the filing of the corresponding patents, although Hall et al. (1986) conclude that the relationship between $R \& D$ and patents at the firm level is quite contemporaneous. Such indicators can also be computed at the company, institutional or regional level, when R\&D data are available.

\section{Notes}

1. In the United States the date of conception comes into play during interference ("first to invent" rule).

2. In the case of the PCT it should be noted that after the transfer to the national or regional phase, it takes approximately six more months before this step is published at the regional/national office. In the case of the Euro-PCT the information on the effective transfer to the EPO is available 36 months after priority (first filing).

3. The reporting of data by year of grant is especially common for USPTO patents because until 2002 the USPTO published only granted patents, not applications. However, even in that case, the grant year generates biased information regarding inventions.

4. For instance, if the object of examination is the inventiveness of a single country (or region or industry), fractional counts based on inventors' country of residence might not be relevant and whole counts would be more appropriate, The use of fractional counts is convenient for aggregation purposes but is questionable as it raises the issue of the extent to which a fraction of a patent with multiple inventors might be less valuable for a given unit of analysis (country, region, etc.) than a patent with a single inventor.

5. Some patent office procedures during the international phase can affect an applicant's decision to proceed to the national/regional phase, notably the international search report and the international search opinion; there is also the publication of the application at 18 months after priority, etc. After one of these stages, the applicant might want to drop out to maintain secrecy.

\section{References}

Dehon, C. and B. van Pottelsberghe (2003), "Implementing a Forecasting Methodology for PCT Applications at WIPO", Hitotsubashi University IIR, IIR Working Paper. 
Dernis, H., D. Guellec and B. van Pottelsberghe (2001), "Using Patent Counts for Crosscountry Comparisons of Technology Output", STI Review No. 27, Directorate for Science, Technology and Industry, OECD, Paris.

Dernis, H. (2007), "Nowcasting Patent Indicators", OECD Science, Technology and Industry Working Paper 2007/3, Directorate for Science, Technology and Industry, OECD, Paris, www.oecd.org/sti/working-papers.

Grupp, H., G. Münt and U. Schmoch (1996), “Assessing Different Types of Patent Data for Describing High-technology Export Performance”, in OECD (ed.), Innovation, Patents and Technological Strategies, OECD, Paris, pp. 271-284.

Hall, B.H., Z. Griliches and J.A. Hausman (1986), "Patents and R\&D: Is There A Lag?", NBER Working Papers 1454, National Bureau of Economic Research, Inc.

Hausman, J., B.H. Hall and Z. Griliches (1984), "Econometric Models for Count Data with an Application to the Patents-R\&D Relationship", Econometrica, Econometric Society, Vol. 52 (4), pp. 909-38.

Hinze, S. and U. Schmoch (2004), "Opening the Black Box. Analytical approaches and their impact on the outcome of statistical patent analyses" in W. Glänzel, H. Moed and U. Schmoch (eds.) (2004), Handbook of Quantitative Science and Technology Research: The Use of Publication and Patent Statistics in Studies on R\&D Systems, Kluwer Academic Publishers, Dordrecht/Boston/London, pp. 215-235.

Khan, M. and H. Dernis (2005), "Impact of Patent Co-Operation Treaty Data on EPO Patent Statistics and Improving the Timeliness of EPO Indicators", OECD Science, Technology and Industry Working Paper 2005/2, Directorate for Science, Technology and Industry, OECD, Paris, www.oecd.org/sti/working-papers.

OECD (2005), Compendium of Patent Statistics 2005, OECD, Paris.

OECD (2007), Compendium of Patent Statistics 2007, OECD, Paris.

Schmoch, U. (1999), "Impact of International Patent Applications on Patent Indicators", Research Evaluation, Vol. 8, No. 2, pp. 119-131. 


\section{ANNEX 4.A1}




\section{Box 4.A1.1. Other definitions of patent families}

In practice, several definitions of patent family are used to establish a relationship between a patent document and its priority document or priority documents as mentioned by the Paris Convention. Three definitions of patent families are described here, based on the following example:

\begin{tabular}{llll}
\hline Document D1 & Priority P1 & & \\
Document D2 & Priority P1 & Priority P2 & \\
Document D3 & Priority P1 & Priority P2 & Priority P3 \\
Document D4 & & Priority P2 & Priority P3 \\
\hline Document D5 & & & \\
\hline
\end{tabular}

Definition 1: All the documents which are directly or indirectly linked via a priority document belong to the same patent family. This is the definition used by INPADOC. In this case, the documents D1 to D5 belong to the same patent family P1.

\begin{tabular}{cccc}
\hline Family P1 & & & \\
Document D1 & Priority P1 & & \\
Document D2 & Priority P1 & Priority P2 & \\
Document D3 & Priority P1 & Priority P2 & Priority P3 \\
Document D4 & & Priority P2 & Priority P3 \\
\hline Document D5 & & & \\
\hline
\end{tabular}

Definition 2: All the documents having at least one priority in common belong to the same patent family. This is the definition used by esp@cenet to obtain the list of family documents by entering the priority number in the appropriate field in the search form. This results in the display of the list of family documents (the "hit list"). In this case, documents D1, D2 and D3 belong to family P1, documents D2, D3 and D4 to family P2 and the documents D4 and D5 belong to family P3.

\begin{tabular}{llll}
\hline & Family P1 & Family P2 & Family P3 \\
Document D1 & Priority P1 & & \\
Document D2 & Priority P1 & Priority P2 & \\
Document D3 & Priority P1 & Priority P2 & Priority P3 \\
Document D4 & & Priority P2 & Priority P3 \\
\hline Document D5 & & & \\
\hline
\end{tabular}




\section{Box 4.A1.1. Other definitions of patent families (cont.)}

Definition 3: All the documents having exactly the same priority or priorities in combination belong to the same patent family. This is the definition used by esp@cenet to select the reference document for display in the "document view" from a list of family documents mentioned in the results list (hit list). In this case, document D1 belongs only to family P1, documents D2 and D3 belong to family P1 P2, document D4 belongs only to family P2 P3, and document D5 belongs only to family P3.

\begin{tabular}{|c|c|c|c|c|}
\hline Document D1 & Priority P1 & & & Family P1 \\
\hline Document D2 & Priority P1 & Priority P2 & & Family P1-P2 \\
\hline Document D3 & Priority P1 & Priority P2 & & Family P1-P2 \\
\hline Document D4 & & Priority P2 & Priority P3 & Family P2-P3 \\
\hline Document D5 & & & Priority P3 & Family P3 \\
\hline
\end{tabular}

Note: After a search, all the documents listed in the hit list are displayed individually to ensure that no information is missed. Displaying the first document of the hit list is not enough in most cases.

Definition 1 corresponds to INPADOC families. Definition 2 corresponds to esp@cenet families. Definition 3 corresponds to esp@cenet equivalents.

Source: European Patent Office. 
Table 4.A1.1. Differences in patent counts (EPO filings and grants) depending on the reference selected, 2000

\begin{tabular}{|c|c|c|c|c|c|c|c|c|}
\hline \multirow{3}{*}{ Reference } & \multicolumn{4}{|c|}{ Number of patents } & \multicolumn{4}{|c|}{ Shares in OECD } \\
\hline & \multicolumn{2}{|c|}{ Grants } & \multicolumn{2}{|c|}{ Applications } & \multicolumn{2}{|c|}{ Grants } & \multicolumn{2}{|c|}{ Applications } \\
\hline & Priority & Grant & Priority & Applic. & Priority & Grant & Priority & Applic. \\
\hline Australia & 103 & 146 & 1850 & 1706 & 0.33 & 0.54 & 1.26 & 1.27 \\
\hline Austria & 554 & 264 & 1393 & 1257 & 1.78 & 0.97 & 0.95 & 0.94 \\
\hline Belgium & 404 & 321 & 1490 & 1470 & 1.29 & 1.18 & 1.02 & 1.09 \\
\hline Canada & 394 & 308 & 2609 & 2353 & 1.26 & 1.13 & 1.78 & 1.75 \\
\hline Czech Republic & 27 & 7 & 107 & 123 & 0.09 & 0.03 & 0.07 & 0.09 \\
\hline Denmark & 312 & 199 & 1196 & 1051 & 1.00 & 0.73 & 0.82 & 0.78 \\
\hline Finland & 385 & 272 & 1814 & 1755 & 1.23 & 1.00 & 1.24 & 1.31 \\
\hline France & 2601 & 2170 & 8439 & 8184 & 8.33 & 8.00 & 5.77 & 6.09 \\
\hline Germany & 9057 & 5585 & 25221 & 24409 & 29.02 & 20.58 & 17.25 & 18.16 \\
\hline Greece & 10 & 8 & 74 & 62 & 0.03 & 0.03 & 0.05 & 0.05 \\
\hline Hungary & 41 & 22 & 207 & 177 & 0.13 & 0.08 & 0.14 & 0.13 \\
\hline Iceland & 7 & 3 & 43 & 41 & 0.02 & 0.01 & 0.03 & 0.03 \\
\hline Ireland & 52 & 33 & 288 & 322 & 0.17 & 0.12 & 0.20 & 0.24 \\
\hline Italy & 1559 & 1025 & 4493 & 4303 & 5.00 & 3.78 & 3.07 & 3.20 \\
\hline Japan & 4989 & 5497 & 24432 & 20909 & 15.98 & 20.26 & 16.71 & 15.56 \\
\hline Korea & 270 & 163 & 2620 & 1985 & 0.86 & 0.60 & 1.79 & 1.48 \\
\hline Luxembourg & 39 & 17 & 102 & 84 & 0.12 & 0.06 & 0.07 & 0.06 \\
\hline Mexico & 7 & 6 & 103 & 103 & 0.02 & 0.02 & 0.07 & 0.08 \\
\hline Netherlands & 839 & 749 & 3908 & 3474 & 2.69 & 2.76 & 2.67 & 2.58 \\
\hline New Zealand & 30 & 23 & 337 & 275 & 0.10 & 0.08 & 0.23 & 0.20 \\
\hline Norway & 139 & 101 & 640 & 565 & 0.44 & 0.37 & 0.44 & 0.42 \\
\hline Poland & 16 & 10 & 121 & 106 & 0.05 & 0.04 & 0.08 & 0.08 \\
\hline Portugal & 14 & 5 & 59 & 38 & 0.04 & 0.02 & 0.04 & 0.03 \\
\hline Slovak Republic & 3 & 3 & 39 & 34 & 0.01 & 0.01 & 0.03 & 0.03 \\
\hline Spain & 305 & 155 & 1058 & 963 & 0.98 & 0.57 & 0.72 & 0.72 \\
\hline Sweden & 666 & 556 & 3269 & 3101 & 2.13 & 2.05 & 2.24 & 2.31 \\
\hline Switzerland & 1005 & 832 & 3081 & 2887 & 3.22 & 3.07 & 2.11 & 2.15 \\
\hline Turkey & 13 & 3 & 90 & 74 & 0.04 & 0.01 & 0.06 & 0.06 \\
\hline United Kingdom & 1653 & 1582 & 7769 & 7320 & 5.30 & 5.83 & 5.31 & 5.45 \\
\hline United States & 5718 & 7074 & 49389 & 45278 & 18.32 & 26.07 & 33.77 & 33.69 \\
\hline OECD & 31210 & 27139 & 146242 & 134410 & 100.00 & 100.00 & 100.00 & 100.00 \\
\hline
\end{tabular}

Note: Patent counts are based on inventor country and fractional counts.

Source: OECD, Patent Database. 
Table 4.A1.2. Country shares in EPO applications with various criteria of attribution

\begin{tabular}{|c|c|c|c|c|c|c|}
\hline & \multicolumn{2}{|c|}{ Priority country } & \multicolumn{2}{|c|}{ Inventor country } & \multicolumn{2}{|c|}{ Applicant country } \\
\hline & $1990-2002$ & $2000-2002$ & $1990-2002$ & $2000-2002$ & $1990-2002$ & $2000-2002$ \\
\hline Australia & 0.80 & 0.63 & 1.06 & 1.27 & 0.99 & 1.16 \\
\hline Austria & 0.73 & 0.87 & 1.02 & 0.99 & 0.95 & 0.82 \\
\hline Belgium & 0.16 & 0.38 & 0.96 & 1.00 & 0.76 & 0.82 \\
\hline Canada & 0.33 & 0.20 & 1.20 & 1.86 & 1.12 & 1.69 \\
\hline Czech Republic & 0.05 & 0.04 & 0.05 & 0.08 & 0.04 & 0.06 \\
\hline Denmark & 0.62 & 0.52 & 0.71 & 0.82 & 0.72 & 0.78 \\
\hline Finland & 0.89 & 0.74 & 0.90 & 1.20 & 0.88 & 1.42 \\
\hline France & 6.18 & 8.07 & 7.70 & 5.89 & 7.49 & 5.70 \\
\hline Germany & 19.91 & 19.40 & 17.93 & 17.21 & 17.64 & 16.79 \\
\hline Greece & 0.05 & 0.03 & 0.06 & 0.06 & 0.05 & 0.05 \\
\hline Hungary & 0.07 & 0.09 & 0.14 & 0.13 & 0.12 & 0.10 \\
\hline Iceland & 0.02 & 0.01 & 0.01 & 0.03 & 0.01 & 0.03 \\
\hline Ireland & 0.11 & 0.08 & 0.13 & 0.22 & 0.13 & 0.25 \\
\hline Italy & 2.84 & 3.52 & 3.51 & 3.18 & 3.26 & 2.84 \\
\hline Japan & 19.56 & 20.37 & 18.16 & 16.69 & 18.00 & 16.63 \\
\hline Korea & 1.59 & 0.27 & 0.29 & 2.22 & 0.30 & 2.22 \\
\hline Luxembourg & 0.05 & 0.05 & 0.05 & 0.06 & 0.10 & 0.12 \\
\hline Mexico & 0.01 & 0.01 & 0.02 & 0.09 & 0.02 & 0.07 \\
\hline Netherlands & 0.80 & 1.43 & 2.32 & 2.84 & 2.93 & 3.44 \\
\hline New Zealand & 0.14 & 0.07 & 0.12 & 0.23 & 0.11 & 0.21 \\
\hline Norway & 0.26 & 0.22 & 0.36 & 0.43 & 0.37 & 0.39 \\
\hline Poland & 0.05 & 0.02 & 0.04 & 0.10 & 0.02 & 0.08 \\
\hline Portugal & 0.02 & 0.01 & 0.02 & 0.04 & 0.01 & 0.04 \\
\hline Slovak Republic & 0.01 & 0.00 & 0.00 & 0.02 & 0.00 & 0.02 \\
\hline Spain & 0.52 & 0.39 & 0.50 & 0.80 & 0.45 & 0.66 \\
\hline Sweden & 1.64 & 1.60 & 1.85 & 2.01 & 1.83 & 2.28 \\
\hline Switzerland & 0.73 & 2.28 & 2.60 & 2.12 & 3.17 & 2.95 \\
\hline Turkey & 0.03 & 0.00 & 0.00 & 0.07 & 0.00 & 0.06 \\
\hline United Kingdom & 5.72 & 6.85 & 6.32 & 5.21 & 5.71 & 4.34 \\
\hline United States & 36.13 & 31.87 & 31.98 & 33.14 & 32.80 & 33.99 \\
\hline OECD & 100.00 & 100.00 & 100.00 & 100.00 & 100.00 & 100.00 \\
\hline
\end{tabular}

Note: Patent counts are based on priority date and fractional counts.

Source: OECD, Patent Database. 



\section{Chapter 5}

\section{Classifying Patents by Different Criteria}




\subsection{Introduction}

Many uses of patent data for research and policy analysis require relating them to a meaningful unit of analysis or classifying them according to particular criteria. By relating or classifying patents in this manner, information can be obtained on these specific units or on the economic or social relevance of certain variables. Analysis may require relating patents to the entity that filed them, to the individual who made the underlying invention, to a particular field of technology, a particular industry, a particular region or a particular institutional sector.

This information is not provided in patent data in a way that allows for its immediate use. It has to be derived by "cleaning" the data (correcting mistakes and standardising the presentation) and by matching them to other data sources, such as lists of companies, lists of technology fields or concordance tables (between technology codes and industries, between city names and regions, etc.). These data sources will permit, in turn, the connection of the information contained in patents with other data. This work requires first identifying and then carefully processing the data provided in patent files.

This chapter summarises the main classifications used for patents patents by technology field, industry, regions and institutional sectors - and briefly describes the methodological approaches commonly implemented for their development. General procedures for matching patent data to companies and for consolidation by inventor are also presented. These guidelines can serve as building blocks for future improvements in the area.

\subsection{Technology fields}

As patents cover mainly technical inventions, they are a natural source of data regarding technical change. In many cases, they are in fact the only reliable source. This is notably the case for investigating new, emerging technical fields, which are not yet stabilised (i.e. which do not yet have an operational definition), are not covered by business surveys, etc.

Because of their broad and long-term coverage, patent data are useful for examining how technologies behave over time and for identifying technology breakthroughs, cross-fertilisation between fields, etc. Figure 5.1 provides the example of patents related to fuel cell technology since the early 1990s. When 
Figure 5.1. Trends in patenting of fuel cells, ${ }^{1}$ share of patents filed under the PCT, ${ }^{2}$ 1987-2004

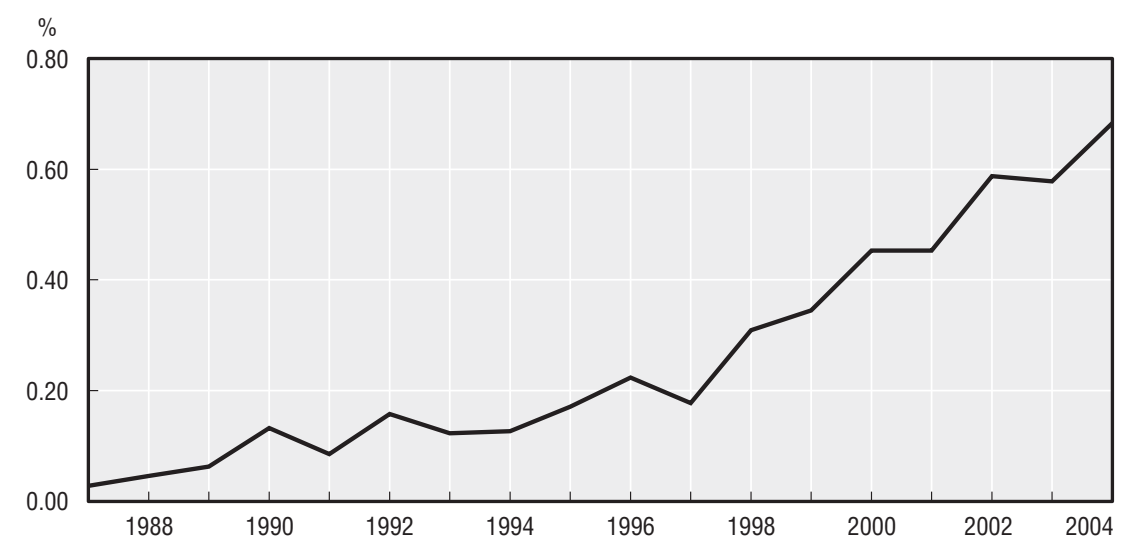

Note: Patent counts are based on the priority date, the residence of the inventors and fractional counts.

1. Fuel cells patents are identified using IPC classes H01M8/00-8/24, and refer to patent applications filed under the PCT, at international phase, designating the EPO.

Source: OECD, Patent Database.

analysing technology development, patent data have been used for studies investigating issues such as:

- New technical fields (emergence and evolution), e.g.polymer-based semiconductors, wind energy technologies.

- Technology life cycles (maturity of technology), e.g. tracking annual growth rates of patenting over long periods of time to learn whether there is a reduction in the rate of new breakthroughs (mature technologies: farming, motor vehicles, etc.).

- Cross-technology fertilisation (how one technology influences others), e.g. the influence of plasma technologies on electronics (new generations of chips), environmental technologies (plasma lamps).

Patent documents contain several types of information which can be used for classifying patents in particular fields: a technical class code and textual information (title, abstract, claims and description). Sometimes other information is used, e.g. the applicant or references.

\subsubsection{The International Patent Classification system}

To facilitate the search of prior art, patent offices classify patents according to their subject matter. These codes are reported on the patent document's front page. These classifications have been established from a technical point of view in order to retrieve patent documents that reflect the state of the art in a particular field. 
In view of the international dissemination of patent information, a common international system has proved useful. The International Patent Classification (IPC) system grew out of the Strasbourg Agreement of 1971 as an internationally acknowledged method of classifying patents for inventions, including published patent applications, utility models and utility certificates. Currently the IPC is used in more than 100 countries as the major or, in some instances, the only form of classifying these documents. The purpose of the IPC system is to group patent documents according to their technical field, whatever the language and terminology.

According to the IPC Guide (8th edition, 2006), an invention is assigned to an IPC class by its function or intrinsic nature or by its field of application. The IPC is therefore a combined function-application classification system in which the application takes precedence. A patent may contain several technical objects and therefore be assigned to several IPC classes. The IPC codes are published on the patent documents. ${ }^{1}$ The IPC system is periodically reviewed in order to improve it and take technical and electronic developments into account. If necessary, it is amended. Prior to 2006, the amendments were not made retroactive, and this can create difficulties for studies that use past series. As of April 2007, over 140 million IPC8 classifications have been applied, approximately $92 \%$ of which have been applied retroactively to documents published prior to the entry into force of IPC8. The subgroups are hierarchical. The level of subgroup is indicated by the number of dots preceding the title. The IPC 8th edition introduces the core and advanced levels (see Table 5.1 for an example).

The EPO works with the ECLA (European Classification System), which is essentially a refined version of the IPC (140 000 categories instead of 70000 for the IPC). The USPTO uses the US patent classification (USPC). The USPC contains over 160000 subdivisions. A fundamental principle of the USPC system is that each class is created by first analysing the claimed disclosures of US patents and then creating various divisions and subdivisions on the basis of that

Table 5.1. Main characteristics of IPC codes (example)

\begin{tabular}{llll}
\hline Subdivision & Number & Symbol (code letter) & Title (code label) \\
\hline Section & 8 & G & Physics \\
Subsection & 20 & & Instruments \\
Class & 118 & G06 & Computing; Calculating; Counting \\
Subclass & 616 & G06F & Electrical digital data processing \\
Main group & 6871 & G06F-9/00 & Arrangements for programme control \\
Subgroup & 57324 & G06F-9/06 & * Using stored programme \\
& & G06F-9/46 & ** Multi-programming arrangements \\
\hline
\end{tabular}

Source: World Intellectual Property Organization (2006), IPC Guide, 8th edition. 
analysis. All similar subject matter is gathered together in large groupings to create classes. These classes are then subdivided into smaller searchable units called subclasses. In terms of depth of classification, USPC usually gives more information on the invention than the IPC. The first-listed USPC for a patent is hierarchical and is its primary classification, assigned according to a welldefined set of classification rules.

In addition to the IPC, the Japan Patent Office (JPO) implements an additional classification system, the FI (file index) classification and the F-term (file-forming term) system. The FI classification is an extension of the IPC and is similar to the ECLA. It consists of an IPC subgroup followed by a three-digit number called "IPC subdivision symbol" and/or by one alphabetical letter called the "file discrimination symbol". IPC subdivision symbols and file discrimination symbols are unique to the FI classes and are structured hierarchically. The F-term system works from multiple technical viewpoints, unlike the IPC which classifies documents mostly from a single technical viewpoint. Each technical field determined by the range of FI, which is called "theme", 2 has a unique F-term list structure containing multiple viewpoints subdivided by many F-term list structure, subdivided by many F-terms. Usually a plurality of F-terms is assigned as a set to each patent document. Both indexes are assigned by the patent examiners of the JPO.

One patent document can contain one or several IPC codes. In the EPO, IPC codes are not hierarchical, i.e. the first is not more important or more relevant than the others. In the JPO, the first IPC code is the main code (indicating technology class), or it is identified with the number one (1). Patent classes are attributed by examiners; when entering the patent procedure, an application is usually pre-classified (using both manual analysis and specialised software), so as to be channelled towards the correct examination unit. Then it is attributed to an examiner, who may refine, modify or complement the list of codes of the application. Fractional counts can be used to count patents by IPC classes (or technology areas: groups of IPC classes).

\subsubsection{The identification of technological fields}

The information provided by the IPC constitutes a first reference for identifying patents in a specific technical domain. It is not enough, however, for all uses of the data; for since analytical or policy interest are not factors that are assigned or easily identifiable in patent classifications, e.g. for ICT (information and communication technology), biotechnology or nanotechnology. Such aggregates have to be reconstructed, on the basis of the available information: the IPC code or the textual data available.

The first step is to have a clear and operational definition of the technical field of interest. This description will be complemented by keywords, which 
reflect the content of the field and are used by engineers working in the field. The definition and keywords may evolve over time, as the technology evolves. One can then:

- Search for such keywords in the definitions of IPC (or other technical classification) codes, and consider as patents belonging to the field all documents which belong to one of the selected codes.

- Search for keywords in the text of patents (in the title, the abstract, etc.).

- Adopt a mixed solution, e.g. by looking for keywords in IPC codes or checking manually the relevance of the results.

A technology expert should confirm that the set of documents identified by these methods truly meets the intended criteria of the desired sample of patents.

For instance, at the EPO, the identification of nanotechnology patents involved a series of steps. First, a nanotechnology working group (NTWG) was created in 2003. At the beginning, it worked on the definition of nanotechnology in order to watch trends in nanotechnology patents. It then identified nanotechnology patents through keyword searches, consultations with nanotechnology experts at the EPO, and peer reviews by external experts. Patent applications from 15 countries or organisations were analysed and tagged to class $\mathrm{Y} 01 \mathrm{~N} .^{3}$

The OECD has designed definitions of various technical fields: ICT, biotechnology, space-related technologies, environmental technologies, etc. These definitions consist of: i) a textual definition of the technical field; and ii) a list of associated IPC classes. Reducing a technical field to a list of IPC classes has the advantage of simplicity of use (it suffices to identify the IPC code of a patent to attribute it to the relevant field). On the other hand, it does not allow discriminating within IPC codes, and thus increases the risk of misusing relevant documents or including irrelevant ones. The Y01N code for nanotechnology, which is attributed partly by examiners on an ad hoc basis, avoids such a drawback, but in view of the cost it cannot be extended to many other fields. Figure 5.1 displays trends in patenting related to fuel cell technology and Figure 5.2 reports the share of countries in this technological domain. As mentioned, patents provide information that makes it possible to track very specific technology areas at a very refined level. Figure 5.3 shows the share of related techniques (identified according to the main IPC code) in fuel cell patents.

A partition of technical fields has been proposed by OST-INPI/FhG-ISI (Observatoire des Sciences et Technologies, Institut National de la Propriété Intellectuelle) and the Fraunhofer Institute for Systems and Innovation Research). It consists of a list of 30 technical categories, which are groupings of IPC subclasses and cover the entire IPC classification. As compared with the IPC itself, this grouping is closer to the concerns of policy-oriented analysis. 
Figure 5.2. Share of countries

in fuel cell patents, ${ }^{2}$ 2000-2004

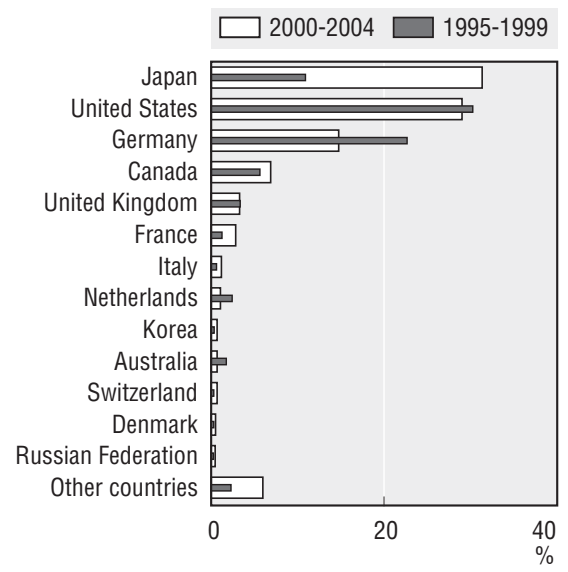

Figure 5.3. Share of relatedtechniques ${ }^{1}$ in fuel cell patents, ${ }^{2}$ 2000-2004

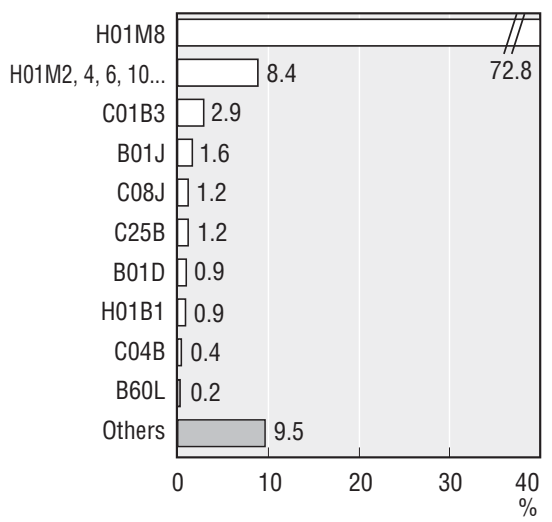

Note: Patent counts are based on the priority date, the residence of the inventors and fractional counts.

1. Fuel cells patents are identified using IPC classes H01M8/00-8/24, and refer to patent applications filed under the PCT, at international phase, designating the EPO.

2. Different techniques were identified according to the main IPC code of fuel cell patent: Separation (B01D); Chemical or physical processes (B01J); Electric equipment or propulsion of electricallypropelled vehicles (B60L); Hydrogen (C01B3); Lime, Magnesia, Slag, Cements (C04B); General processes of compounding (C08); Electrolytic or electrophoretic processes (C25B); Cables, Conductors, Insulators (H01B1); Batteries - unclassified fuel cells (H01M2, 4, 6, 10, 12); Fuel cells (H01M8).

Source: OECD, Patent Database.

\subsubsection{The sectoral specialisation of countries}

The identification of technology domains and industries in patent data makes it possible to analyse the relative technological position of a country relative to others or to the world average. More specifically, the sectoral structure of countries' patenting activity can be investigated using patent indicators of specialisation (Soete and Wyatt, 1983). The most frequently used indicator is called the "specialisation index" or the "revealed technological advantage" (RTA) index and is defined as the share of a country $i$ in patents in a particular field of technology d divided by the country's share in all patents: ${ }^{4}$

$$
\mathrm{RTA}=\frac{\left(P_{d, i} l \sum_{d} P_{d, i}\right)}{\left(\sum_{d i} P_{d, i} l \sum_{d, i} P_{d, i}\right)}
$$

The index is equal to zero when the country holds no patents in a given sector, is equal to 1 when the country's share in the sector is equal to its share in all fields (no specialisation), and grows rapidly (the upper limit will depend on the 
world distribution used) when a positive specialisation is found. The logarithm of the index can be used to obtain a new indicator with a distribution ranging from -1 to +1 . Figures based on RTA indicators must be interpreted with caution, especially for international comparisons. A country with a very large total patent output will tend to have all its RTAs in the neighbourhood of 1 , whereas a country with a low output of patents will have a very high value for the fields in which its output is slightly higher than the average for the country.

Specialisation indicators can be calculated for different periods, to show how countries' specialisation patterns have evolved over time. It should be remembered, however, that such indicators are relative to the world sectoral distribution of patents; if one country holds its distribution of patents steady while others increase their activity in an emerging field, its specialisation index in that field will decline. Figure 5.4 displays the specialisation index in biotechnology patenting for countries with more than 150 EPO applications for the period 1995-2002.

Figure 5.4. Specialisation index of biotechnology patents filed at the EPO, ${ }^{1} \mathbf{2 0 0 0 - 2 0 0 2}$

1995-97

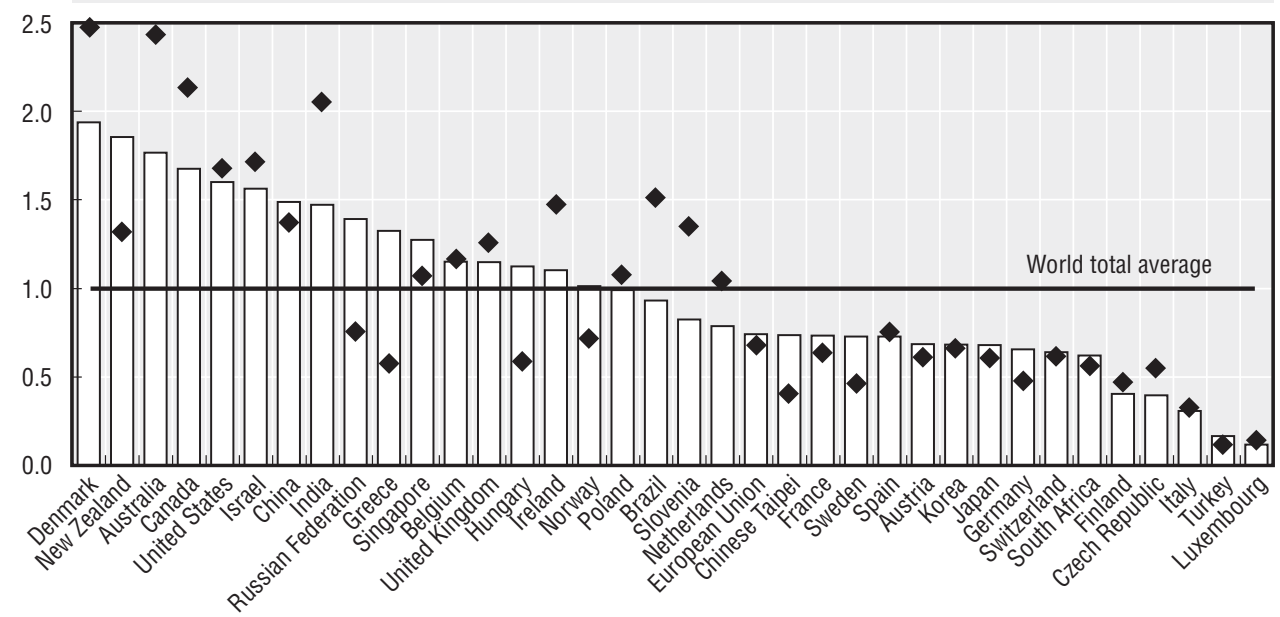

Note: Patent counts are based on the inventor's country of residence, the priority date and fractional counts. 1. The graph only covers countries/economies with more than 150 EPO applications for the period 2000-02. Source: OECD, Patent Database.

\subsection{Industry classification}

Patents can be used as indicators of the output of $R \& D$, or inputs to innovation at the industry level. However, patent data cannot be directly attributed to particular industries, as patent documents do not explicitly include the information that makes it possible to identify the economic sector to which the technology embodied in the patent is associated. The association of patents to industries allows patent data to be matched with other industry 
data, such as the OECD STAN database, and thus to analyse important policy issues, for example:

- The inventiveness of industries: estimating knowledge production functions at industry level, with inputs (notably R\&D) on the right-hand side and outputs (patent-based indicators) on the left-hand side (e.g. Pavitt, 1984; Ulku, 2007).

- The industry specialisation of countries, in connection with trade and production specialisation (e.g. Dosi et al., 1990; Malerba and Montobio, 2003).

- Cross-industry technology transfers (for example using patent citations associated with the source and the recipient industries).

The attribution of patents to industries can be made in the following ways:

- Direct attribution, by ad hoc examination of the patent.

- Attribution to the patent of the industry code of its applicant (company).

- Establishing a priori (with experts) a correspondence between IPC classes and industries, and integrating this into a concordance table.

In certain cases a mix of methods has been used to maximise the quantity of information integrated in the process.

Several methods have been developed over the last two decades. As explained by Schmoch et al. (2003), a reliable concordance should meet the following conditions: i) international comparability: it should be adaptable to other industry classifications; ii) adequate level of desegregation: it should allow backward breakdown of industries to technology fields; iii) strong empirical basis: it should be consistent with trends in countries' technological and production activity; and iv) it should be easily applicable to specific problems.

Two different criteria can be used to designate patents' industry affiliation: i) patents can be allocated to the industrial sector of origin (to the main economic sector of the inventing/applicant company), or ii) they can be allocated to the sector of use (to the main industry to which the product incorporating the invention belongs).

Nearly all available concordance tables have taken the first approach. However, these classifications encounter numerous difficulties as not all inventions can be allocated to a sector or, as in most cases, they can be pertinent to different industries at the same time. The classification by main economic activity of companies presents problems as well: large firms in particular patent in a variety of fields which do not necessarily correspond to their main economic activity. While small companies are likely to be more specialised, their field of activity might not be accessible from any database. As patent and industrial classifications change over time, concordance tables need to be regularly updated. 
An early attempt to build an industry concordance table for patents was the "Yale Concordance" developed by Evenson, Putnam and Kortum (1991) on the basis of the industry classification implemented by the Canadian Intellectual Property Office (CIPO). Between 1972 and 1995, examiners from the CIPO assigned IPC codes along with an industry of manufacture (IOM) and sector of use (SOU) code to each of over 300000 granted patents.

Another attempt was the "OTAF Concordance", the USPTO concordance between the US Patent Classification (USPC) system and the US Standard Industrial Classification (SIC) system, created in 1974. It relies on a manual review and mapping of classification categories in the USPC, which are associated with a limited set of industry-based product fields based on the 1972 SIC. These are high-level SIC classifications which are generally at the two- to three-digit SIC level (41 industrial sectors). The concordance is based on the industry of manufacture and is regularly updated, generally annually, to accommodate the changes and revisions that are made annually to the USPC. Efforts are being made to update this concordance to the recently adopted North American Industry Classification System (NAICS). Other work in this field includes the concordance proposed by Johnson (2002) based on data from the Canadian Patent Office. It includes linkages of technologies, based on probabilities of matching, to about 115 sectors of manufacture and use.

A more recent concordance table has been designed by Schmoch etal. (2003) from the Fraunhofer Institute for Systems and Innovation Research, the Observatoire des Sciences et des Techniques (OST) and the University of Sussex, Science and Policy Research Unit (SPRU). The authors rely on the economic activity of companies to relate technologies to industries. ${ }^{5}$ Their methodology involves four steps. First, a set of industrial sectors, defined by NACE and ISIC codes (two-digit level), was selected as a basis. Second, technical experts associated 625 IPC subclasses to technological categories (44 fields) and to industrial categories according to the manufacturing characteristics of products. Third, the technical and industrial approaches were compared by investigating patent activities by technology-based fields for 3400 large patenting firms classified by industrial sector (44 industrial sectors). This computation led to the elaboration of a transfer matrix or concordance between technology and industry classifications. Fourth, the adequacy and empirical power of the concordance were verified by comparing the resulting country structures (e.g. similarities in the distribution of a given technology across and within industries, by country and over time). This table was sponsored by Eurostat. It is used by the OECD for the ANPAT database, the patent segment of the STAN database (which also includes databases of value added, employment, $R \& D$, etc., at industry level for 20 industries, starting in 1971).

Based on this concordance, Figure 5.5 displays the relationship between patenting and R\&D expenditure (OECD averages) for manufacturing industries. 


\section{Figure 5.5. Patenting by industry and business R\&D, 1,2 PCT applications 2002-04}

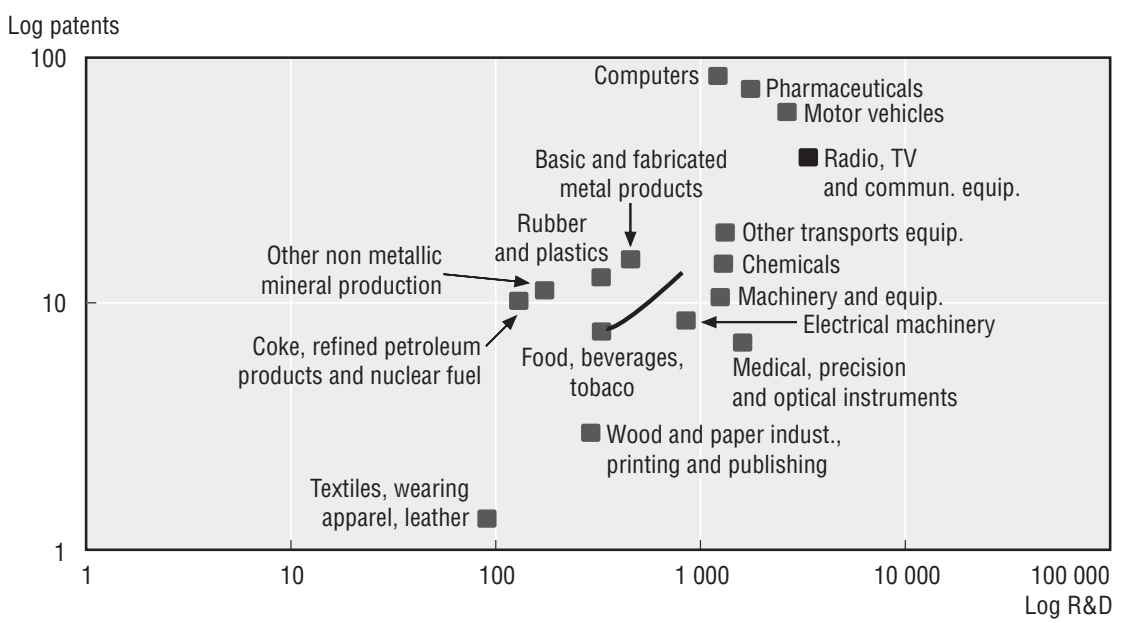

Note: Patent counts are based on the priority date and fractional counts.

1. Patent applications filed under the Patent Cooperation Treaty, at international phase, designating the European Patent Office.

2. Average business R\&D expenditure in 1999-2000, USD millions (2000) using purchasing power parities and patenting by industry in 2002-04 in OECD countries.

Source: OECD, Patent Database.

R\&D-intensive industries, such as pharmaceuticals, computers, precision and optical instruments, are among those that patent the most. Inversely, weaker technological activity, in terms both of $R \& D$ and patenting, is frequently found in textiles, leather, and wood and paper-related industries.

\subsection{Regional classification}

Describing and understanding regional patterns of innovation is important both for regional and national policy makers; it provides regional policy makers with benchmarks and references, while for national policy makers it captures an important dimension of national innovation policies. Attributing patents to regions makes it possible to address important policy questions such as:

- The comparative technological performance and profile of regions.

- The importance of geographical proximity for innovation (Jaffe et al., 1993; Audretsch and Feldman, 1996).

- The spatial distribution (or concentration) of innovative and productive activity across regions (e.g. Paci and Usai, 2000).

- Interaction and technological co-operation within and across regions (e.g. Breschi and Lissoni, 2001). 
Information provided on the front page of a patent includes the address of the inventors and applicants. This information, which includes city, region and postal (ZIP) code, makes it possible to link patents to a particular region (of the inventor or of the applicant) with the use of lookup tables (postal codes, city names, etc.). Regionalisation of patent information depends on the details (and quality of information) given in the address. This information is not always consistent across patent offices and is not very detailed in some countries. As the information is often partial, and sometimes missing, sophisticated algorithms have to be run to identify the relevant information and match it to information given in specialised regional databases. For instance, USPTO patents usually do not include the ZIP code of the inventor, but only the city name and (not always) the state code. ${ }^{6}$ For regionalising such patents the city name should be used, while recognising the need to deal with difficulties such as the fact that several cities may have the same name.

Regions are defined in standard ways. The OECD uses the TL ("territorial levels") classification, which has different levels of aggregation (TL 2 consists of about 300 macro-regions; TL 3 consists of 2300 regions, e.g. the US Bureau of Economic Analysis (BEA) economic areas, Japanese prefectures, French départements). In EU countries, regions are defined by NUTS (Nomenclature des Unités Territoriales Statistiques), an official classification of the European Commission. The OECD has compiled databases of patents (PCT, EPO) at TL3 level (see Maraut et al., 2008). ${ }^{7}$ Figure 5.6 gives the example of the top patenting regions for ICT technologies.

When using regionalised patent data, two particular issues need to be kept in mind. First, regarding inventors, it is important not to use too detailed a level in certain large urban areas. The inventor may live in a different postal code from that of the laboratory (which will then be in a neighbouring area). Co-inventors of the same invention may live in different zones of the same (large) city but work at the same place. Hence, for large urban areas with several detailed sub-areas it may be preferable to work data at a more aggregate level (e.g. TL 2 instead of TL 3). In Europe, the Paris and London areas would be examples. Second, a patent application may be filed by an affiliate of a firm, or co-filed by the firm and one of its affiliates. The address of the affiliate will appear in these cases and may not reflect the location of the entity actually controlling the patent. Consolidation of company ownership by groups will solve that problem.

\subsection{Institutional sectors}

The institutional sector of a patent holder is determined by its legal status: it can be an individual, a company (business sector, a government entity, a university or a hospital). The identification of patenting by universities and 
Figure 5.6. ICT patents by region in Europe, the United States and Japan ${ }^{1,2,3}$

The number of PCT applications (a) and PCT applications per million labour force (b) in 2004
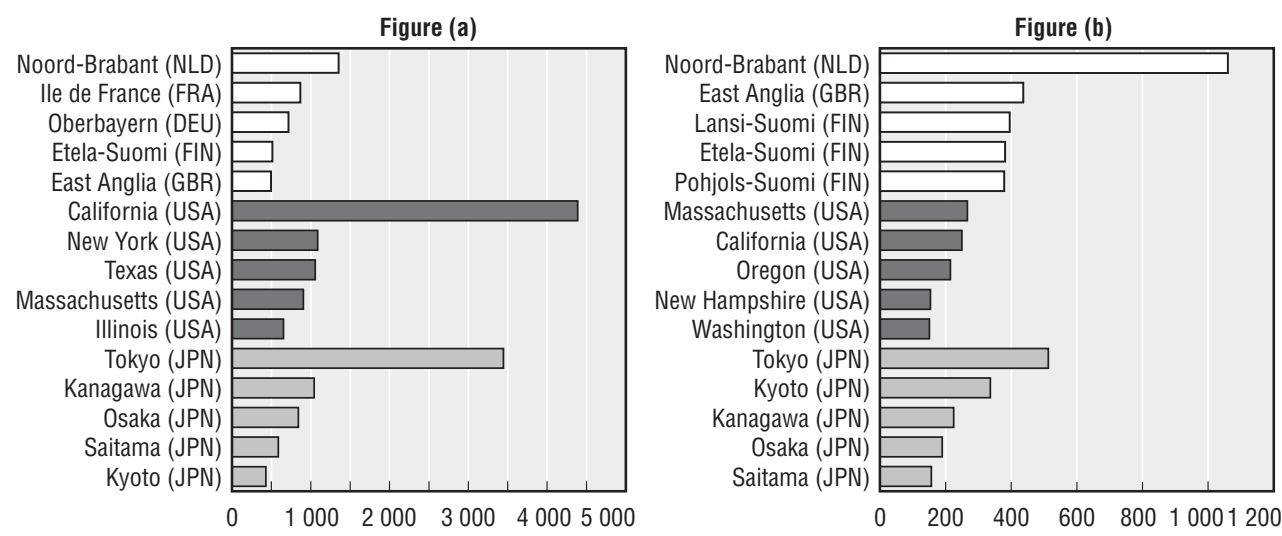

Note: Patent counts are based on the priority date, the inventor's region of residence and fractional counting.

1. Only countries with more than 100 PCT applications in 2004 are included.

2. Countries in which $60 \%$ or more inventors' addresses are assigned to regions are included.

3. Only regions with more than 100 PCT applications in 2004 are included. ICT patents are identified by the International Patent Classification (IPC).

Source: OECD, Patent Database.

public institutions (government research centres) allows for the examination of issues such as:

- The impact of certain policies on university patenting (e.g. the Bayh-Dole Act in the United States and similar policies in other countries; see Mowery et al., 2001).

- Patterns in co-operative research between universities and public research centres and private companies (e.g. Cassiman and Veugelers, 2005).

Patent data can be matched with other data, such as $R \& D$, if the list of institutional sectors for the two data sources is compatible.

Methods for allocating institutional categories to patents rely on algorithms designed to identify relevant information from the name field of patents which can provide clues to the "sector" (see Table 5.1). Such clues can be parts of names, specific words (e.g. government) and/or terms signalling specific legal forms (e.g. Inc., Ltd.). If such clues can be identified in a systematic manner, they can be integrated into one script that allows for an automated allocation of sector codes.

Van Looy et al. (2006) have recently developed, for Eurostat, a methodology based on this approach (see Table 5.2). In line with the OECD Frascati Manual (2002), ${ }^{8}$ this algorithm permits the allocation of patents to: i) individuals, ii) private enterprises, iii) government, iv) universities, $v$ ) hospitals or vi) private non-profit organisations. ${ }^{9}$ Their analytical procedure combines both rule-based 
Table 5.2. Examples of keywords/clues used to identify patentee sectors

\begin{tabular}{|c|c|}
\hline Sector & Keywords \\
\hline (1) Individual & 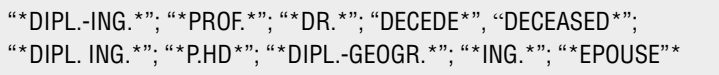 \\
\hline (2) Private enterprise & 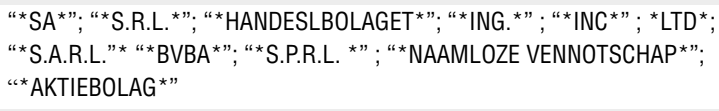 \\
\hline (3) University & 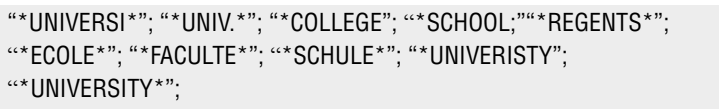 \\
\hline (4) Hospital & 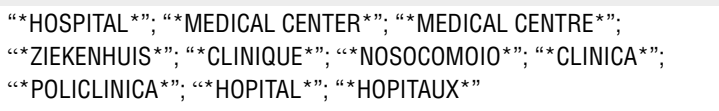 \\
\hline (5) Public and private non-profit & 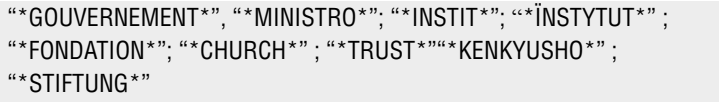 \\
\hline
\end{tabular}

Source: Van Looy et al. (2006).

and case-based logic. The former works on the assumption that information incorporated in patentee names can provide keywords on institutional membership, which can then be translated into a set of rules for the allocation of sector codes. In practice, however, as the authors found out, such a rule-based approach is insufficiently complete and accurate. The absence of clues, as well as the simultaneous presence of several clues that suggest different sectors, are common features. In order to remedy this situation, a second, case-based, layer is introduced. Conditionality is introduced to minimise the number of multiple sector assignments.

The matching of name characteristics to the different categories is sometimes not clear-cut for certain types of organisation. For instance, hospitals can be classified as either "business enterprise", "private non-profit" or "higher education" depending on the governance mode under which they operate. The sector in which a given organisation should be classified is not always clear from looking solely at name field information found in the patent system. To deal with these issues, these authors introduced different types of rules; besides generic ones that relate several patentees to one sector, rules were added targeting specific organisations. This approach is implemented by Eurostat and by the OECD.

It should be noted that using universities as patent applicant for university-originated patents results in incomplete coverage. Inventions from university researchers are not necessarily patented by the university: they may be patented by the researcher, or by a company that funded the researcher. Searching this type of invention requires identifying the university inventors (inventors' names and addresses). By matching inventors to author names 
(based on lists of researchers) it is possible to show that in many countries about $50 \%$ or more of the university-based patents cannot be identified by the use of applicants (Noyens et al., 2003). Other strategies are to identify university or related institutions in the inventors' addresses; for some countries this has increased the share of patents coming from universities by around $10 \%$.

\subsection{Patents by companies}

Attributing a patent to particular entities which own them is a key step in much statistical and analytical work based on patents. It allows reconstructing the patent portfolio of companies, which can be used to:

- Compile classifications of patents by industry, technical field, region, institutional sector, etc.

- Analyse the patenting strategy of firms (timing and orientation of their patent filings, in relation to competitors).

Matching patent information with other information at the firm level, such as R\&D, innovation, stock market value, etc., makes it possible to relate the technology or patenting strategy of companies to other characteristics: What is the impact of patents on market value? What is the efficiency of R\&D (in terms of patent numbers)?

The name and address of the patent holder are published in patent documents: however, the attribution of a patent to a particular entity is not so simple. There can be spelling mistakes; there is the fact that many companies are known under several different names (e.g. acronyms: IBM, International Business Machines); some qualifications can be added to the name (e.g. Siemens, Siemens AG); patents can be taken by affiliates, some of which are easily identified (e.g. Sony US is an affiliate of Sony), whereas others are more difficult (Citroen is part of the PSA group). It is not unusual for a large group to have an affiliate in charge of managing its intellectual property, and the affiliate files in its own name many of the group's patents (e.g. Philips).

Changes in the company's legal status, as well as changes in company names, affiliations, and mergers and acquisitions make the use of patentees' names in patent data an imperfect way to analyse company patenting and questions related to companies' patenting and innovation strategies. For instance, when aiming at harmonisation of a legal entity, all patents held by Hewlett Packard, Digital Equipment Corporation and Compaq might be considered as belonging to one and the same legal entity; likewise, "Andersen Consulting" would become harmonised to "Accenture" (name change).

Patent offices do some cleaning and harmonisation of names themselves. For instance, the USPTO deals with the name of the first applicant for any patent. The EPO attributes a standardised code to patent applicants, as does 
the JPO for applicants filing electronically. This is not sufficient, however, to address the needs of statisticians. The cleaning and harmonisation of names may go through several steps (not all necessary or exclusive of each other):

- Basic cleaning (standardising abbreviations such as "Ltd", "GmbH", etc.) and standardisation of names.

- Matching the standardised name of applicants with a company database of reference (e.g. Amadeus for Europe, Compustat for the United States).

- Reconstructing the group structure by using information on the ownership structure (including affiliates) as reported in specialised databases (e.g. the "Who owns whom" database).

The first stage consists of identifying spelling variations in order to clean the names of applicants to obtain a standardised name in order to group companies. This is done with the aid of approximate matching techniques. Two approaches are used to group similar names and standardise. The rulebased approach involves the definition of rules to compare the similarity of names. ${ }^{10}$ The second approach relies on the use of dictionaries, large collections of names which serve as examples for a specific entity class. Some examples are: USPTO and EPO standard assignee names file; Derwent Patentee Codes. It is also possible to build own dictionaries with a harmonisation procedure (e.g. Magerman et al., 2006).

The second stage is to link the standardised names to the names contained in a company database (e.g. Amadeus, Compustat, etc.) directly or in combination with other methods to find as many potential matches as possible. For instance, other available information about the company (in addition to the name) can be used, e.g. addresses and searches based on related patentee names of priority patent filings or PCT applications. The matches obtained need to be validated and doubtful matches can only be solved by hand. Lastly, the companies identified can be legally consolidated using information on the ownership structure. These two stages, matching and legal consolidation, can also be carried out at the same time if the company data used already include information on the legal relationships between companies. However, data on ownership structure are rarely codified over time. As a result, most of the available information records only the most recent legal structure of companies. In consequence, further information is needed to track changes (e.g. mergers and acquisitions) over time and properly separate patenting activity by companies in different periods of time.

Major work done in this field includes the NBER database of USPTO patents, harmonised with Compustat (www.nber.org/patents), the KUL algorithms for Eurostat (Magerman et al., 2006), and the work done by Thoma and Torrisi (2007) and Thoma et al. (forthcoming). 


\subsection{Patents by inventors}

The proper identification of inventors in patent filings makes it possible to reconstruct the inventive record of the concerned individuals and to match this record with complementary data on these individuals available from other databases. A wide array of interesting and highly policy-relevant topics can be investigated with the aid of data on the harmonised names of inventors. For instance:

- The productivity of inventors - over time, across fields, countries, etc. (Hoisl, 2007).

- The mobility of inventors - across cities, regions, countries, sectors (i.e. shifts between the public and private sectors), and the resulting spillovers of such turnover (Kim et al., 2005; Crespi et al., 2005).

- The networking strategies of inventors - who invents with whom - and their impact on productivity (Singh, 2003; Breschi and Lissoni, 2003).

- Gender issues: Share and profile of genders among inventors (Naldi et al., 2004).

Advances in this area have been hindered by the difficulties associated with the recording of names in patent data and the difficulty of recognising "who is who" in the population of inventors contained in patent data. Three fundamental problems have made the information on inventors relatively ineffective for investigation. First, the name of the same inventor can be spelled slightly differently across some of his/her patents (it may be with or without the middle name and/or initial, with or without surname modifiers, etc). Second, even if there are two exact names, it is not certain that the two names correspond to the same person (the "John Smith" problem). In other words, different inventors having exactly the same name may appear in various patents. Third, the transcription into the Latin alphabet of nonwestern names is imperfect and can create ambiguities ("Li" vs. "Lee").

Researchers have attempted to harmonise names using computerised matching algorithms which they have so far applied to specific subsets of patent data. For example, the methodology developed by Trajtenberg, Shiff and Melamed (2006), which has been used on USPTO patent data, can be summarised as follows:

- Stage 1: grouping similar names. In order to address the problem of the name of the same inventor being spelled slightly differently from patent to patent, a two-track approach is used. The first is to "clean up" and standardise the names as much as possible; the second is to complete the list of harmonised names with the aid of the "Soundex system" to encode names with similar pronunciation. ${ }^{11}$ 
- Stage 2: comparing names and matching. To deal with the problem of identifying a given individual among the "suspects" with the same name, the names are compared and matching criteria are imposed. Pair-wise comparisons can be made between any two "suspects" using a series of variables such as middle name, geographic location (e.g. postal codes, cities, etc.), the technological area (i.e. patent class), the assignee, the identity of the co-inventors, etc. If a data item is the same in two suspect records (i.e. if two records display the same address, or are in the same patent class, or share the same partners, etc.), then the pair is assigned a certain score. If the sum of these scores is above a predetermined threshold, the two records are "matched" and they are regarded as being the same inventor. ${ }^{12}$

\section{Notes}

1. The IPC is structured into sections, classes, subclasses, main groups and subgroups. The IPC divides patentable technology into eight key areas (A: Human Necessities; B: Performing Operations, Transporting; C: Chemistry, Metallurgy; D: Textiles, Paper; E: Fixed Constructions; F: Mechanical Engineering, Lighting, Heating, Weapons; G: Physics; H: Electricity). Within these areas technology is divided and subdivided to a detailed level, which allows the subject matter of a patent specification to be very thoroughly classified.

2. F-terms do not exist for all Japanese documents; the coverage depends on the field of technology.

3. The Y code is a "parallel tag". This means that an application can be in almost any technical IPC class area, but if the size is small so that it is nano, it gets a Y code. The EPO definition of nanotechnology is the following: "The term nanotechnology covers entities with a controlled geometrical size of at least one functional component below $100 \mathrm{~nm}$ in one or more dimensions susceptible to make physical, chemical or biological effects available which are intrinsic to that size. It covers equipment and methods for controlled analysis, manipulation, processing, fabrication or measurement with a precision below $100 \mathrm{~nm}$."

4. The RTA index can be applied not only relative to world sectoral distribution but also to other comparison groups (e.g. national or regional distribution).

5. Other decisions in generating the concordance matrix are: only large patents are included, only manufacturing companies are considered, only the "principal" product group of a firm is considered (although some large companies are multiproduct) and only first IPC class is considered.

6. Addresses provided in EPO patents are more complete than those of USPTO and PCT (WO): in most cases, both the town name and the postal codes are available in the address field of EPO patents. In USPTO patents, the postal codes are often missing and the regionalisation process is mostly based on town names.

7. The data sources of the Regional Patent Database (OECD) are EPO's Worldwide Statistical Patent database (PATSTAT): extraction of patents taken at the EPO, the USPTO and PCT filings (WO publications); and inventors and applicants records from EPO patents (data extracted from Epoline web services). 
8. It should be noted that individual (private) applicants do not show up as a separate category in the Frascati classification; in addition, the "Abroad" category carries little relevance when classifying patentee names. In the OECD Frascati Manual (2002), five sectors are identified: i) business enterprise; ii) government; iii) private non-profit; iv) higher education; and v) abroad. Households are considered part of the private non-profit sector.

9. The USPTO uses a classification with seven categories: unassigned (those patents for which the inventors have not yet granted the rights to the invention to a legal entity), and assigned to: US non-government organisations, non-US non-government organisations, US individuals, non-US individuals, the US federal government, and non-US governments.

10. Two examples are the Levenshtein's "Edit Distance", which measures similarity by the number of operations to switch from one word to another; and the Jaccard Similarity Measure, which is token-based and accounts for differences due to the position of the same tokens between otherwise identical strings. Other algorithms - such as Token-based or N-grams, among others - may often use Jaccard-style indicators for the final computation of similarity.

11. Soundex is a phonetic algorithm for indexing names by sound, as pronounced in English. The goal is for names with the same pronunciation to be encoded to the same representation so that they can be matched despite minor differences in spelling.

12. Once that is done for all the pairs in the comparison set, the condition of transitivity is imposed, i.e. if record $A$ is matched to record $B$, and $B$ to $C$, then the three are regarded as the same inventor.

\section{References}

Audretsch, D.B. and M.P. Feldman (1996), "R\&D Spillovers and the Geography of Innovation and Production", American Economic Review, No. 86, pp. 630-640.

Breschi, S. and F. Lissoni (2001), "Knowledge Spillovers and Local Innovation Systems: A Critical Survey", Industrial and Corporate Change, Oxford University Press, Vol. 10(4), pp. 975-1005, December.

Breschi, S. and F. Lissoni (2003), "Mobility and Social Networks: Localised Knowledge Spillovers Revisited", CESPRI Working Papers 142, Centre for Research on Innovation and Internationalisation, Universita Bocconi, Milan, Italy.

Crespi, G.A., A. Geuna and L.J. Nesta (2005), "Labour Mobility of Academic Inventors: Career Decision and Knowledge Transfer", SPRU Electronic Working Paper Series 139, University of Sussex, SPRU - Science and Technology Policy Research.

Dosi, G., K. Pavitt and L. Soete (1990), The Economics of Technical Change and International Trade, Harvester/Wheatsheaf.

Evenson, R.E., J. Putnam and S. Kortum (1991), "Estimating Patent Counts by Industry Using the Yale-Canada Concordance", final report to the National Science Foundation.

Hoisl, K. (2007), “Tracing Mobile Inventors: The Causality between Inventor Mobility and Inventor Productivity", Research Policy, No. 36, pp. 619-636. 
Jaffe, A.B., M. Trajtenberg and R. Henderson (1993), "Geographic Localization of Knowledge Spillovers as Evidenced by Patent Citations", Quarterly Journal of Economics, No. 108, pp. 577-598.

Johnson, D. (2002), “The OECD Technology Concordance (OTC): Patents by Industry of Manufacture and Sector of Use", OECD Science, Technology and Industry Working Paper 2002/5, Directorate for Science, Technology and Industry, OECD, Paris, www.oecd.org/sti/working-papers.

Kim, J., S.J. Lee and G. Marschke (2005), “The Influence of University Research on Industrial Innovation", NBER Working Paper 11447, June.

Magerman, T., B. Van Looy and X. Song (2006), "Data Production Methods for Harmonized Patent Statistics: Patentee Name Harmonization”, KUL Working Paper No. MSI 0605.

Malerba F. and F. Montobbio (2003), "Exploring Factors Affecting International Technological Specialization: the Role of Knowledge Flows and the Structure of Innovative Activity", Journal of Evolutionary Economics, Vol. 13, No. 4, pp. 411-434.

Maraut, S., H. Dernis, C. Webb, V. Spiezia and D. Guellec (2008), “The OECD REGPAT Database: A Presentation", OECD Science, Technology and Industry Working Paper 2008/2, Directorate for Science, Technology and Industry, OECD, Paris, www.oecd.org/sti/working-papers.

Mowery, D.C., B.N. Sampat and A.A. Ziedonis (2001), "Learning to Patent: Institutional Experience, Learning, and the Characteristics of US University Patents after the Bayh-Dole Act, 1981-1992”, Management Science No. 48(1), pp. 73-89.

Naldi, F., D. Luzi, A. Valente and I.V. Parenti (2004), "Scientific and Technological Performance by Gender", in H.F. Moed et al. (eds.), Handbook of Quantitative Science and Technology Research: The Use of Publication and Patent Statistics in Studies on R\&D Systems, Kluwer Academic Publishers, Dordrecht/Boston/London, pp. 299-314.

Noyons, E.C.M., R.K. Buter, A.F.J. van Raan, U. Schmoch, T. Heinze, S. Hinze and R. Rangnow (2003), "Mapping Excellence in Science and Technology across Europe. Nanoscience and Nanotechnology", CWTS, Leiden.

OECD (2002), Frascati Manual: Proposed Standard Practice for Surveys on Research and Experimental Development, OECD, Paris.

Paci, R. and S. Usai (2000), “Technological Enclaves and Industrial Districts: An Analysis of the Regional Distribution of Innovative Activity in Europe", Regional Studies, Taylor and Francis Journals, Vol. 34 (2), April, pp. 97-114.

Pavitt, K. (1984), Sectoral Patterns of Technical Change: Towards a Taxonomy and a Theory, Research Policy No. 13 (6), pp. 343-373.

Schmoch, U., F. Laville, P. Patel and R. Frietsch (2003), "Linking Technology Areas to Industrial Sectors", final report to the European Commission, DG Research.

Singh, J. (2003), "Multinational Firms and Knowledge Diffusion: Evidence Using Patent Citation Data", mimeo.

Soete, L. and S. Wyatt (1983), The Use of Foreign Patenting as an Internationally Comparable Science and Technology Output Indicator, Scientometrics No. 5, January, pp. 31-54.

Thoma, G.L.D., S. Torrisi, A. Gambardella, D. Guellec, B.H.Hall and D. Harhoff (forthcoming), "Harmonisation of Applicants' Names in Patent Data", OECD Science, Technology and Industry Working Papers, Directorate for Science, Technology and Industry, OECD, Paris, www.oecd.org/sti/working-papers. 
Thoma, G.L.D. and S. Torrisi (2007), “Creating Powerful Indicators for Innovation Studies with Approximate Matching Algorithms. A test based on PATSTAT and Amadeus databases", CESPRI Working Papers 211, CESPRI, Centre for Research on Innovation and Internationalisation, Universita' Bocconi, Milan, Italy, revised December 2007.

Trajtenberg M., G. Shiff and R. Melamed (2006), “The 'Names Game': Harnessing Inventors' Patent Data for Economic Research", NBER Working Papers 12479, National Bureau of Economic Research, Inc.

Ulku, H. (2007), "R\&D, Innovation and Growth: Evidence from Four Manufacturing Sectors in OECD Countries”, Oxford Economic Papers, No. 59 (3), pp. 513-535.

Van Looy B., M. Du Plessis and T. Magerman (2006), "Data Production Methods for Harmonized Patent Statistics: Patentee Sector Allocation", Eurostat/K.U. Leuven Working Paper.

Veugelers, R. and B. Cassiman (2005), "R\&D Cooperation between Firms and Universities: Some Empirical Evidence from Belgian Manufacturing", International Journal of Industrial Organization, No. 23, 5-6, pp. 355-379. 



\section{Chapter 6}

\section{The Use and Analysis of Citations in Patents}




\subsection{Introduction}

The use of patent and non-patent citations as indicators of innovation has increased dramatically in the last decade. As citations indicate the S\&T precedents in inventions, they make it possible to track knowledge. It is possible to identify the influence of particular inventions or particular sets of inventions and map their diffusion through the economy. In particular, the number of citations a patent receives has been found to reflect, on average, the technological and commercial importance of a patent, and thus helps to deal with the problem of the heterogeneity of patents' value.

Citations also make it possible to investigate connections between technologies, between science and technology, or between firms, industries, countries or regions. These linkages can be broken down in a variety of ways: by technical field, by type of entity (e.g. multinational or domestic firm, university, etc.), by inventor, etc.

This chapter describes the meaning of citations in patents and explains how they can be used to compile S\&T indicators. It stresses in particular the issues to take into account when compiling indicators based on patent citations in order to analyse innovation. These guidelines can serve as building blocks for future improvements in the area.

\subsection{What are citations?}

Patent and non-patent citations are the references provided in the search report which are used to assess an invention's patentability and help to define the legitimacy of the claims of the new patent application. As they refer to the prior art, they indicate the knowledge that preceded the invention and may also be cited to show the lack of novelty of the citing invention. However, citations also indicate the legal boundaries on the claims of the patent application in question. They therefore serve an important legal function, since they delimit the scope of the property rights awarded by the patent. If a patent $B$ cites patent $A$, it means that patent $A$ represents a piece of previously existing knowledge upon which patent $B$ builds or to which patent $B$ relates, and over which B cannot have a claim. Hence citations may be used to preclude the issuance of a patent or limit the scope of the protection to what was specifically known at the time of filing the patent application. 
In most cases, citations are the product of an extensive search of the state of the art conducted by examiners in order to assess the degree of novelty and inventive steps of inventions (resulting in the "search report"), which is necessary to justify their patentability. Citations can also be used to refuse patent applications if the claimed invention appears not to be novel after confrontation with the state of the art. The search includes publicly available scientific or technical documents or any other testimony that constitutes a relevant precedent of the invention.

There are basically two kinds of citations. Patent references are citations to previous relevant technology protected by or described in other patents filed anywhere in the world, at any time, in any language. References categorised as non-patent literature (NPL) are scientific publications, conference proceedings, books, database guides, technical manuals, standards descriptions, etc.

\subsection{Uses and applications of citations indicators}

The potential of patent citation measures for policy analysis is tremendous. Three applications of patent citations dominate the innovation literature: i) the measurement of knowledge flows or spillovers (e.g. Jaffe et al., 1993); ii) the measurement of patent quality (e.g. Harhoff et al., 2002); and iii) the strategic behaviour of companies (e.g. Podolny et al., 1996).

Backward citations - citations to previous patent documents - can help to track knowledge spillovers in technology. They make it possible to estimate the curve of obsolescence of technologies, the diffusion of knowledge emanating from specific inventions to institutions, areas, regions, etc. Yet patent and nonpatent citations are in some cases a "noisy signal" of knowledge flows, as the inventor of the citing patent is not always aware of the existence of the one cited in the search report, as citations are frequently given by examiners or by patent attorneys (e.g. Jaffe et al., 2000). ${ }^{1}$

Forward citations - the citations subsequently received by a patent - can be used to assess the technological impact of inventions, e.g. their crosstechnology and/or geographical impact. The technological impact of inventions can indicate the economic importance of patents. The value of a patent and the number and quality of its forward citations have repeatedly been found to be correlated. Citation-weighted indicators (e.g. patent stocks of companies) have been seen to have a close relationship to economic indicators (market value of companies). It has been consistently reported that patents that receive more citations than the average are more likely to be renewed (Lanjouw et al.,1998) and opposed or litigated in tribunals (e.g. Lanjouw and Schankerman, 1997; Harhoff et al., 2002). 


\subsection{Citation practices in patent offices}

Citation practices differ across patent offices and indicators are not directly comparable. Owing to differences in disclosure obligations and examination procedures, European searches differ substantially from USPTO searches, and so do the citations generated in the two processes. This means that researchers wishing to employ patent citation analysis need to be aware of these differences.

Applicants to the USPTO are legally required to include a full list of prior art known or believed to be relevant ("duty of candour"). These are then evaluated and/or supplemented by the examiner. Examiners consider all disclosed prior art with few exceptions. There is a strong motive to provide references to prior art in the USPTO system, because failure to provide all relevant references can result in patent litigation and severe penalties. ${ }^{2}$

At the EPO no such requirement exists. The applicant or the applicant's patent attorney may cite prior art within the application document but this is optional. ${ }^{3}$ Most citations in PCT and EPO publications (about 95\%) are added by examiners in the search report. Although examiners are responsible for constructing the list of prior art references (provided in the search report) against which patentability is judged, they rely in part on the applicant's disclosure of prior art submitted with the patent application (e.g. at the EPO, this is done in the information disclosure statements).

Furthermore, the European search report should include (as references) the most important documents, or the earliest of equally important documents. According to EPO philosophy, a good search report contains all relevant information within a minimum number of citations. ${ }^{4}$ Some have noted that certain applicants to the USPTO may provide more references than necessary (until the 2006 reform). This, combined with EPO examiners' minimalist approach, goes some way towards explaining the fact that the significantly greater average number of citations in USPTO than in EPO patents (see Table 6.1). ${ }^{5}$

At the JPO, patent examiners conduct the search of the prior art; however, applicants are also required to disclose information on prior art beforehand (in practice since September 2002 and in full force since May 2006). There is no limitation on the number of references to be included.

For EPO and PCT citations, the following issues must be considered (Webb et al., 2005):

- Citations contained in international and/or regional search reports may differ. One problem concerns the (partial) substitute character of information contained in WO search reports (the international search reports). ${ }^{6}$ If the EPO receives filings that were treated first by other ISAs (international search 
Table 6.1. Occurrence of patent and non-patent references (USPTO and EPO)

\begin{tabular}{|c|c|c|c|c|c|}
\hline \multicolumn{6}{|c|}{ USPTO granted patents with application year between 1991 and 2001} \\
\hline Total number of patents (1) & 1299817 & $\begin{array}{l}\text { Total number } \\
\text { of references }\end{array}$ & 17757797 & & \\
\hline $\begin{array}{l}\text { Number of patents containing } \\
\text { patent references }\end{array}$ & $\begin{array}{l}1173593 \\
(90 \%)\end{array}$ & $\begin{array}{l}\text { Number of patent } \\
\text { references }\end{array}$ & $\begin{array}{l}14738854 \\
(83 \%)\end{array}$ & $\begin{array}{l}\text { Technology intensity. } \\
\text { With (1) as denominator }\end{array}$ & $\begin{array}{l}12.55 \\
11.33\end{array}$ \\
\hline $\begin{array}{l}\text { Number of patents containing } \\
\text { non-patent references }\end{array}$ & $\begin{array}{l}445466 \\
(34 \%)\end{array}$ & $\begin{array}{l}\text { Number of non- } \\
\text { patent references }\end{array}$ & $\begin{array}{l}3018943 \\
(17 \%)\end{array}$ & $\begin{array}{l}\text { NPR intensity. } \\
\text { With (1) as denominator }\end{array}$ & $\begin{array}{r}6.77 \\
2.2\end{array}$ \\
\hline \multicolumn{6}{|c|}{ EPO granted patents with application year between 1991 and 2001} \\
\hline Total number of patents (1) & 342704 & $\begin{array}{l}\text { Total number } \\
\text { of references }\end{array}$ & 1698218 & & \\
\hline $\begin{array}{l}\text { Number of patents containing } \\
\text { patent references }\end{array}$ & $\begin{array}{l}334413 \\
(98 \%)\end{array}$ & $\begin{array}{l}\text { Number of patent } \\
\text { references }\end{array}$ & $\begin{array}{l}1404241 \\
(83 \%)\end{array}$ & $\begin{array}{l}\text { Technology intensity. } \\
\text { With (1) as denominator }\end{array}$ & $\begin{array}{l}4.20 \\
4.09\end{array}$ \\
\hline $\begin{array}{l}\text { Number of patents containing } \\
\text { non-patent references }\end{array}$ & $\begin{array}{l}130511 \\
(38 \%)\end{array}$ & $\begin{array}{l}\text { Number of non- } \\
\text { patent references }\end{array}$ & $\begin{array}{l}293977 \\
(17 \%)\end{array}$ & $\begin{array}{l}\text { NPR intensity } \\
\text { With (1) as denominator }\end{array}$ & $\begin{array}{l}2.25 \\
0.86\end{array}$ \\
\hline
\end{tabular}

Source: Callaert et al. (2006).

authorities), the EPO undertakes a supplementary search which is summarised in the supplementary search report. ${ }^{7}$

- This phenomenon is particularly important given that an increasing number of applicants file patents under PCT before entering the EPO process in the "regional phase". When this occurs, most citations appear in the international (WO) document rather than the EPO document. In order to count citations correctly, information from both the international and the European searches should be combined.

Until recently, most citation indicators were restricted to a single office: references from EPO patents to prior EPO patents or US references to US patents. For EPO patents, it has been pointed out that roughly three-quarters of the references are not used. Taking the full data into account may powerfully affect citation indicators. For instance, the inclusion of citations in the PCT international stage (WO) with European patent equivalents shifts the citation lag (time difference between the cited and the citing patents) significantly: the median lag shifts from 4.0 to 6.7 years; the maximum lag moves from 25.7 to 132 years (Harhoff et al., 2006).

Several issues need to be taken into account when working with patent and non-patent citations. Some of the most important for counting citations are:

Patent documents do not have a one-to-one relationship to inventions. Citations to a patent can vary. A given invention can be covered by a number of documents issued by different national or supranational offices (Harhoff et al., 2006). ${ }^{8} \mathrm{~A}$ patent can be cited as a national or an international/regional patent publication or as one of its equivalents (at the USPTO, EPO or JPO). As explained in Chapter 4, all of the published patent applications from various countries and the 
subsequently granted patents on an invention are commonly referred to as patent equivalents. A group of patent equivalents makes up a patent family; that is, a set of patents (or applications) filed in several countries to protect the same invention. They are related to each other by one or several common

\section{Box 6.1. The problem of equivalents}

\section{The case of European patent citations (Harhoff et al., 2006)}

Counts of European patent citations have been used in economic analysis in a number of cases, but rarely have these studies tackled the problem of equivalents (a patent that relates to the same invention and shares the same priority application as a patent from a different issuing authority; see Chapter 4 for definitions of patent families). The structure of this problem is described in the figure below. The search report for patent application EP-x references patent document WO-a, EP-w and US-z. However, document WO-a has an equivalent EP-y among EPO filed applications. The patent application underlying document US-z has two equivalents (EP-z and EP-v) within the EP system.

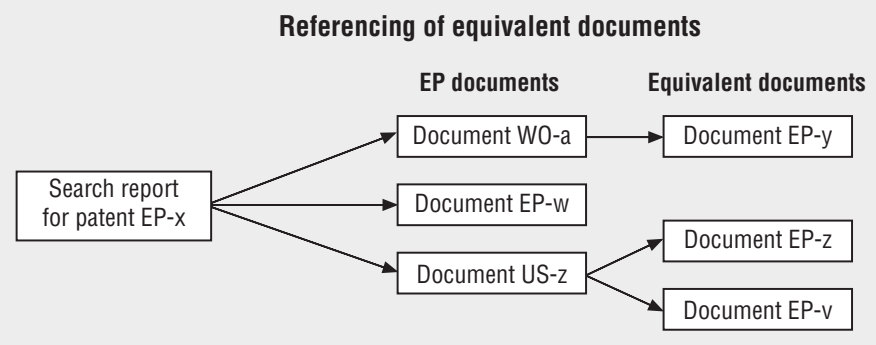

This pattern of referencing is in no way erroneous. Given time constraints, bottlenecks in documentation systems or simply language preferences, this is a frequently observed pattern. However, for a researcher who wishes to know how often particular patents (e.g. EP-y, EP-z or EP-x) have been cited in one of its (equivalent) incarnations, simply counting the uncorrected occurrence of references is misleading. Prior to the count, all non EP documents would have to be re labelled to their EP equivalent application number(s) in order to obtain correct counts of citations. More precisely, the rule that can be applied can be summarised as follows: Let $\mathrm{X}$ and $\mathrm{Z}$ be different patent offices. A reference to an $\mathrm{X}$ system patent document should be taken as a valid citation count of a particular $Z$ system patent if the $X$ system document is an equivalent of the $Z$ system patent. In a significant number of cases, the referenced non EP document is linked to more than one EP equivalent, as indicated in the figure above. In these cases, fractional counts can be used, i.e. the citation counts and other statistics will weigh the incidence (or statistical data) of each of the multiple EP equivalents by the inverse of the number of multiple EP equivalents. 
priority numbers. When these different citations are not taken into account, counts of citations are underestimated because citations of a given invention are spread across the different versions of a patent family.

At the EPO, referencing seeks to use the earliest and most easily available "incarnation" of an invention, preferably in the language of the applicant. In EPO documents, the majority (about three-quarters) of references refer to nonEP documents. In this regard, Michel and Bettels (2001) show that $90 \%$ of patent citations made by the EPO refer to EP patent documents (EPO), DE (Deutsches Patent- und markenamt - DPMA), GB (United Kingdom Intellectual Property Office), WO (WIPO) or US (USPTO) documents. Citation counts based only on EP documents are biased downwards. In the case of US patent citations, the problem also exists but to a much smaller extent as the USPTO mainly references USPTO documents. At the USPTO and the JPO, $90 \%$ or more of the references in the search reports refer to national documents (Michel and Bettels, 2001).

\subsection{Citation-based indicators}

\subsubsection{Benchmarking citations}

Information on patent citations is meaningful only when used comparatively. There is no natural scale or value measurement associated with citation data, so the fact that a given patent has received 10 or 100 citations does not indicate whether or not that patent is "highly" cited. In other words, the evaluation of the citation intensity of an invention, an inventor, an institution, or any other group of reference, can only be made with reference to some "benchmark" citation intensity.

In principle, it is possible to identify and quantify the changes in citation intensity that are associated with various effects. However, it is not clear if the observed pattern is real or artefactual, and indicators can be therefore misinterpreted. Consider for instance, some of the stylised facts in USPTO patent citation data: i) the average number of citations received by patents in their first five years has been rising over time; ii) the average number of citations per patent has been rising over time; and iii) the observed citation-lag distributions for older cohorts have fatter "tails" than those of more recent cohorts.

With respect to the first, one might conclude either that more recent patent cohorts are more "fertile", or that the citation-lag distribution has shifted to the left (citations are coming sooner than they used to). Considering the second, one may think that there has been an artefactual change in the propensity to cite. But since the stock of patents available to be cited has been growing at a rapid (and accelerating) rate, this is not clear. The third, taken in isolation, seems to suggest that the citation-lag distribution has shifted to the 
right. Without further assumptions one cannot know which of these competing scenarios is "correct", and hence one cannot make any statistical adjustments to the citation data, including adjustments for truncation of lifetime citations.

The determination of the appropriate benchmark is complicated by several phenomena that are inherent to the patent citation data (Hall et al., 2001).

- First, the number of citations received by any given patent is truncated because only the citations received so far are known. More importantly, patents of different ages are subject to differing degrees of truncation. There has been less time to cite more recent patents.

- Second, differences in patent examination practices across time may produce differences in citation intensities that are unrelated to the true impact for which citations are used as a proxy. In the NBER USPTO patent citation data, the average patent issued in 1999 had over twice as many citations as the average patent issued in 1975 (10.7 versus 4.7).

- Third, the problem created by the increase in the number of citations per patent is exacerbated by the fact that the number of patents issued has also been rising steeply in several patent offices. Even if each patent issued had the same number of citations as in the past, the increase in the universe of "citing patents" would increase the total number of citations. The combination of more patents making more citations suggests a kind of citation "inflation" that may mean that later citations are less significant than earlier ones from a statistical perspective.

- And lastly, the number of citations made (and received) per patent varies considerably by technological field or maturity of technology. In general, traditional technological fields cite more and are cited less, whereas the emerging fields of computers and communications and drugs and medical are cited much more but cite somewhat less. The degree of dependence on past technology or "cumulativeness" determines the propensity to cite other patents; for instance, technologies such as semiconductors show typically higher backward citation intensity. $^{9}$

Two generic approaches are used to deal with these problems. The first, the fixed-effects approach, involves scaling citation counts by dividing them by the average citation count for a group of patents to which the patent of interest belongs. This approach assumes that all sources of systematic variation over time in citation intensities are artefacts that should be removed before comparing the citation intensity of patents from different cohorts. That is, citation intensities are "re-scaled", i.e. expressed as ratios to the mean citation intensity for patents in the same cohort.

To compare a 1990 patent with two citations to a 1985 patent with four citations, each is divided by the average number of citations received by other 
patents in the same cohort. This rescaling purges the data of effects due to truncation, effects due to systematic changes over time in the propensity to cite, and effects due to changes in the number of patents making citations. Unfortunately, it also purges the data of any systematic movements over time in the importance or impact of patent cohorts. The advantage of this approach is that it does not require making assumptions about the underlying processes that may be driving differences in citation intensities across groups. The disadvantage is that, precisely because no structure is assumed, it does not distinguish between differences that are "real" and those that are likely to be artefactual.

The second or quasi-structural approach attempts to distinguish multiple effects on citation rates via econometric estimation. Once the different effects have been quantified, the researcher has the option to adjust the raw citation counts to remove one or more of the estimated effects. If the assumptions inherent in the econometric estimation are correct, this approach makes it possible to extract a stronger signal from the noisy citation data than the nonstructural, fixed-effects approach (see Hall et al., 2001, for further details on the estimation method).

\subsubsection{Backward citation indicators}

Two groups of indicators can be constructed with citations. The first is indicators based on backward citations, which are useful to assess the degree of novelty of the invention and knowledge transfer patterns (e.g. citation networks). The second is impact-type indicators, based on forward citations. Beyond that, one can construct citation-based measures that may capture other aspects of the patented inventions, such as originality, generality, sciencebased (e.g. Trajtenberg et al., 1997, Narin et al., 1997; Sampat and Ziedonis, 2004).

Technological cumulativeness is defined by the frequency of self-citation of patents produced by a company's prior research. The identification of selfcitation (applicant/assignee) has important implications, among other things, for the study of spillovers: presumably citations to patents that belong to the same assignee represent transfers of knowledge that are mostly internalised, whereas citations to patents of "others" are closer to the pure notion of (diffused) spillovers. It is more convenient to exclude self-citations (when information on consolidated patent data by applicant is available) when investigating the knowledge transfer and/or citation impact of inventions.

A common measure of cumulativeness at the level of the company is the sum of backward citations made to patents the firm owns over the total patents owned by the firm (at a given time $t$ ). According to Malerba and 
Orsenigo (1995), cumulativeness implies that leading innovators have an edge over laggards and the former may continue to lead in the future.

Citation lags. The term "citation lag" refers to the time between a characteristic date of the referencing patent application and a characteristic date of the cited document. The lag is then the time difference between the application, publication or grant year of the citing patent, and that of the cited patents. Citation lags can be computed in various ways, e.g. based on priority, application or publication dates. Citation lags can be looked at backwards and forward. The lag measure computed in the OECD EPO citation dataset is defined as the time between the publication of the cited patent application (in general, patent or non-patent literature cannot be cited before it is published, except for an invention applied for by the same applicant) and the publication date of the referencing search report (Webb et al., 2005). Some implications of this choice need to be pointed out:

- For most of the cited patent documents originating at European patent offices or the JPO, publication (including the disclosure of search results to the public at large in the case of the EPO) occurs exactly 18 months after the priority date. Hence, for the computation of citation lags of European or Japanese patents, it does not matter if one chooses the date of the search report (the priority date for Japanese patents) or the date of the publication of the application. One may take as reference the priority date of the citing patent and the publication date of the cited patent.

- If the cited document is a US patent that was only pursued within the United States, the earliest publication date until November 2000 was the grant date, and applicants can still use this rule if they wish. If the cited US patent has an international equivalent, the corresponding international application is again published 18 months after the US priority date. ${ }^{10}$

- Patent documents with an international search report published by WIPO and a supplementary search report published by the EPO or another ISA have multiple publication dates. If the referenced documents have no overlap, the lag can be computed with respect to the date of publication of the relevant search report. If the international search report and the EPO supplementary search report reference the same document, the later entry can be dropped from the list and the earliest publication date of the two search reports can be used to compute the citation lag.

Technology cycle time (TCT): Based on the measure of citation lags, a company-level indicator can be computed. The technology cycle time indicates speed of innovation or how fast the technology is turning over, defined as the median age in years of the patent references cited on the front page of the company's patents. Companies with shorter cycle times than their competitors are advancing more quickly from prior to current technology. In 
semiconductors, cycle times are short (three to four years); in shipbuilding they are long (more than ten years). The average is eight years.

\subsubsection{Forward citation indicators}

Forward citations per patent. This is considered as a measure of the technological impact of inventions. Several studies have shown that the number of citations a patent receives is associated with its technological importance and social value (Trajtenberg, 1990; Scherer et al., 1999) and is correlated with the renewal of patents, the estimated economic value of inventions and the probability of the patent being litigated or opposed (Lanjouw and Schankerman, 1999; Harhoff et al., 2002).

The citation impact is the count of forward citations expressed as a relative term (see the disadvantages of using this approach when comparing indicators over time in Section 6.5.1). It is the number of times a patent is cited relative to the number of citations received on average by a patent in the same technology field (four-digit IPC subclass) and with the same invention date (priority year). This approach allows for controlling for differences in citation frequency across technology fields and the truncation effect related to time (earlier patents having an intrinsically lower probability of being cited, see Hall et al., 2001).

The generality of a patent is built as a Herfindahl index (Trajtenberg et al., 1997; Hall et al., 2001): Generality $=1-\sum_{i}^{n i} s_{i j}{ }^{2}$, where $s_{\mathrm{ij}}$ denotes the percentage of citations received by patent $i$ that belong to patent class $j$, out of $n_{i}$ patent classes. ${ }^{11} \mathrm{~A}$ high generality score suggests that the patent had a widespread impact, since it influenced subsequent innovations in a variety of fields. The geographical impact of a patent can be built in a similar way (1-Herfindahl index of geographical concentration), i.e. across the different countries of origin of inventors in the citing patents. The originality of a patent can be defined in the same way, except that it refers to backward citations. Thus, if a patent cites previous patents that belong to a narrow set of technologies the originality score will be low, whereas citing patents in a wide range of fields would give a high score.

Some considerations must be taken into account when calculating this type of indicator:

- The originality and generality measures depend upon the patent classification system: a finer classification would give higher measures and a coarser system lower ones. Thus a finer classification within a field (e.g. in terms of number of three-digit patent classes), will likely result, other things being equal, in higher originality and generality measures, and one may regard that as an artefact of the classification system.

- As shown by Hall et al. (2001), the generality measure is biased upward when the number of patents on which it is based is small. Basically, if there 
is some "true" probability of a random patent being in one of many classes, the true concentration may be low; if very few patents are actually observed, they can only be in a few classes, and the measured concentration will be high. The indicator needs to be adjusted by the size of observations. ${ }^{12}$

At the company level, several indicators are used to measure the impact of patents (Narin, 2000):

- Current Impact Index (CII): The number of times a company's previous five years of patents are cited in the current year, relative to all patents in the US patent system, indicates patent portfolio quality. A value of 1.0 represents average citation frequency; a value of 2.0 represents twice the average citation frequency; and 0.25 represents $25 \%$ of the average citation frequency. This allows benchmarking a company's technological quality against other companies and against the average for the technology. CIIs vary by technology area. For example, they are high in semiconductors, biotechnology and pharmaceuticals, and low in glass, clay and cement, and textiles. The CII has been found to be predictive of a company's stock market performance.

- Technology strength (TS): Quality-weighted portfolio size, defined as the number of patents multiplied by the current impact index. Using TS one may find that although one company has more patents, a second may be technologically more powerful because its patents are of better quality. Companies with highly cited patents may be more advanced than their competitors and have more valuable patent portfolios.

- The Citation Performance Index: This consists in computing a relative index comparing the number of patents found in the most highly cited (e.g. 10\%) for a particular country (entity) with those of the world (or other reference). This indicator also measures the impact of the quality of the patents of a certain reference group. For a country, the formula for the indicators is the percentage of country i's patents appearing among the most cited $10 \%$ relative to the same percentage for the world's patents.

\subsection{Non-patent literature}

Science linkage indicators are based on counts of references to the nonpatent literature considered as scientific. The identification of "scientific" non-patent references provides insights into technologies that are closer to scientific R\&D and thus more dependent on the progress of scientific knowledge. There is some recognition that non-patent references are useful for investigating the interplay between science and technology. The average level of non-patent references has frequently been used as a proxy for quantifying the relationship of a technology field with a scientific domain (Narin et al., 1997; Meyer, 2000; Verbeeck et al., 2002). The more scientific references are found in patents, the closer the technology is considered to be to basic research. The analysis of 
science linkages in patents can be extended to important policy topics, notably the influence of science on new emerging technology domains or the value of science for industry (e.g. the impact on the economic value of companies).

However, non-patent references need to be treated with caution and some contextual elements should be taken into account when interpreting these indicators. As noted in Section 6.4, differences among patent offices in terms of examination procedures may influence the number and type of references cited. At the EPO, as references come essentially from the examiner's revision of the prior art, it has been argued that citations rarely reflect or coincide with the science used by inventors. Other researchers indicate that non-patent references rarely represent a unidirectional direct link to science and that it is difficult to establish causation between the citing patent and the cited article (Tijssen, 2002).

Non-patent literature (NPL) consists not only of peer-reviewed scientific papers but also includes other types of publications: conference proceedings, databases (DNA structures, gene sequences, chemical compounds, etc.) and other relevant literature (translation guides, statistical manuals, etc.). Table 6.2 displays the occurrence of journal and non-journal sources in USPTO and EPO references and Table 6.3 reports the types of non-journal sources. Among the non-journal sources, conference proceedings, industry-related documents and databases are the most frequently cited. References to non-scientific documents such as "patent abstracts" and commercial online patent database services should be removed for the purposes of analysis of science linkage in patents.

Table 6.2. Occurrence of USPTO and EPO journal and non-journal references Observed values (row percentages in brackets)

\begin{tabular}{llll}
\hline & Journal & Non-journal & Total NPRs \\
\hline USPTO & $2766(55 \%)$ & $2242(45 \%)$ & 5008 \\
EPO & $3218(64 \%)$ & $1803(36 \%)$ & 5021 \\
Total & 5984 & 4045 & 10029 \\
\hline
\end{tabular}

Source: Callaert et al. (2006).

An analysis of over 540000 international patent applications (filed under the Patent Cooperation Treaty) published by the EPO shows that in the last 15 years the IPC sub-classes with a higher than average share of citations to NPL (over 15\%) are mainly in the fields of biotechnology, pharmaceuticals, other fine organic chemistry and ICT (Figure 6.1). ${ }^{13}$ Higher shares of NPL in citations occur in countries whose international patenting activity is more concentrated in these high-activity or emerging technology fields (Figure 6.1). For example, Indian inventors have a recent history of international patenting activity and a 
Table 6.3. Occurrence of USPTO and EPO non-journal sources

Observed values (column percentages in brackets)

\begin{tabular}{lrrr}
\hline & \multicolumn{1}{c}{ USPTO } & \multicolumn{1}{c}{ EPO } & \multicolumn{1}{c}{ Total } \\
\hline Conference proceedings & $381(17 \%)$ & $612(34 \%)$ & 993 \\
Industry-related documents & $560(25 \%)$ & $304(17 \%)$ & 864 \\
Books & $333(15 \%)$ & $186(10 \%)$ & 519 \\
Reference books/databases & $234(10 \%)$ & $600(33 \%)$ & 834 \\
Patent-related documents & $327(15 \%)$ & $46(3 \%)$ & 373 \\
Research/technical reports & $138(6 \%)$ & $27(2 \%)$ & 165 \\
Newspapers & $106(5 \%)$ & $10(0 \%)$ & 116 \\
Unclear/other & $163(7 \%)$ & $18(1 \%)$ & 181 \\
Total & $\mathbf{2 2 4 2 ( 1 0 0 \% )}$ & $\mathbf{1 8 0 3 ( 1 0 0 \% )}$ & $\mathbf{4 0 4 5}$ \\
\hline
\end{tabular}

Source: Callaert et al. (2006).

relatively high proportion of their applications are in biotechnology and pharmaceuticals, which have closer links to science.

For 1990-2004, about 55\% of citations in biotechnology-related international patents are to NPL. There is little cross-country variation; this suggests some general homogeneity in the rate of technological progress but hides some structural differences among countries. For ICT (Figure 6.2), the average share is about $18 \%$ and varies across countries in a range of 10 to $25 \%$. Low shares suggest that recent ICT innovations are based more on existing technology while high shares suggest that certain countries still benefit from scientific R\&D in ICT.

Once non-patent references with a scientific content have been identified, the influence of science can be disentangled in a more substantive manner. With the aid of databases on scientific publication, scientific disciplines and affiliations of the authors and institutions can be linked to patent information. Linking the technology domain of the citing patent to the science field of the cited publication, for instance, results in matrices which represent the presence of specific scientific disciplines and relate them to different technological domains (Schmoch, 1997; Verbeek et al., 2002).

A simple indicator at the company level is the average number of science references cited on the front page of the company's patents. Strong science linkages indicate that a company is building its technology on advances in science ("closeness to science"). High-technology companies tend to have more science linkages than their competitors and science linkages have been found to be predictive of a company's stock market performance (e.g. Nagaoka, 2007). 


\section{Figure 6.1. Share of NPL in citations in search reports of PCT patent applications}

1990-2004, by IPC sub-class ${ }^{1}$

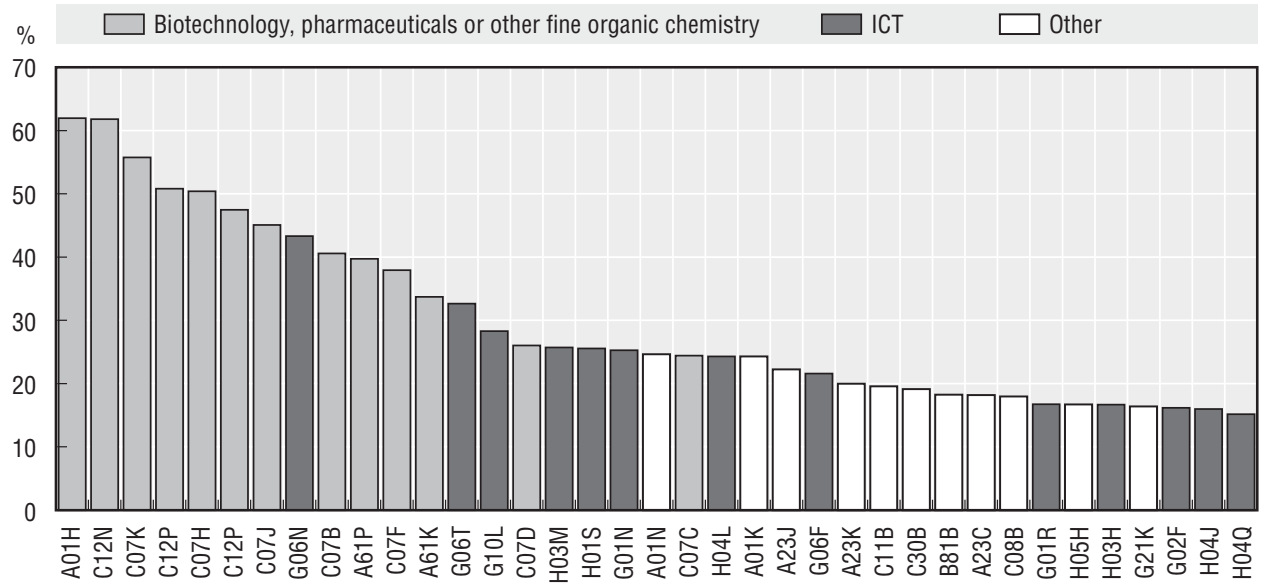

Figure 6.2. Share of NPL in citations - all patents 1990-2004, by country of inventor ${ }^{2}$

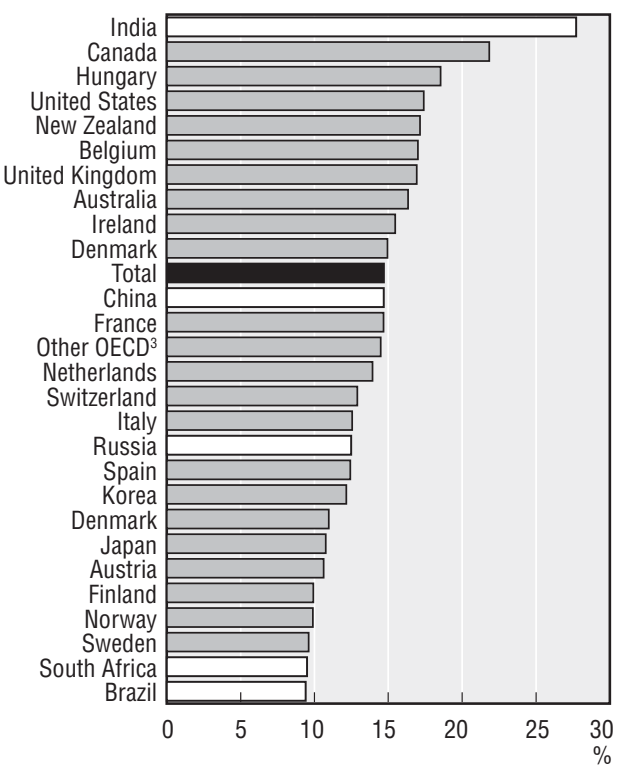

Figure 6.3. Share of NPL in citations - ICT 1990-2004, by country of inventor ${ }^{2}$

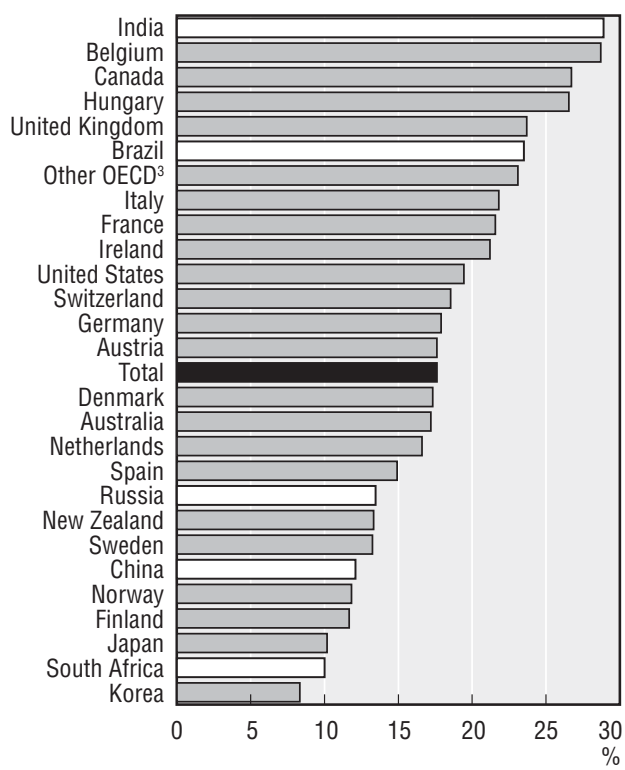

1. Only those IPC sub-classes (out of over 600) with a share of NPL citations greater than the average (14.7\%) and with more than 150 patent applications published in the period 1990-2004.

2. Fractional counts used when there is more than one inventor on the patent application.

3. Other OECD includes the Czech Republic, Greece, Iceland, Luxembourg, Mexico, Poland, Portugal, the Slovak Republic and Turkey.

Source: OECD-EPO Patent Citations Database. 


\subsection{Other indicators based on the categories of citations (EPO and PCT search reports)}

PCT and EPO search reports assign codes to the references constituting the prior art of an invention (Schmoch, 1993). EPO publications include information on five different types of citations: i) added by examiners during the search (whether or not provided by the applicant); ii) provided by the applicant but not used in the search report; iii) added during examination; iv) provided during opposition proceedings; and $v$ ) other. All documents cited are identified by a particular letter in the first column of the search report representing the cited category (combinations of codes are possible). See Table 6.4 for definitions of citation categories.

\section{Table 6.4. Citation categories at the EPO and PCT}

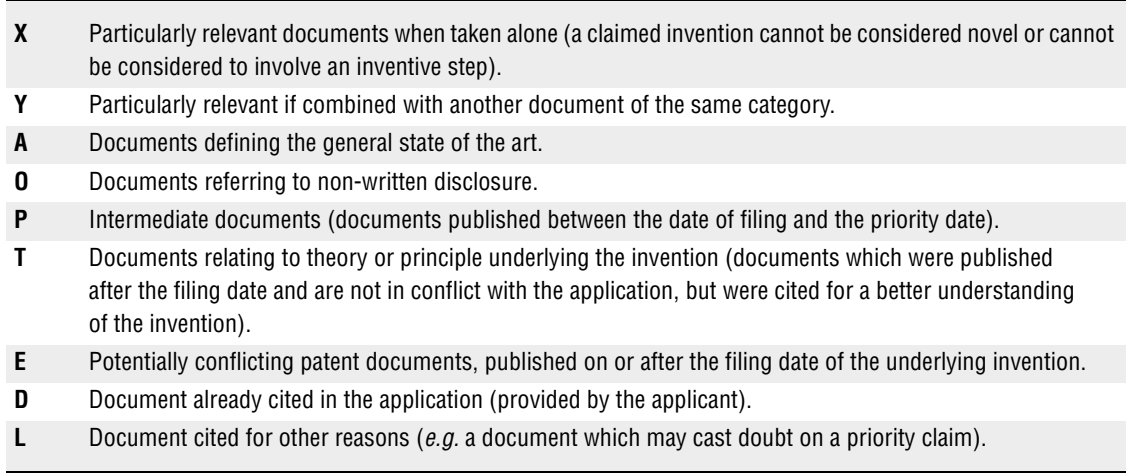

Source: EPO Guidelines for Examination in the European Patent Office, 2003 (176 ff.).

This categorisation can be helpful for building more refined citation indicators, such as indicators on patents with the capacity of blocking other inventions (based on $\mathrm{X}, \mathrm{Y}$ and $\mathrm{E}$ categories). The categories $\mathrm{X}$ and $\mathrm{Y}$, which designate the citation to a relevant document in the prior art, are very important for assessing the patentability of a new invention and can compromise the grant of a patent. X-type references are the most important in this respect. If an application receives an $\mathrm{X}$ classification, this indicates that the claimed invention does not meet, wholly or in part, the requirements of novelty or of inventive step, and that one claim at least needs to be modified in order not to interfere with the legal boundaries of existing inventions. As a result, when looking at granted patents with these categories of backward citations, the claims that appear have been, in most cases, modified during the granting process. In the search report, the search officer or examiner indicates to which claim or claims of the application the prior art applies. 
Documents cited by the applicant (type D) should be considered in the search report if they are decisive in terms of the state of the art or are necessary to understand the application. Citations submitted by the applicant which do not fulfil these requirements may be disregarded by the examiner. Type A references merely provide technical background information (state of the art). The fact that a patent is frequently cited as invalidating some or all of the claims of other patent applications may also reflect strategic behaviour on the part of patent holders, who design their applications in broad terms in order to bar or reduce the patentability of follow-up inventions by competitors.

\section{Notes}

1. In a survey of patentees and inventors, around one-half of all patent citations (in a cohort of 1993 patentees at the USPTO) were found not to correspond to any perceived communication, or even to a perceptible technological relationship between the inventions (e.g. Jaffe et al., 2000).

2. Published applications of the USPTO (called pre-grant publications) include the applicant's citations but they do not include those of the examiner. The latter are only published if and when the patent is granted.

3. For further details, see the Guidelines for Examination in the European Patent Office, updated regularly. Following a general section, the guidelines are divided into five sections comprising among others, guidelines for formalities, guidelines for search, and guidelines for substantive examination.

4. If the search results in several documents of equal relevance, the search report should normally contain no more than one of them. The choice of citation is made on the basis of the examiner's expert knowledge. In case of two documents of equal relevance, one of which was published before the date of priority and the other published between priority date and filing date, the search examiner should choose the earlier one.

5. As shown by Callaert et al. (2007) in a comparative study of USPTO and EPO patents, these differences are noticeable both in terms of the occurrence and the type of the reference cited. USPTO patents include on average about three times as many patent references than EPO patents. As regards non-patent literature, 34\% of USPTO patents contain non-patent references whereas they are $38 \%$ at the EPO. They also find that journal references are more prominent in EPO patents (64\% of non-patent references are journal references compared to $54 \%$ in USPTO patents).

6. For patents which later enter the regional phase at the EPO, the EPO acts as the ISA. Formally, the international search report has a different function from the search report issued by the EPO for applications filed directly at the EPO. Practically, there are few differences. International search reports for WO documents are generated by one of 12 ISAs. These are the patent offices of Australia, Austria, China, Finland, Japan, Korea, Russia, Spain, Sweden, the United States and the European Patent Office.

7. For further information see the PCT International Search and Preliminary Examination Guidelines of the WIPO; www.wipo.int/pct/en/texts/pdf/ispe.pdf .

8. In the context of EPO patent citations, if an invention is protected in more than one country and, therefore, several documents belong to a single patent family, the examiner should preferably cite the patent document in the language of the 
application. The choice is also affected by the languages with which the examiner is familiar. When patent documents are not referenced as European, but as equivalent documents issued by other patent offices such as WIPO, USPTO, DPMA and others, citation counts will typically inform the analyst about the source of references, but not about the importance of particular inventions.

9. The propensity to cite also differs over time and across technological areas. Citations in computers and communications arrive fastest, followed by electric and electronics, and drugs and medical technologies (Hall et al., 2001).

10. Under the American Inventors Protection Act (AIPA) enacted 29 November 1999, all patents which seek some form of patent protection outside the United States are published by the USPTO 18 months after the US priority date. That does not change the timing of the earliest publication, but the publication is available from the USPTO and will show up in the data even if European equivalents of the US patent are not detected.

11. If a patent is cited by subsequent patents that belong to a wide range of fields the measure will be high (close to one), whereas if most citations are concentrated in a few fields it will be low (close to zero).

12. The methodology to calculate the magnitude of the bias - and to correct the bias are reported in Hall et al. (2001).

13. This is consistent with other observed patterns of science-industry linkages in these fields, such as university spin-offs, industry-university co-operation on R\&D and the tendency for biotechnology companies to cluster around universities.

\section{References}

Callaert J., B. Van Looy, A. Verbeek, K. Debackere and B. Thijs (2006), “Traces of Prior Art. An Analysis of Non-Patent References Found within Patent Documents", Scientometrics, Vol. 69, No. 1, April, pp. 3-20.

Hall B.H., A. Jaffe and M. Trajtenberg (2001), "Market Value and Patent Citations: A First Look", Economics Department Working Paper E00-277, University of California.

Hall, B.H., A. Jaffe and M. Trajtenberg (2005), "Market Value and Patent Citations", Rand Journal of Economics, No. 36, Spring.

Harhoff, D., K. Hoisl and C. Webb (2006), "European Patent Citations - How to Count and How to Interpret Them?", unpublished document, August.

Harhoff, D., F.M. Scherer and K. Vopel (2002), "Citations, Family Size, Opposition and the Value of Patent Rights, Research Policy”, Elsevier, No. 32(8), pp. 1343-1363.

Jaffe, A.B., M. Trajtenberg and R. Henderson (1993), "Geographic Localization of Knowledge Spillovers as Evidenced by Patent Citations", Quarterly Journal of Economics, No. 108, pp. 577-598.

Jaffe, A.B., M. Trajtenberg and M.S. Fogarty (2000), "Knowledge Spillovers and Patent Citations: Evidence from a Survey of Inventors", American Economic Review, American Economic Association, Vol. 90(2), pp. 215-218.

Lanjouw, J.O. (1998), "Patent Protection in the Shadow of Infringement: Simulation Estimations of Patent Value", The Review of Economic Studies, Vol. 65, pp. 671-710. 
Lanjouw, J.O., A. Pakes and J. Putnam (1998), "How to Count Patents and Value Intellectual Property: Uses of Patent Renewal and Application Data", The Journal of Industrial Economics, Vol. XLVI, No. 4, December, pp. 405-433.

Lanjouw, J.O. and M. Schankerman (1997), "Stylised Facts of Patent Litigation: Value, Scope and Ownership", NBER working paper series, NBER, Cambridge, MA.

Malerba, F. and L. Orsenigo (1995), "Schumpeterian Patterns of Innovation", Cambridge Journal of Economics, Oxford University Press, Vol. 19 (1), February, pp. 47-65.

Meyer, M. (2000), “Does Science Push Technology? Patents Citing Scientific Literature”, Research Policy, Vol. 29, No. 3, March, pp. 409-434.

Michel, J. and B. Bettels (2001), "Patent Citation Analysis - A closer look at the basic input data from patent research reports", Scientometrics, No. 51, pp. 181-201.

Nagaoka, S. (2007), "Assessing the R\&D Management of a Firm in Terms of Speed and Science Linkage: Evidence from the US Patents", Journal of Economics and Management Strategy, Vol. 16, No. 1, Spring, pp. 129-156.

Narin, F., K. Hamilton and D. Olivastro (1997), "The Increasing Linkage between US Technology and Public Science”, Research Policy, No. 26, pp. 317-330.

Podolny, J.M., T.E. Stuart and M.T. Hannan (1996), "Networks, Knowledge and Niches: Competition in the Worldwide Semiconductor Industry, 1984 - 1991", American Journal of Sociology, No. 102 (3), November, pp. 659-689.

Sampat, B.N. and A. Ziedonis (2004), "Patent Citations and the Economic Value of Patents: A Preliminary Assessment”, with B.N. Sampat in H. Moed, W. Glänzel and U. Schmoch (eds.), Handbook of Quantitative Science and Technology Research: The Use of Publication and Patent Statistics in Studies on R\&D Systems, Kluwer Academic Publishers, Dordrecht/ Boston/London, pp. 277-298.

Schmoch, U. (1997), "Indicators and the Relations between Science and Technology", Scientometrics, Vol. 38 (1), pp. 103-116.

Schmoch, U. (1993), “Tracing the Knowledge Transfer from Science to Technology as Reflected in Patent Indicators”, Scientometrics, Vol. 26, (1), pp. 193-211.

Tijssen, R.J.W. (2002), “Science Dependence of Technologies: Evidence from Inventions and their Inventors", Research Policy, No. 31, pp. 509-526.

Trajtenberg, M., R. Henderson and A. Jaffe (1997), "University versus Corporate Patents: A Window on the Basicness of Invention", Economics of Innovation and New Technology, Vol. 5 (1), pp. 19-50.

Trajtenberg, M. (1990), “A Penny for Your Quotes: Patent Citations and the Value of Innovation", RAND Journal of Economics, No. 21 (1), pp. 172-187.

Verbeek, A., K. Debackere and M. Luwel (2002), "Science Cited in Patents: A Geographic 'Flow' Analysis of Bibliographic Citation Patterns in Patents", Scientometrics, No. 58 (2), pp. 241-263 (2003).

Webb, C., H. Dernis, D. Harhoff and K. Hois (2005), "Analysing European and International Patent Citations: A Set of EPO Patent Database Building Blocks", OECD Science, Technology and Industry Working Paper 2005/9, Directorate for Science, Technology and Industry, OECD, Paris, www.oecd.org/sti/working-papers. 



\section{Chapter 7}

\section{Indicators of the Internationalisation of Science and Technology}




\subsection{Introduction}

Inventive activities are increasingly organised at the international level (OECD, 2007). Inventions made by researchers residing in one country can be funded and owned by foreign companies, companies from different countries can join their resources to sponsor research, and researchers from different countries can co-operate on inventions, etc. Alliances across different geographical locations are formed to obtain research synergies and complementarities and to acquire new technological competences. The advent of global value chains, differences in research and development (R\&D) costs, increased flexibility in handling cross-border R\&D projects (owing to information and communication technology - ICT), and major policy changes (such as stronger intellectual property rights or the tax treatment of R\&D) have all favoured this trend. Given the importance of these changes and their implications for the technological capacity of countries, it is important to quantify the intensity and geographical patterns of these activities.

Different indicators are available to measure the internationalisation of science and technology (S\&T). They are based notably on R\&D and international trade statistics, such as the share of R\&D financed by sources abroad, exports and imports of high-technology products, and receipts and payments related to technology services (OECD, 2005). As regards the internationalisation of R\&D activities, the analysis relies on survey data on the activities of multinational firms and case studies. Information from business surveys provides important insight into the activities of foreign affiliates (i.e. OECD-AFA Database) but their coverage remains limited to few countries.

Internationalisation of technological activities can also be examined in patents resulting from the output of inventive activities. Patent documents show the inventor(s) and the applicant(s) - the owner of the patent at the time of application - along with their addresses and thus their country or countries of residence. The exploitation of this information, separately or jointly, can tell much about the geographical organisation of inventions. This is reflected in the indicators presented in this chapter. Citations can also be used: patents citing other patents corresponding to inventions made in another country reflect international knowledge flows. Citation-based indicators are discussed in Chapter 6 and are not addressed in this chapter. 


\subsection{Indicators}

\subsubsection{Cross-border ownership of inventions}

When the applicant's and inventors' country of residence differ, this indicates cross-border ownership. Using the information contained directly or indirectly in patent documents, two indicators of cross-border ownership can be computed at the country or regional level (Guellec and van Pottelsberghe, 2001):

- Foreign ownership of domestic inventions. This refers to the number of patents which are granted to applicants residing abroad (for reference country $i$, foreign country $j=1, \ldots . N, j=i$ ) and which have at least one domestic inventor $\left(P_{i, j}\right)$, divided by the total number of patents invented domestically $\left(P_{i}\right)$. The foreign ownership in the total of domestic invention for country $i$ is then:

$$
\frac{{ }_{j=1}^{N} \sum P_{i, j}}{P_{i}}
$$

- Domestic ownership of inventions made abroad. This refers to the number of patents which are granted to a country whose inventions have been made abroad with at least one foreign inventor $\left(P_{i, j}\right)$, divided by the total number of patents owned by the country $\left(\mathrm{P}_{\mathrm{i}}\right)$. The domestic ownership in the total of owned patents, for country $i$, is then: $\frac{{ }_{j=1}^{N} \sum P_{i, j}}{P_{i}}$.

In most cases, patents with inventors from abroad correspond to inventions made at the research laboratories of multinational companies and applied for at company headquarters (although in some cases national subsidiaries also may own or co-own the patents). Hence, the first indicator expresses the extent to which foreign firms control domestic inventions. Similarly, the second reflects the extent to which domestic firms control inventions made by residents of other countries. ${ }^{1}$ These indicators therefore reflect the role of foreign affiliates of multinational companies in inventive activities. They complement data on the R\&D of foreign affiliates of multinational firms. Foreign control means that the economic benefits arising from the inventions are shared among countries: the country of invention, the country of ownership, but also partly other countries, as multinational companies may implement part of their technology worldwide (in terms of manufacturing or sales).

\subsubsection{International co-operation in research}

Another measure of the internationalisation of technology is international co-operation on research as measured by patents involving inventors from a different country of residence. It refers to the number of patents invented by a 
country (reference country $i$, foreign country $j=1, \ldots . N, j=i$ ) with at least one inventor located in a foreign country $\left(P^{i, j}\right)$ in the total number of patents invented domestically $\left(\mathrm{P}^{i}\right)$. The share of international co-inventions in the total of domestic inventions for country $i$ is then: $\frac{{ }_{j=1}^{N} \sum P_{i, j}}{P_{i}}$.

As countries differ in their specialisation and knowledge assets, complementary external knowledge can be found abroad. International collaboration by researchers can take place either within a multinational corporation (with research facilities in several countries) or through co-operative research among several firms or institutions (collaboration between inventors belonging to different universities or public research organisations). In that sense, co-invention indicators also reflect international flows of knowledge.

Indicators of cross-border ownership and of co-invention are not independent. By definition international co-invention involved cross-border ownership. In fact, cross-border ownership can be broken down by inventions which do or do not involve co-invention (the applicant country also being an inventor). Naturally, what is accounted for as foreign ownership in one inventor country implies a domestic-owned invention abroad by domestic firms in another country. Not surprisingly, worldwide totals are much lower than the figures reported by some countries, as counts are consolidated.

Figure 7.1 reports the evolution of worldwide cross-border ownership and co-invention in patent applications at the European Patent Office (EPO) from 1990 to 2002. The former is the percentage of patents with at least one inventor residing in a different country from the owner of the patent (in total worldwide inventions), whereas the latter is the share of patents with at least two inventors residing in different countries in total worldwide. Over this period, international co-invention more than doubled from around 3\% in 1990 to over $7 \%$ in 2002. The share of cross-border ownership has grown steadily worldwide; it increased by $50 \%$ between the early 1990 s and the early 2000 s. That is, in 2002, more than 1.5 out of 10 patents applied for at the EPO were subject to cross-border ownership. Figures 7.2 and 7.3 report the indicators on foreign ownership and domestic ownership of inventions made abroad for a group of countries.

\subsubsection{Advantages of patents for measuring internationalisation of $\mathrm{S} \& \mathrm{~T}$ and relevant caveats}

The advantages of using patent indicators for tracking the internationalisation of technology are numerous. Patents provides a reasonably complete description of the invention, the technology field concerned, the inventor (name, geographical location, etc.), the applicant, references or citations to previous patents and 
Figure 7.1. Globalisation of S\&T based on patent indicators

PCT applications, 1990-2002

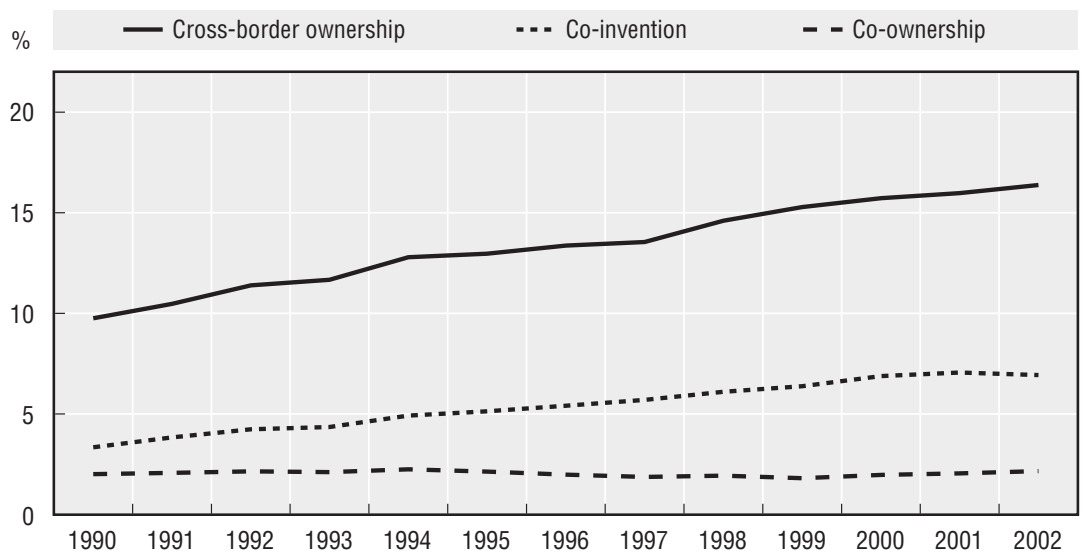

Note: Patent counts are based on the inventor's country of residence, the priority date and fractional counts. Patent applications filed under the Patent Cooperation Treaty and designating the European Patent Office. Cross-border ownership: share of patents in total inventions worldwide having an applicant located in a country different from the inventor country. Co-invention: share of patents in total inventions worldwide having at least two inventors located in different countries. Co-ownership: share of patents for which at least two co-applicants are located in different countries (in total inventions worldwide).

Source: OECD, Patent Database.

\section{Figure 7.2. Foreign ownership of domestic inventions}

PCT applications, 1991-2003
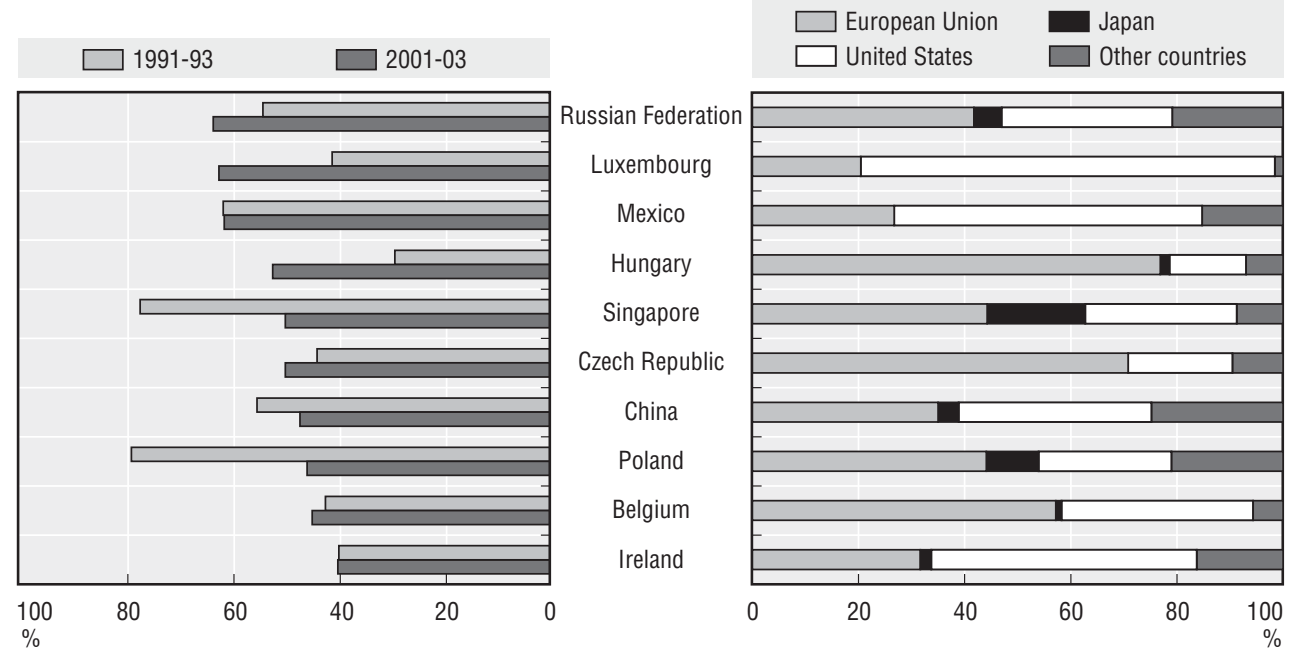

Note: Patent counts are based on the priority date and the inventor's country of residence, using simple counts. Share of patent applications to the European Patent Office (EPO) owned by foreign residents in total patents invented domestically.

Source: OECD, Patent Database. 


\section{Figure 7.3. Domestic ownership of inventions made abroad}

PCT applications, 1991-2003
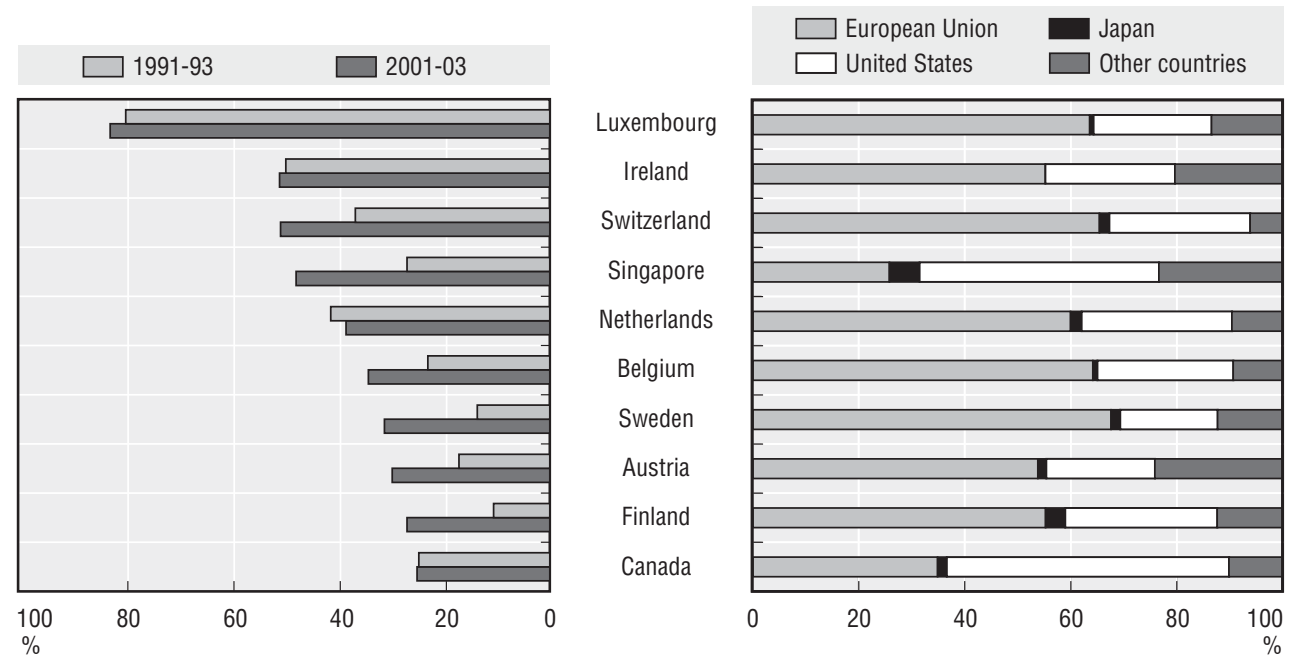

Note: Patent counts are based on the priority date and the applicant's country of residence, using simple counts. Share of patent applications to the European Patent Office invented abroad in total patents owned by country residents.

Source: OECD, Patent Database.

scientific articles to which the invention relates, among other things. The internationalisation of technology can be tracked by technology field, type of firm (when company data are available, e.g. size), university-industry linkages, etc.

The most important difficulties in measuring the internationalisation of technology with patent information come from the complexity of and lack of information on companies' ownership structure and strategy, which sometimes makes it difficult to attribute a particular country to the owner company declared in the patent file. Many of these difficulties, however, simply have to do with the issue of attributing a country to a company, a problem for all indicators of internationalisation (OECD, 2005). Examples of misleading cases are:

- The owner's country as declared in the patent file may be the affiliate of a multinational group which is in charge of managing its international intellectual property and not the multinational company itself. As this affiliate may be located in a different country from the group headquarters (for strategic or tax-related reasons), this will give a distorted picture of cross-country linkages.

- A patented invention can be controlled by a foreign entity ex post, after its initial owner was acquired by or merged with this foreign entity or the patent right was transferred to the foreign entity. Conversely, a foreignowned company may become national for similar reasons. The new owner 
may or may not take direct control of the patent. Standard patent databases do not register such changes in the ownership of patents when they occur after the grant and thus provide an imprecise picture of the actual control of inventions.

- The patent can be owned (or applied for) directly by the domestic subsidiary of a multinational group, which therefore is not mentioned as such in the patent file (see Chapter 5). In that case, foreign ownership is underestimated (e.g. the case of Belgium in Cincera et al., 2006), and, symmetrically, domestic ownership of foreign inventions is underestimated for the owner's country.

Some care must be taken when using patents to interpret international co-invention activity. Inventors located in different countries frequently belong to the same multinational firm and company management practices may influence who is mentioned as an inventor (or first inventor, see Bergek and Bruzelius, 2005). Conversely, inventors located abroad can be involved in research that is contracted out.

The submission of company information (companies' country of origin and international ownership of companies) is not required in patent applications. When compiled solely with the information available in patent files, the indicators proposed here may underestimate the importance of internationalisation. It is recommended to complement the information on the owner provided in the patent databases with other information regarding company ownership to get more accurate indicators of the internationalisation of technology.

\section{Box 7.1. Regional dispersion of patenting}

Indicators presented in this chapter can be compiled at the level of regions as well as countries: indicators of cross-regional ownership and crossregional co-operation. Although the formulae are similar, the economic interpretation may differ somewhat as cross-regional differences and barriers are usually much lower than cross-country ones (e.g. language, regulation, tax system, distance). Adaptation of existing technology to local tastes, an important motive for locating R\&D closer to final demand, applies more to cross-country investment than to cross-regional investment.

The OECD uses the TL ("territorial levels") classification, which has different levels of aggregation (level 2 consists of about 300 macro-regions; level 3 consists of 2300 regions, e.g. the US BEA economic areas, Japanese prefectures, French “départements", etc.). In EU countries, regions are defined by "NUTS" (Nomenclature des Unités Territoriales Statistiques), an official classification of the European Commission (which is equivalent to the OECD classification for Europe). 


\subsection{Ownership and research strategies}

Globalisation of technological activities as illustrated in patents reflects a mix of research and ownership strategies. Patent data provide further insight into these matters when one looks at the combinations of types of ownership (or co-ownership) and types of invention (invention made only abroad or through co-invention). Five patterns of internationalisation can be identified in patent data:

1. Purely domestic ownership of foreign inventions (country A owner and country B inventor). This type of strategy concerns patents for which the research has been entirely conducted in the foreign laboratory (subsidiary of a multinational corporation).

2. Domestic ownership implying co-ownershipwith a single inventor (countries $A$ and B owners but only country B inventor). This pattern may reflect coownership by the multinational and an affiliate abroad or a research joint venture between companies of two different countries.

3. Domestic ownership with co-invention (countries A and B inventors but only country A owner). This pattern concerns patents by multinational firms engaged in twofold internationalisation strategies: exploiting their own knowledge assets and accessing foreign knowledge.

4. Co-ownership jointly with co-invention (countries $\mathrm{A}$ and $\mathrm{B}$ inventors and owners). This strategy is a combination of the last two types. It may reflect the joint involvement of the headquarters and a foreign affiliate of a multinational firm, or research co-operation between companies in two different countries.

5. Cross-border ownership or inventorship with distinct inventor and owner countries (A and B owners and C inventor). This complex and uncommon pattern requires case-by-case analysis. It may for instance reflect an international network of companies having assigned a third company the management of their patents (e.g. technology pools).

Figure 7.4 displays the breakdown of patents subject to cross-border ownership. It appears that the predominant strategy in cross-border inventions is a single country owning one invention located in a single inventor country: $47 \%$ of patents subject to cross-border ownership are in this category, followed by single owner country patents with co-invention (with the owner country also an inventor). The latter increased from $23 \%$ during $1990-92$ to $29 \%$ in $2000-02$, and is evidence of the growing deployment of mixed strategies (e.g. strategic partnerships aimed at achieving technological synergies for innovation).

The three remaining combinations (ownership and co-invention, coownership and co-invention, and co-ownership with a third country as the inventor) are less important and their share has actually decreased: patents implying coownership in two different countries (multinationals jointly with subsidiaries, or 


\section{Figure 7.4. Composition of cross-border ownership in PCT applications}

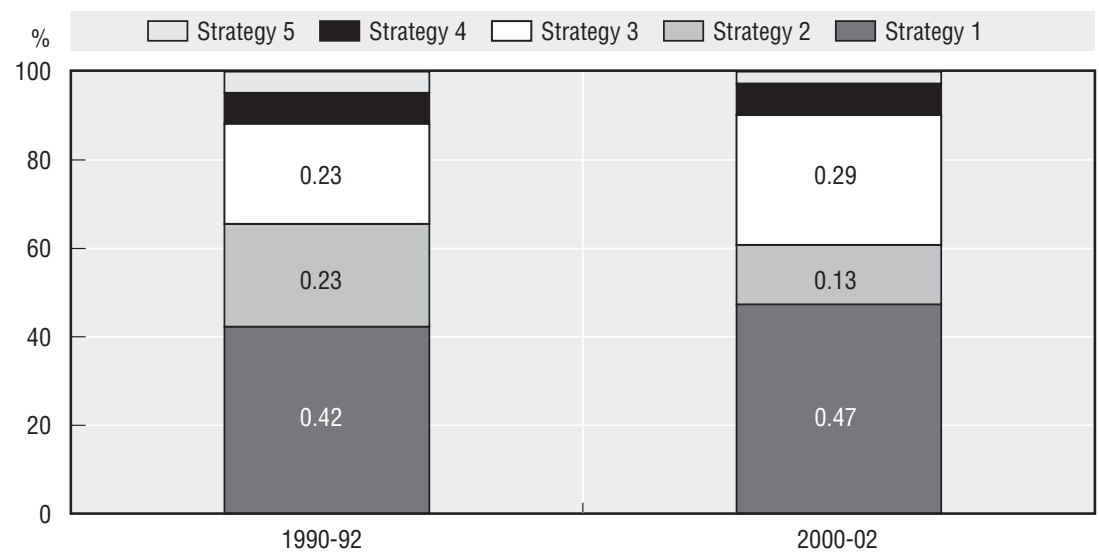

Note: Fractional counts of patent applications filed under the Patent Cooperation Treaty and designating the European Patent Office, by strategy and priority year.

Source: OECD, Patent Database.

two non-affiliated firms located in different countries with only one country inventor or implying co-invention) represented less than $11 \%$ of cross-border patents. Lastly, patents under co-ownership shared between different countries, none of which is inventor, account for less than $2 \%$.

\section{Note}

1. Some fraction of these patents subject to cross-border ownership may also represent co-ownership between two companies located in different countries; again, this more likely concerns cases of co-ownership between headquarters and foreign subsidiaries. However, this represents a very small share of total patents with cross-border ownership.

\section{References}

Bergek, A. and M. Bruzelius (2005), "Patents with Inventors from Different Countries: Exploring Some Methodological Issues through a Case Study", presented at the DRUID conference, Copenhagen, 27-29 June.

Guellec, D. and B. van Pottelsberghe (2001), “The Internationalisation of Technology Analysed with Patent Data", Research Policy, 30 (8), pp. 1256-1266.

OECD (2005), Compendium of Patent Statistics 2005, OECD, Paris.

OECD (2007), Compendium of Patent Statistics 2007, OECD, Paris. 

Chapter 8

\section{Indicators of Patent Value}




\subsection{Introduction}

The term "patent value" has several different meanings. It can mean the economic "private" value to the holder, defined as the discounted flows of revenue generated by the patent over its lifetime. It can mean the "social" value of the patent, that is, its contribution to society's stock of technology. The two concepts are closely related, as the revenue generated should be commensurate with the technological contribution, but they are not identical, as part of the social value is not appropriated by the patent holder (there are externalities): the published knowledge for instance can be used by other inventors and/or competitors to improve on the initial invention.

In addition, one should distinguish between the value of the patent itself and the value of the underlying invention. The former comprises only the value added by the fact that the invention is patented - it is the difference between the value of the invention as it is patented and the value it would have had if it had not been patented. The latter refers to the technological content or "quality" of the invention, that is, its contribution to the state of the art. An invention with a significant contribution to the state of the art will affect future technological developments. The two notions differ to the extent that the patent improves the appropriability of the benefits of certain inventions more than others. ${ }^{1}$ Yet the capacity of patents to ensure appropriability of the income generated by inventions is known to differ, for instance, across technical fields.

Such considerations show that the value of a patent is a complex notion: it is necessary, however, to take it into account for patent statistics aimed at reflecting technological performance. All studies investigating the value either of patented inventions or of patent protection have shown that their statistical distribution is quite skewed: while some patents have high value, many others have little (e.g. they remain unexploited). As a result, patent counts, which give the same weight to all patents, can be misleading: a set of 100 patents can reflect various levels of technological performance depending on its composition in terms of high-value vs. low-value patents. If one has information on the value of patents, there are two ways of dealing with this problem in indicators: one solution is to compile weighted counts, with the value as a weight; the other is to count only patents of sufficient value, ignoring the rest.

One difficulty in estimating the value of a patent is timeliness, i.e. the need to have reliable indicators reflecting the economic or technological value 
of an invention early enough so that they can be used to assess the recent position of a company or a country (in the patent value landscape). Three main lines of work have been followed by researchers to estimate or infer the private economic value of patents:

- Conducting surveys asking inventors (holders) about the economic value of their patents (e.g. Scherer et al., 1999).

- Analysing data from the patenting procedure (e.g. grant or refusal of the application, citations, renewal, geographical scope of protection, etc.).

- Estimating value from financial data (e.g. market value of companies, the value of initial public offerings, etc.; Hall et al., 2005)

In the first methodology, patent holders or inventors are asked about the monetary value of their patents (the price at which they would be willing to sell the invention, including the revenues that the patent will generate in subsequent years). ${ }^{2}$ Studies have shown that the size distribution of private value returns from patents is quite skewed with a peak at zero. A patent can generate economic returns in different ways: exploitation in-house, licensing, "strategic use" (to block others or to exchange technology), etc.

The second approach attempts to cast light on the value of patents by using patent information mainly provided by bibliographic sources (publications, search and examination reports, opposition, etc.) which can be correlated with the value of patents. Some of these indicators rely on the observed behaviour of patent owners in order to estimate the private value of patents (based on the renewal of patents, number of countries in which a patent is filed, decisions to sell [re-assign] patents, etc.). Other indicators that have been consistently found to be good predictors of patent value include forward citations, the number of claims, and patent oppositions or litigation.

The third approach involves the econometric estimation of the contribution of categories of patents or patent portfolios to the economic performance of companies (e.g. stock market valuations, spin-offs), after controlling for their stock of R\&D and physical capital. For instance, the use of market value (e.g. Tobin's q) ${ }^{3}$ to estimate rents attributed to patents assumes that investors' behaviour can reveal patent value. This research has consistently reported a positive and significant marginal value of patent stocks and their quality (i.e. citation-weighted patent stock).

This chapter reports major findings relating to the second approach. It aims at indicating possible avenues for patent statistics that would control for the dispersion of the value of patents and thus gain relevance in economic terms. This area of work is largely still at the research stage, and many of the results reported here are being debated among experts. It is, however, important for the design and interpretation of patent indicators to have value issues in mind. 
Using proxies of patent value, patent-based indicators can be compiled which are less affected by the skewed value distribution of patents:

- Weighted counts: weight the count of patents by the number of forward citations, the number of family members, etc.

- Counts of selected patents (dropping lower value patents): triadic families, highly cited patents (top $10 \%$ of the distribution), grants (instead of applications), patents renewed until some age (e.g. five years); etc.

\subsection{Forward citations}

The prior art of the invention (patent and erature) cited in patent documents provides useful information about the diffusion of technologies (see Chapter 6 on the use of citations). The number of citations a patent application receives in subsequent patent applications (forward citations) has been found to be strongly associated with the economic value of patents (Scherer et al., 1999) and the social value of inventions (Trajtenberg, 1990). The number of forward citations is one of the most frequently used value indicators.

Two main arguments support the validity of forward citations as indicators of patent value: first, they indicate the existence of downstream research efforts, suggesting that money is being invested in the development of the technology (and there is a potential market); and second, the fact that a given patent has been cited by subsequent patent applications suggests that it has been used by patent examiners to limit the scope of protection claimed by a subsequent patentee, to the benefit of society. In this sense, forward citations indicate both the private and the social value of inventions.

Nevertheless, the main difficulty in computing forward citations is that they appear over time, and sometimes a long while after the cited patent was filed, granted or even reached full term. For the sake of relevance it is important to ensure the timeliness of indicators. One remedy to this problem consists in counting citations received by patent applications within a given time window (e.g. within the first five years of publication).

A common approach used to count forward citations is as follows: $C I T_{i, T}=\sum_{t=P_{i}}^{P_{i}+T} \sum_{j \in J(t)} C_{j, i}$ where $\mathrm{CIT}_{\mathrm{i}, \mathrm{T}}$ is the number of forward citations received by patent application $i$ published in year $P_{i}$ within $T$ years from its publication. $C_{j, i}$ is a dummy variable which is equal to 1 if application $j$ is citing application $i$, and 0 otherwise. $J(t)$ is the set of all applications published in year $t$. A time window frequently used is five years after publication of the cited patent, as it has been calculated with USPTO patents that more than $50 \%$ of the citations received in an entire life of a patent occur within the first five years. ${ }^{4}$ 


\subsection{Indicators based on procedural information and applicants' behaviour}

Information on the value of patents can be inferred using data from the patent application process (notably the fate of a patent application: withdrawal, refusal or grant) and applicants' behaviour in terms of the survival span of patents (renewal rates) and the geographical scope of protection (e.g. the number of jurisdictions in which patent protection has been sought, the number of international patent families; see Chapter 3).

\subsubsection{The fate of the patent application}

A first indicator of the quality of an invention is whether a patent is granted or not. A granted patent corresponds to an invention which is officially recognised as fulfilling the patentability criteria: novelty, inventive step (nonobviousness) and industrial applicability. Such patents are of higher technological and economic value than unsuccessful patent applications. ${ }^{5}$ Pending applications may have some value on the market as they signal potential rights that may be enforced retroactively once granted. For instance, the European Patent Convention says that a published patent application provisionally confers upon the applicant the same rights in all designated states as that in which the patent was granted.

The USPTO used to publish granted patents only, and all patents used for indicators would then be similar from that perspective. However, as most indicators are now based on applications, not grants, one has to be aware of this source of heterogeneity: some of the applications counted have been/will be granted, others have not/will not be granted. Applications offer a notable benefit in terms of timeliness, as grant or refusal takes place years after the application.

By analysing characteristics of the patent application (e.g. type of ownership, number of inventors; domestic and international co-operation, technology class, date of priority or application, etc.) one can identify probabilistically factors underlying the refusal, withdrawal or grant of patent applications (see Guellec and van Pottelsberghe, 2000). ${ }^{6}$

\subsubsection{Renewal of patents}

Data on the renewal of patents and on family size (commonly defined in the economic literature as the number of countries in which protection has been sought; see Chapter 4 for definitions of patent families) have been widely used to draw inferences on the value of patents. Studies in this field exploit the fact that it is expensive to holders to maintain patent protection for an additional period of time and in additional countries. Hence it is hypothesised that the value of continuing patent protection over time and of expanding it 
Table 8.1. Main indicators of patent value discussed in the literature

\begin{tabular}{|c|c|c|}
\hline Indicator & Rationale & Main limitations \\
\hline Granted & $\begin{array}{l}\text { Limited legal protection if not granted; } \\
\text { check by examiners. }\end{array}$ & $\begin{array}{l}\text { Not very informative (large share: about } \\
60 \% \text { of patent applications are granted); } \\
\text { USPTO: } 95 \% \text { of patents are granted. }\end{array}$ \\
\hline Forward citations & $\begin{array}{l}\text { Technological importance of inventions; } \\
\text { impact on further technology } \\
\text { developments. }\end{array}$ & $\begin{array}{l}\text { Timeliness (availability over time), } \\
\text { interpretation. }\end{array}$ \\
\hline $\begin{array}{l}\text { Family size } \\
\text { (number of jurisdictions) }\end{array}$ & $\begin{array}{l}\text { Costly to have protection in different } \\
\text { jurisdictions; sign of market potential } \\
\text { of an invention. }\end{array}$ & $\begin{array}{l}\text { Representativeness issues; large share } \\
\text { of patent applications are international. }\end{array}$ \\
\hline Number of inventors & $\begin{array}{l}\text { Proxy the cost of an invention } \\
\text { (cost of research). }\end{array}$ & $\begin{array}{l}\text { Rough measure which treats inventors } \\
\text { equally; need for complementary } \\
\text { information on the inventors } \\
\text { (e.g. careers, patenting, etc.). }\end{array}$ \\
\hline Renewals & $\begin{array}{l}\text { Cost of maintaining a patent; renewal } \\
\text { rates allow estimation of the distribution } \\
\text { of value. }\end{array}$ & $\begin{array}{l}\text { Timeliness, influence of technology life } \\
\text { cycles, renewal rates different across } \\
\text { technologies (different value). }\end{array}$ \\
\hline Opposition & $\begin{array}{l}\text { Market value of a patent. Costs and risks } \\
\text { associated with legal disputes. }\end{array}$ & $\begin{array}{l}\text { Timeliness, very small share (about } 5 \% \\
\text { in EPO); how to detect mutual settlements. }\end{array}$ \\
\hline Litigation & $\begin{array}{l}\text { Costs and risks associated with legal } \\
\text { disputes. }\end{array}$ & $\begin{array}{l}\text { Timeliness, very small share, friendly } \\
\text { settlements are frequent, data availability. }\end{array}$ \\
\hline $\begin{array}{l}\text { Firm market value, } \\
\text { spin-offs, etc. }\end{array}$ & $\begin{array}{l}\text { Patent value embedded as intangible } \\
\text { asset. }\end{array}$ & $\begin{array}{l}\text { Selected type of companies } \\
\text { (stock markets, etc.). }\end{array}$ \\
\hline $\begin{array}{l}\text { Surveyed economic } \\
\text { value }\end{array}$ & $\begin{array}{l}\text { Patent value known by inventors } \\
\text { or managers. }\end{array}$ & $\begin{array}{l}\text { Subjectivity, selection issues, limited } \\
\text { samples. }\end{array}$ \\
\hline
\end{tabular}

Source: Modified from Van Zeebroeck (2007).

geographically is associated with the economic importance of the invention. Not surprisingly, the two types of indicators have been found to be highly correlated.

In most patent systems, patent holders must pay a periodic fee in order to keep their patents in force. Typically, the renewal fee increases over time, and, at the end of every period, patent holders must decide whether or not to renew. Failure to do so results in the lapse of the patent, which releases the invention into the public domain. Observations of the proportion of patents that are renewed at different ages, together with the relevant renewal fee schedules, provide information on the distribution of the value of patents and the evolution of this distribution over a patent's lifespan (Griliches, 1990).

The rationale behind this approach is based on economic criteria. Patents are renewed only if the value of keeping the patent alive (based notably on the discounted expected stream of profits) is higher than the cost of renewing the patent: when the renewal fee is not paid, the patent has expected returns (in future periods) which are lower than the threshold. As the fees increase over time in most countries, patentees must consider the profitability of renewing for the following period during the current period (the protection "option"; 
Lanjouw and Schankerman, 1997) against the costs of maintenance. It is usually difficult for holders to know the expected returns of a patent. Frequently, it takes some time to learn the market potential of inventions as the decision to patent is frequently made at early stages of the innovation process. ${ }^{7}$ In Japan and the United States, the renewal fees for the patents granted to universities and small and medium-sized enterprises (SMEs) as well as government entities may be reduced (preferential treatment).

Investigations in this field have confirmed the highly skewed distribution of patent values, with a median far below the mean. According to Pakes and Schankerman (1986), half of the estimated value belongs to about $5 \%$ of the entire patent population. ${ }^{8}$ In a study of renewal of patents in Finland and Norway, Pakes and Simpson (1989) found that patents in the pharmaceutical sector and the lumber, wood and paper sector had the highest renewal rates, followed by patents for inventions in the machinery sector, the chemical sector, food products and the primary metals sector.

There are a number of limitations to the patent renewal approach. The results of these studies rely on assumptions about the functional form of the relationship and on an unobserved value of the most valuable patents - those which are renewed to full statutory term ("open-ended"). In some cases, the dropping of a patent may not be indicative of low value but of a change in a company's strategy, related for instance to an external shock. In technologies that change rapidly, many inventions are of high value when introduced but become obsolete shortly thereafter. Exogenous factors may also influence the decision to renew patents. For instance, Schankerman (1998) finds evidence of

\section{Table 8.2. Shares of countries in total patent applications} under different indicators (priority date 2000)

\begin{tabular}{lcccc}
\hline & PCT & Triadic & EPO & PCT most cited \\
\hline Canada & 0.02 & 0.01 & 0.01 & 0.01 \\
France & 0.05 & 0.05 & 0.06 & 0.06 \\
Germany & 0.13 & 0.13 & 0.19 & 0.17 \\
Japan & 0.10 & 0.31 & 0.19 & 0.17 \\
Netherlands & 0.03 & 0.02 & 0.03 & 0.03 \\
United Kingdom & 0.06 & 0.03 & 0.05 & 0.05 \\
United States & 0.40 & 0.33 & 0.27 & 0.31 \\
World & 1.00 & 1.00 & 1.00 & 1.00 \\
\hline
\end{tabular}

Note: Criteria for counting are country of residence of inventor(s) and priority date. PCT patent applications at international phase, designating the EPO; EPO are direct EPO filings plus EURO-PCT in regional phase, and triadic patent families are a subset of patents all filed together at the EPO, at the JPO and granted by the USPTO (protecting the same set of inventions; same priority date). PCT most cited are PCT patent applications at the international phase (designating the EPO) which are among the most highly cited (at the top tenth percentile). Data on triadic patent families are mainly derived from PATSTAT. 
oil shocks in French patent renewal data. ${ }^{9}$ Finally, the time profile of revenues may depend upon the technical field and other characteristics of the invention; inventions are obsolete more rapidly in electronics than in pharmaceuticals.

\subsubsection{Patent family size}

The value of patents is also associated with the geographical scope of patent protection; that is, with the number of jurisdictions in which a patent grant has been sought (see Chapter 4 for definitions of patent families). The fact of applying for patent protection abroad already constitutes a sign of economic value, as the decision reflects the owner's willingness to bear the costs of international patent protection. The rationale is closely related to the decision to renew a patent; it is costly to make a patent valid in more than one country (as it implies applying for a patent directly or indirectly via regional or international offices) and to maintain the protection (Putnam, 1996).

In contrast with the data on renewal which are available over time (or data on forward citations, see Chapter 6), the number of countries in which protection is sought is available earlier in time (one year priority right according to the Paris Convention). An advantage of this source of information is that it allows the construction of indicators early in the life of a patent application.

The geographical scope of protection, as reflected in international patent grants for a given invention, reflects the market coverage of an invention: the higher the number of countries in which protection has been sought, the greater the potential for commercialisation and profit. ${ }^{10}$ There is consistent evidence that family size reflects economic value. For instance, Lanjouw and Schankerman (2004) find a strong positive relationship between a quality index of patents and family size (in a sample of US patents). Guellec and van Pottelsberghe de la Potterie (2000) report a positive association between family size and the likelihood that a European patent will be granted. Harhoff et al. (2002) provide evidence that patents that are part of large international patent families are more strongly associated with economic value. In the group of pharmaceuticals and chemicals, this indicator carries the highest coefficient of all technology-specific sets of results.

In the European patent system, the list of EPC (European Patent Convention) countries in which protection is sought is provided in the application. The payment of application fees to the EPO depends on this list, although the relationship has become flatter over time. For European and international applications filed on or after 1 July 1999 at the EPO, the designation fees are deemed paid for all contracting states upon payment for at least seven countries. In fact, under the EPC 2000, applications will be deemed to designate all available contracting states through a single flat designation fee (see Box 3.2). From April 2009, European patent applications designate all contracting states as in the PCT procedure. ${ }^{11}$ 


\section{Box 8.1. Reforms concerning the designation of states}

When computing indicators on the size of geographical protection based on countries designated in EPO and PCT applications, it is important to know that these indicators will no longer be relevant as indicators of market coverage as procedures at the PCT and EPO have converged towards automatic designation (all contracting states) with a single flat fee. It is important to know when these reforms take place when working with time series of patent data:

\section{Designation in the Patent Cooperation Treaty}

For international applications with an international filing date on or after 1 October 1998: for the first 11 national or regional offices designated there is a designation fee per country or region. There is no additional charge for each designation in excess of 11 offices. From April 2009, European patent applications designate all contracting states as in the PCT procedure.

For international applications with an international filing date on or after 1 January 2004: the filing of an international application request constitutes the designation of all contracting states that are bound by the Treaty on the international filing date.

\section{Designation at the EPO}

Since 1 July 1999 and applicable to European and international applications entering the regional phase (filed on or after this date), each designated contracting state is subject to a designation fee up to seven designated states. There is no additional fee for designation in excess of seven offices.

As of 1 April 2009: Automatic designation of contracting states under a single fee. A flat fee will be charged regardless of the number of designated contracting states. This decision applies to European patent applications filed on or after 1 April 2009 as well as to international applications entering the regional phase on or after that date.

After it has been granted, the family size of a European patent can be quantified as the number of EPC member states in which the patent was effectively validated. The size of the EPC family can diminish naturally over time as patents are abandoned in different countries, hence the need to observe the geographical scope at different points in time. Information on the renewal and geographical scope of protection can be used to produce more refined indicators that take into account the evolution of protection over time and across countries (as patents may lapse in some countries each year, see Box 8.2). 


\section{Box 8.2. A combined indicator (European protection): the scope year index}

Data on the interaction of the renewal and the geographical scope of protection of a patent can be used to produce a more refined index that takes into account the evolution of geographical protection over time (as patents may lapse in some countries each year). This indicator can reflect both the age reached and the European family size (van Pottelsberghe and van Zeebroeck, 2007):

$\mathrm{SY}_{\mathrm{CT}, \mathrm{i}}=\frac{\sum_{t=1}^{T} \sum_{c=1}^{C} G_{i}(c, t)}{C x T}$

where $\mathrm{SY}_{\mathrm{CT}, \mathrm{i}}$ stands for the scope year (SY) index of a given patent $i$ over $C$ countries and $T$ years of maintenance, and $\mathrm{Gi}(C, t)$ is a variable that takes the value 1 if the granted patent $i$ was active in country $c$ in year $t$ from its filing date, and 0 otherwise. The index is normalised to its maximum value representing $\mathrm{T}$ years of maintenance in $C$ countries. In this way, the indicator sums for each year in a patent life the number of countries in which the patent was active in Europe. To enable the comparability of the indicator over time and to ensure its availability within ten years from the date of filing, the indicator proposed by the authors was based on ten countries over ten years. This makes it possible to overcome the institutional bias to family size (the institutional expansion of the EPC, from ten countries in 1977 to 32 in 2007).

Extensions of this indicator can consider weighing validation in jurisdiction by their economic importance, for instance, by the magnitude of their GDP. As such, the SY index score of non-granted applications is necessarily zero, since patents can be validated in EPC members only once they have been granted by the EPO. A provisional version of the SY index has been proposed, which takes into account the duration of the grant procedure (the number of years during which the application has been maintained). See van Pottelsberghe de la Potterie and van Zeebroeck (2007) for further details about this formulation.

\subsection{Other indicators}

\subsubsection{The number of claims}

The scope of a patent is an important determinant of its economic value, as it defines the legal dimensions of protection and thereby the extent of market power attributed to the patent. A broader scope refers to a broader area of technology from which others are excluded.

However, the "scope" or "breadth" of a patent is difficult to measure. The scope is reflected in its claims but also in conjunction with the backward 
patent citations which define the patent's legal boundaries with respect to the prior art. ${ }^{12}$ A number of economists have used the number of claims to proxy the legal scope of patents. It has been argued that, as each individual patent represents a bundle of inventive components, each reflected in a claim, the number of claims can be indicative of the value of the entire patent. Nevertheless, the tendency of certain applicants to "inflate" the number of claims for strategic purposes makes the relationship between scope and number of claims quite noisy. In addition, the claims that appear in granted patents are those that are included following the examination.

Empirical analysis on this matter is scarce but quite positive. In their factor model of patent quality used to analyse research productivity in the United States, Lanjouw and Schankerman (2004) found that the number of claims was the most important indicator of the quality of patents in six out of seven technological fields studied. It has also been found that the likelihood of a patent being litigated, which reflects its scope, increases with its number of claims (Lanjouw and Schankerman, 1997).

\subsubsection{The number of technical classes}

The number of technical classes (as indicated by the number of IPC classes) attributed to a patent application has also been used as a proxy for the scope, and hence the value, of a patent. This approach was proposed by Lerner (1994) in a study of the market value of biotechnology patents as a measure of the value of a patent portfolio. He finds a positive and sizeable correlation between the firm's market value and the average scope of its patents.

However, there is limited evidence of a correlation between the number of classes and the value of a patent. Lanjouw and Schankerman (1997) find that the number of IPC classifications has a small positive effect on the probability of infringement litigation relating to US patents. Using information from a survey on the perceived economic value of patents by German inventors, Harhoff et al. (2002) did not find the number of four-digit IPC classes informative of the patent value in any of the technology fields analysed. ${ }^{13}$

\subsubsection{The number of inventors in a patent}

Several economic studies have associated the number of inventors listed in a patent with the economical and technological value of patents. The number of inventors may proxy the cost of the research behind the invention, which itself is statistically related to the technical value of the invention: the more resources involved, the more research-intensive and expensive the project (Guellec and van Pottelsberghe, 2001; Gambardella et al., 2005). 


\subsubsection{Opposition and litigation}

Certain patent offices offer the possibility for third parties to oppose granted patents that they deem invalid. As opposing a patent is a costly move, it can be inferred that only patents with some damaging effects on competition, and thus some economic value, will be opposed. Hence the fact that a patent is opposed can be interpreted as a signal of value. Further, patents that survive such opposition are proven to be strong patents that offer their holders the prospect of high profitability.

Few patents are opposed. In 2006, the opposition rate at the EPO was around 5.4\% (oppositions were filed against 2990 patents). Of the patents opposed at the EPO, roughly one-third are revoked, one-third are maintained unchanged, and one-third are maintained amended. At the USPTO, interested parties wishing to challenge a US patent after it has been issued have two options: i) challenge the patent in federal court; or ii) request a "re-examination" of the patent by the USPTO. The opposition rate at the EPO is much higher than the re-examination rate at the USPTO for all technology classes (Merges, 1999; Graham et al., 2002). The rate of re-examination at the USPTO between 1981 and 1998 was $0.3 \%$ (of grants), whereas at the EPO, the average opposition rate for the same period was $8.6 \%$ of grants. However, in absolute terms, patent litigation grew significantly in the United States from 1985 to 2000, although the rate of litigation relative to the number of issued patents has remained constant (Graham et al., 2002).

Some authors have found that opposed and litigated patents are of higher than average value. Harhoff et al. (2002) find that successful defence against opposition (in the German patent system) is a particularly strong predictor of patent value. ${ }^{14}$ They explain that stronger patent rights survive what amounts to a two-tier selection process (grant and survival of opposition), which provides a highly reliable indicator of their quality. According to Lanjouw and Schankerman (1998), patents that are litigated have particular characteristics. Compared to a random sample of US patents from the same cohorts and technology areas, the authors find that more valuable patents and those with domestic owners are considerably more likely to be involved in litigation. Patents owned by individuals are at least as likely to be the subject of a case as corporate patents and litigation is particularly frequent in new technology areas.

\section{Notes}

1. Inventions with high technical value might be widely appropriable (e.g. because a patent is easy to circumvent in the invention's particular field of technology). Inventions with small technical value may generate high economic value, e.g. if the inventor, for various reasons, already has a monopoly position on the market. 
2. The merit of this approach is to gather information directly from the source. However, it may be subject to bias, as the inventor or the patent owner might not have, or might not be willing to provide, accurate information.

3. Tobin's $q$ is defined as the ratio of the market value of a firm's assets to the replacement cost of the firm, which is typically measured as the replacement value of firm's physical assets.

4. Lanjouw and Schankerman (1998) suggest that limiting the time period subsequent to a patent's issuance to five years is sufficient to construct meaningful measures of a patent's "importance" based on "forward" citations.

5. However, the grant is not always a good indicator. For instance, a better knowledge of the European system can lead to higher grant rates for EP countries than for US applicants at the EPO (Hinze and Schmoch, 2004).

6. Some studies (e.g. Reitzig, 2004; Burke and Reitzig, 2007) suggest that a "request for accelerated examination" at the EPO (similar procedures exist at the JPO and USPTO) may signal high-value inventions for which the owner wants protection as soon as possible.

7. Few patents are renewed through the end of their term. For instance, Pakes and Schankerman (1986) found that only $10 \%$ of all patents survive the entire renewal period. According to Lemley (2001), using renewal data for United States patents in 1998, nearly two-thirds of all issued US patents lapse before the end of their term owing to failure to pay renewal fees, and nearly half of all patents are abandoned before their potential lifespan is half over.

8. Pakes (1986) explained that the stream of revenues behaves differently along the cycle of patent protection and that the earlier years of the patent are frequently characterised by a high level of economic uncertainty. As learning about the profitability of the invention increases, the uncertainty gradually fades as patents reach an age threshold of four to five years (Pakes, 1986; Lanjouw, 1998).

9. In the pharmaceutical industry, institutional factors such as long regulatory delays between drugs development and their introduction on the market may make renewal rates intrinsically higher than in other industries.

10. Measures of family size (or number of inventors) depend on the country of origin, e.g. the family size of European countries is always higher than that of Japanese applicants (due to the high number of neighbouring European countries).

11. Applying through the PCT may already be seen as an indicator of inventions with higher market expectations. This indicator can be broken down into PCT I and PCT II. Further insight can be obtained by looking at the time elapsed between two stages, i.e. if the period of time between filing date and entry into the regional phase is 20 months or less (PCT I) or exceeds 20 months (PCT II). One argument would be that the greater the applicant's willingness to pay for the delay of costintensive decisions during the application, the higher the applicant's uncertainty about the patent's commercial value (see Burke and Reitzig, 2007).

12. As evidenced in interviews with patent lawyers and examiners, a patent application seeking to protect an invention with broad scope might induce the examiner to delineate the patent claims by inserting more references to the relevant patent literature. Such backward citations reflect the scope of a patent as well as the existence of subject matter that may restrict its scope (Harhoff et al., 2002).

13. The authors explained that the difference in results may be due to the use of patents that cover a broad set of technical areas, while Lerner's study focuses only 
on biotechnology patents. They also pointed out that there may also be important differences in the way the German and the US patent offices assign the IPC classification.

14. They find that a patent which has defeated opposition in Germany ("Einspruchsverfahren") is considerably more valuable - as measured by the monetary value of inventions estimated by inventors (by a factor of 11.2) - than a patent that was never attacked. Further, if the patent has been under attack in the more expensive annulment procedure, its value is again much higher than the value of unchallenged patent rights, in this case by a factor of 42.6 .

\section{References}

Burke, P. and M. Reitzig (2007), "Measuring Patent Assessment Quality - Analyzing the Degree and Kind of (In)consistency in Patent Offices' Decision Making", Research Policy, Vol. 36, pp. 1404-1430.

Gambardella, A., D. Harhoff and B. Verspagen (2005), “The Value of Patents”, mimeo.

Graham, S.J.H., B.H. Hall, D. Harhoff and D.C. Mowery (2002), "Post-Issue Patent Quality Control: A Comparative Study of US Patent Re-examinations and European Patent Oppositions", NBER Working Paper 8807, National Bureau of Economic Research, Inc.

Griliches, Z. (1990), "Patent Statistics as Economic Indicators: A Survey”, Journal of Economic Literature, No. 28, pp. 1661-1707.

Guellec, D. and B. van Pottelsberghe (2000), "Applications, Grants and the Value of Patents”, Economic Letters, No. 69 (1), pp. 109-114.

Guellec, D. and B. van Pottelsberghe (2001), “The Internationalisation of Technology Analysed with Patent Data", Research Policy, No. 30 (8), pp. 1256-1266.

Hall, B.H., A. Jaffe and M. Trajtenberg (2005), "Market Value and Patent Citations", Rand Journal of Economics, No. 36, Spring.

Harhoff, D., F.M. Scherer and K. Vopel (2002), Citations, Family Size, Opposition and the Value of Patent Rights, Research Policy, Elsevier, No. 32 (8), pp. 1343-1363.

Hinze, S. and U. Schmoch (2004), "Opening the Black Box. Analytical approaches and their impact on the outcome of statistical patent analyses", in W. Glänzel, H. Moed and U. Schmoch (eds.) (2004), Handbook of Quantitative Science and Technology Research: The Use of Publication and Patent Statistics in Studies on R\&D Systems, Kluwer Academic Publishers, Dordrecht/Boston/London, pp. 215-235.

Lanjouw, J. and M. Schankerman (2004), "Patent Quality and Research Productivity: Measuring Innovation with Multiple Indicators", The Economic Journal, No. 114, pp. 441-465.

Lanjouw, J.O. (1998), "Patent Protection in the Shadow of Infringement: Simulation Estimations of Patent Value”, The Review of Economic Studies, Vol. 65, pp. 671-710.

Lanjouw, J.O., A. Pakes and J. Putnam (1998), "How to Count Patents and Value Intellectual Property: Uses of Patent Renewal and Application Data", The Journal of Industrial Economics, Vol. XLVI, No. 4, December, pp. 405-433.

Lanjouw, J.O. and M. Schankerman (1997), "Stylised Facts of Patent Litigation: Value, Scope and Ownership”, NBER working paper series, NBER, Cambridge, MA. 
Lanjouw, J.O. and M. Schankerman (1998), "Patent Suits: Do They Distort Research Incentives?", Centre for Economic Policy Research, London, CEPR working paper series, No. 2042.

Lemley, M.A. (2001), "Rational Ignorance at the Patent Office", Northwestern University Law Review, No. 95:4, pp. 1497-1532.

Lerner, J. (1994), “The Importance of Patent Scope: An Empirical Analysis”, RAND Journal of Economics, No. 25 (2), pp. 319-333.

Merges, R. P. (1999), "As Many as Six Impossible Patents Before Breakfast: Property Rights for Business Concepts and Patent System Reform", Berkeley High Technology Law Journal 14, pp. 577-615.

Pakes, A. (1986), “Patents as Options: Some Estimates of the Value of Holding European Patent Stocks", Econometrics, No. 54 (4), pp. 755-784

Pakes, A. and M. Schankerman (1986), "Estimates of the Value of Patent Rights in European Countries During the Post-1950 Period", Economic Journal, December, pp. 1052-1076.

Pakes, A. and M. Simpson (1989), “Patent Renewal Data”, NBER Reprints 1265, National Bureau of Economic Research, Inc.

van Pottelsberghe, B. and N. van Zeebroeck (2007), "A Brief History of Space and Time: The Cope-Year Index as a Patent Value Indicator Based on Families and Renewals", CEPR Discussion Papers 6321.

Putnam, J. (1996), “The Value of International Patent Rights”, Ph.D. thesis, Yale University.

Reitzig, M. (2004), "Improving Patent Valuations for Management Purposes: Validating New Indicators by Analyzing Application Rationales”, Research Policy, Vol. 33 (6-7), pp. 939-957.

Schankerman, M. (1998), "How Valuable Is Patent Protection? Estimates by Technology Field”, RAND Journal of Economics, Vol. 29 (1), pp. 77-107, The RAND Corporation.

Trajtenberg, M. (1990), “A Penny for Your Quotes: Patent Citations and the Value of Innovation", RAND Journal of Economics, No. 21 (1), pp. 172-187.

van Zeebroeck, N. (2007), "The Puzzle of Patent Value Indicators", CEB Working Papers 07-023.RS, Université Libre de Bruxelles, Solvay Business School, Centre Emile Bernheim (CEB). 



\section{Glossary}

Appeal: A procedure by which the applicant or patent holder can request reversal of a decision taken by the patent office.

- USPTO: An applicant for a patent dissatisfied with the primary examiner's decision in the second rejection of his or her claims may appeal to the Board of Patent Appeals and Interferences (BPAI) for review of the examiner's rejection. The Board is a body of the USPTO which reviews adverse decisions of examiners in patent applications and determines priority and patentability of invention in interferences. Decisions of the Board can be further appealed to the Court of Appeals for the Federal Circuit (CAFC) or to a district court.

- EPO: Decisions of the first instances of the EPO can be appealed before the Boards of Appeal of the EPO, in a judicial procedure (proper to an administrative court), as opposed to an administrative procedure. These boards act as the final instances in the granting and opposition procedures before the EPO. In addition to the Boards of Appeal, the European Patent Office has an Enlarged Board of Appeal. This instance takes decisions only when the case law of the Boards of Appeal becomes inconsistent or when an important point of law arises.

- JPO: An applicant who receives a rejection can appeal. The panels consist of three or five trial examiners in the Appeals Department of the JPO. Decisions of the panels can be further appealed to the Intellectual Property High Court, a special branch within the Tokyo High Court.

Applicant: The holder of the legal rights and obligations on a patent application. It is most often a company, a university or an individual.

Application date: The date on which the patent office received the completed patent application. A unique number is assigned to a patent application when it is filed.

Assignee: In the United States, the person(s) or corporate body to whom all or limited rights under a patent are legally transferred by the inventor (equivalent to "applicant" in this context).

Citations: References to the prior art in patent documents. Citations may be made by the examiner or the applicant. They comprise a list of references which are believed to be relevant prior art and which may have contributed to defining the scope of the claims of the application. References can be made to 
other patents, to technical journals, textbooks, handbooks and other sources. USPTO: Applicants before the USPTO are required to disclose prior art known to them that is material to patentability; EPO: No such obligation for the applicant; JPO: The requirement for disclosure of information on prior art documents was introduced as of 1 September 2002 and entered into full force on 1 May 2006.

Claim(s): Definition of the scope of the invention and the aspects of the invention for which legal protection is sought.

Continuation(s) (USPTO): Second or subsequent applications for the same invention claimed in a prior non-provisional application and filed before the first application is abandoned or patented. Continuations must claim the same invention as the original application to gain the benefit of the parent filing date. At the time of filing the claims are often the same but the claims may change during prosecution so that they are not exactly the same but not patentably distinct. There are three types of continuing applications: division, continuation and continuation-in-part.

Designated countries: In international and regional patent systems, countries in which patent applicants wish to protect their invention if/when the patent is granted. International application filing automatically includes the designation for all PCT contracting countries that are bound by the PCT on the international filing date (since 2004). A similar rule will apply to the EPO from April 2009, as European patent applications designate all contracting states as in the PCT procedure.

Direct European route (application): A patent application filed under Article 75 EPC (also known as an "Euro-Direct application"). With the direct European route, the entire European patent grant procedure is governed by the EPC alone while with the Euro-PCT route, the first phase of the grant procedure (the international phase), is subject to the PCT.

Division: If the patent office decides that an application covers too broad an area to be considered as a single patent, the application is split into one or more divisional applications, which may or may not be pursued by the applicant. A division can also be requested at the initiative of the applicant.

Equivalent: A patent that protects the same invention and shares the same priority application as a patent from a different issuing authority.

Euro-PCT route: A way to obtain a European patent by designating the EPO in a PCT application (Article 11 PCT). The first phase of the grant procedure (the international phase) is subject to the PCT, while the regional phase before the EPO as designated or elected office is governed primarily by the EPC.

- Euro-PCT application - international phase (or Euro-PCT application or PCT international): A PCT application designating the EPO [Article 150(3) EPC]. With 
the Euro-PCT route, the first phase of the grant procedure (international phase) is subject to the PCT, while the regional phase before the EPO as designated or elected office is governed primarily by the EPC.

- Euro-PCT application - regional phase (or PCT regional): PCT application entering the European (or regional) phase once the applicant has fulfilled the conditions under Article 22 or 39 PCT, Article 158 and Rule 107 EPC.

Euro-PCT search (or PCT Chapter I): Search carried out by the EPO acting as International Searching Authority for a Euro-PCT application in the international phase (Article 16 PCT).

European patent: A European patent can be obtained for all EPC countries by filing a single application at the EPO in one of the three official languages (English, French or German). European patents granted by the EPO have the same legal rights and are subject to the same conditions as national patents (granted by the national patent office). It is important to note that a granted European patent is a "bundle" of national patents, which must be validated at the national patent office in order to be effective in member countries. The validation process may include submission of a translation of the specification, payment of fees and other formalities of the national patent office (once a European patent is granted, competence is transferred to the national patent offices).

European Patent Convention (EPC): The Convention on the Grant of European Patents was signed in Munich in 1973 and entered into force in 1977. It is a multilateral treaty instituting the European Patent Organisation and providing an autonomous legal system according to which European patents are granted. The EPC provides a legal framework for the granting of European patents, via a single, harmonised procedure before the European Patent Office. It enables the patent applicant, by means of a single procedure, to obtain a patent in some or all of the contracting states. As of January 2008 there are 34 EPC member countries. In addition, extension agreements exist with five countries, offering the possibility to extend European patents to those countries upon request. EPC member countries are Austria, Belgium, Bulgaria, Croatia, Cyprus, the Czech Republic, Denmark, Estonia, Finland, France, Germany, Greece, Hungary, Iceland, Ireland, Italy, Latvia, Liechtenstein, Lithuania, Luxembourg, Malta, Monaco, the Netherlands, Norway, Poland, Portugal, Romania, the Slovak Republic, Slovenia, Spain, Sweden, Switzerland, Turkey and the United Kingdom. EPC extension countries are Albania, Bosnia and Herzegovina, Croatia, Former Yugoslav Republic of Macedonia, and Serbia.

European Patent Office (EPO): The European Patent Office (a regional patent office) was created by the EPC to grant European patents, based on a centralised examination procedure. By filing a single European patent application in one of the three official languages (English, French or German), it is possible to 
obtain patent rights in all EPC member and extension countries. The EPO is not an institution of the European Union.

Family: a set of patents (or applications) filed in several countries to protect the same invention. They are related to each other by one or several common priority numbers. There are different definitions of patent families (e.g. triadic patent families, extended families including continuations, etc.). Depending on the use sought, a different family concept can be chosen, e.g. equivalents, triadic family or trilateral family.

First to file: A patent system in which the first inventor to file a patent application for a specific invention is entitled to the patent. This law is increasingly becoming the standard for countries adhering to the Traderelated Aspects of Intellectual Property (TRIPs) guidelines. In the EPO and the JPO, patents are awarded on a first-to-file basis, whereas in the USPTO the patent is awarded on the first to invent basis.

First to invent (USPTO): A system in which a patent is awarded to the first person who made the invention, even if another person filed for a patent before the person who invented first.

Grant: A patent application does not automatically give the applicant a temporary right against infringement. A patent has to be granted for it to be effective and enforceable against infringement.

Grant date: The date when the patent office issues a patent to the applicant.

Infringement: Unauthorised making, using, offering for sale or selling any patented invention in the country in which the patent is enforceable or importing that invention into said country during the term of the patent.

Intellectual property rights (IPR): The exclusive legal rights associated with creative work, commercial symbols or inventions. There are four main types of intellectual property: patents, trademarks, design and copyrights.

International patent application: See "PCT application". A patent application filed under the Patent Cooperation Treaty (PCT) is commonly referred to as an "international patent application". However, international patent (PCT) applications do not result in the issuance of "international patents" (i.e. at present, there is no global patent system that issues and enforces international patents). The decision of whether to grant or reject a patent filed under PCT rests with the national or regional (e.g. EPO) patent offices.

International Patent Classification (IPC): The IPC is based on an international multilateral treaty administered by WIPO. The IPC is an internationally recognised patent classification system, which provides a common classification for patents according to technology groups. The IPC is a hierarchical system in which the whole area of technology is divided into eight sections broken down into classes, subclasses and groups. IPC is periodically revised in order to 
improve the system and to take account of technical development. The eighth edition of the IPC entered into force on 1 January 2006.

International Searching Authority (ISA): An office with competence to carry out the international search for a PCT application. It may be either a national office (Australia, Austria, Canada, China, Finland, Japan, Korea, the Russian Federation, Spain, Sweden, the United States) or an intergovernmental organisation (EPO), (Article 16 PCT, Article 154 EPC).

Inventive step: At the EPO and JPO, an invention is considered to include an inventive step if it is not obvious to a person skilled in the art. Inventive step is one of the criteria (along notably with novelty and industrial applicability) that need to be fulfilled in order to obtain a patent. See also "non-obviousness"(USPTO).

Inventor country: Country of residence of the inventor.

Japan Patent Office (JPO): The JPO administers the examination and granting of patent rights in Japan. The JPO is an agency of the Ministry of Economy, Trade and Industry (METI).

Lapse: The date when a patent is no longer valid in a country or system owing to failure to pay renewal (maintenance) fees. Often the patent can be reinstated within a limited period.

Licence: The means by which the owner of a patent gives permission to another party to carry out an action which, without such permission, would infringe the patent. A licence can thus allow another party to legitimately manufacture, use or sell an invention protected by a patent. In return, the patent owner will usually receive royalty payments. A licence, which can be exclusive or non-exclusive, does not transfer the ownership of the invention to the licensee.

National application: A patent application that is filed at a national patent office according to a national procedure.

Novelty: An invention cannot be patented if certain disclosures of the invention have been made.

Non-obviousness (USPTO): Something is obvious if the differences between the subject matter to be patented and the prior art are such that the subject matter as a whole would have been obvious at the time the invention was made to a person with ordinary skills in the art to which said subject matter pertains. See also "inventive step"(EPO, JPO).

Opposition: This is a procedure usually before the issuing patent office, initiated by third parties to invalidate a patent:

- EPO: Opposition to the grant of a European patent can be filed within nine months of the mention of the grant in the European Patent Bulletin. 
- JPO: Opposition to a grant could be filed within six months of the issue of the grant before the reform of appeals for invalidation was introduced in January 2004.

Paris Convention: The Paris Convention for the Protection of Industrial Property was established in 1883 and is generally referred to the Paris Convention. It established the system of priority rights, under which applicants have up to 12 months from first filing their patent application (usually in their own country) in which to make further subsequent applications in each signatory country and claim the original priority date. There are 172 countries party to the treaty (March 2008).

Patent: A patent is an intellectual property right issued by authorised bodies which gives its owner the legal right to prevent others from using, manufacturing, selling, importing, etc., in the country or countries concerned, for up to 20 years from the filing date. Patents are granted to firms, individuals or other entities as long as the invention satisfies the conditions for patentability: novelty, nonobviousness and industrial applicability. A patent is known as a utility patent in the United States.

Patent Cooperation Treaty (PCT): As of March 2008, there were 138 countries party to the treaty, which was signed in 1970 and entered into force in 1978, enabling a patent applicant, by means of a single procedure, to obtain a patent in some or all of the contracting states. The PCT provides the possibility to seek patent rights in a large number of countries by filing a single international application (PCT application) with a single patent office (receiving office). PCT applications do not result in the issuance of "international patents". The decision on whether to grant or reject patent rights rests with national or regional patent offices. The PCT procedure consists of two main phases: i) an "international phase"; and ii) a PCT "national/regional phase". PCT applications are administered by the World Intellectual Property Organization (WIPO).

PCT international search: A search carried out by a designated office (international searching authority) for PCT applications.

Pending application: An application has been made at the patent office, but no decision has been taken on whether to grant or reject the patent application

Prior art: Previously used or published technology that may be referred to in a patent application or examination report. In a broad sense, this is technology that is relevant to an invention and was publicly available (e.g. described in a publication or offered for sale) at the time an invention was made, In a narrow sense, it is any technology that would invalidate a patent or limit its scope. The process of prosecuting a patent or interpreting its claims largely consists of identifying relevant prior art and distinguishing the claimed invention from that prior art. The objective of the search process is to identify patent and non- 
patent documents constituting the relevant prior art in order to determine whether the invention is novel and includes an inventive step.

Priority country: Country where the patent is first filed worldwide before being extended to other countries. See "Paris Convention".

Priority date: The priority date is the first date of filing of a patent application, anywhere in the world (usually in the applicant's domestic patent office), to protect an invention. The priority date is used to determine the novelty of the invention, which implies that it is an important concept in patent procedures. Among procedural data, priority date can be considered as the closest date to the date of invention. In the United States the date of conception comes into play during interferences.

Priority rights: see "Paris Convention".

Processing time: Duration of a process in the patent procedure (e.g. search, examination, grant, and possible opposition and appeal).

Publication: In most countries, a patent application is published 18 months after the priority date:

- EPO: All patent applications are published in this manner, whether the patents have been granted or not.

- JPO: Patent applications that are no longer pending in the JPO, e.g. granted, withdrawn, waived or rejected, are not published. While official patent gazettes are only published in Japanese, the abstracts and bibliographic data of most of the unexamined patent applications are translated into English, and are published as the Patent Abstracts of Japan (PAJ).

- USPTO: Prior to a change in rules under the American Inventors Protection Act of 1999, USPTO patent applications were held in confidence until a patent was granted. Patent applications filed at the USPTO on or after 29 November 2000 are required to be published 18 months after the priority date. However, there are certain exceptions for the publication of pending patents. For example, an applicant can ask (upon filing) for the patent not to be published by certifying that the invention disclosed in the application has not and will not be the subject of an application filed in another country. Also, if the patent is no longer pending or subject to a secrecy order, then the application will not be published.

Renewal fees: Once a patent is granted, annual renewal fees are payable to patent offices to keep the patent in force. In the USPTO they are referred to as "maintenance fees". In most offices, renewal fees are due every year. USPTOgranted (utility) patents are subjected to maintenance fees which are due threeand-a-half years, seven-and-a-half years, and eleven-and-a-half years from the date of the original patent grant. 
Request for examination: Patent applications filed at the EPO and JPO do not automatically enter the examination process. The applicant has to submit a request for examination within six months of the transmission of the search report at the EPO, and within three years of filing at the JPO. Patent applications filed at the USPTO are automatically examined by a patent examiner without the need for a separate request by the applicant.

Revocation: A patent is revoked if after it has been granted by the patent office, it is deemed invalid by a higher authority (appeal body within the patent office or a court).

Search report: The search report is a list of citations of all published prior art documents which are relevant to the patent application. The search process, conducted by a patent examiner, seeks to identify patent and non-patent documents constituting the relevant prior art to be taken into account in determining whether the invention is novel and includes an inventive step.

Triadic patent families: The triadic patent families are defined at the OECD as a set of patents taken at the European Patent Office (EPO) and the Japan Patent Office (JPO) and granted by the US Patent and Trademark Office (USPTO) which share one or more priorities. Triadic patent families are consolidated to eliminate double counting of patents filed at different offices (i.e. regrouping all the interrelated priorities in EPO, JPO and USPTO patent documents).

Trilateral patent families: A trilateral patent family is part of a filtered subset of patent families for which there is evidence of patenting activity in all trilateral blocs. It is then similar to a triadic family, except that it would also include applications filed in any EPC state that do not go to the EPO (in addition to going to the JPO and USPTO). Trilateral patent families are usually counted in terms of individual priorities, without consolidation.

United States Patent and Trademark Office (USPTO): The USPTO administers the examination and granting of patent rights in the United States. It falls under the jurisdiction of the US Department of Commerce.

Utility model: This type of patent, also known as a "petty patent", is available in some countries. It usually involves less stringent patentability requirements than a traditional patent, it is cheaper to obtain and it is valid for a shorter time period.

Withdrawal: Under the European Patent Convention, the applicant can withdraw an application at any stage of the procedure either by informing the office or by abstaining from one or more of the following: pay fees in due time, file a request for examination within the given time period, or reply in due time to any communication within the examination procedure.

World Intellectual Property Organization (WIPO): An intergovernmental organisation responsible for the administration of various multilateral treaties dealing with the legal and administrative aspects of intellectual property. In the patent area, the WIPO is notably in charge of administering the Paris Convention, the Patent Cooperation Treaty (PCT) and the International Patent Classification system (IPC). 
OECD PUBLICATIONS, 2, rue André-Pascal, 75775 PARIS CEDEX 16 PRINTED IN FRANCE

(92 2009021 P) ISBN 978-92-64-05412-7 - No. Code OCDE 2009 


\section{OECD Patent Statistics Manual}

Patent data are an outstanding resource for the study of technical change. Alongside other science and technology (S\&T) indicators such as R\&D expenditure and personnel or innovation-survey data, patent data provide a uniquely detailed source of information on inventive activity and the multiple dimensions of the inventive process (e.g. geographical location, technical and institutional origin, individuals and networks). Furthermore, patent data form a consistent basis for comparisons across time and across countries. Yet such data are complex, and patent-based indicators must be designed and interpreted carefully. Since the publication of the first OECD manual on patents in 1994 (The Measurement of Scientific and Technological Activities: Using Patent Data as Science and Technology Indicators), significant progress has been made both in data provision and statistical analysis based on patent data.

The 2009 edition of the OECD Patent Statistics Manual takes stock of the recent developments in the field. It provides guiding principles for the use of patent data in the context of S\&T measurement, and recommendations for the compilation and interpretation of patent indicators in this context. It aims to show what patent statistics can be used for, what they cannot be used for, and how to count patents in order to maximise information on S\&T activities while minimising statistical noise and biases. Finally, it describes how patent data can be used in the analysis of a wide array of topics related to technical change and patenting activity including industry-science linkages, patenting strategies by companies, internationalisation of research, and indicators on the value of patents.

The full text of this book is available on line via these links:

www.sourceoecd.org/sciencelT/9789264054127

www.sourceoecd.org/statisticssourcesmethods/9789264054127

Those with access to all OECD books on line should use this link: www.sourceoecd.org/9789264054127

SourceOECD is the OECD online library of books, periodicals and statistical databases.

For more information about this award-winning service and free trials, ask your librarian, or write to us at SourceOECD@oecd.org. 